Andrews University

Digital Commons @ Andrews University

\title{
The Impact Of Student Self-Discipline And Parental Involvement in Students' Academic Activities on Student Academic Performance
}

Susan N. Mbaluka

Andrews University, mbaluka@andrews.edu

Follow this and additional works at: https://digitalcommons.andrews.edu/dissertations

Part of the Education Commons

\section{Recommended Citation}

Mbaluka, Susan N., "The Impact Of Student Self-Discipline And Parental Involvement in Students' Academic Activities on Student Academic Performance" (2017). Dissertations. 1654.

https://digitalcommons.andrews.edu/dissertations/1654

https://dx.doi.org/10.32597/dissertations/1654

This Dissertation is brought to you for free and open access by the Graduate Research at Digital Commons @ Andrews University. It has been accepted for inclusion in Dissertations by an authorized administrator of Digital Commons@ Andrews University. For more information, please contact repository@andrews.edu. 


\begin{abstract}
THE IMPACT OF STUDENT SELF-DISCIPLINE AND PARENTAL INVOLVEMENT IN STUDENTS' ACADEMIC ACTIVITIES ON STUDENT ACADEMIC PERFORMANCE
\end{abstract}

by

Susan N. Mbaluka

Chair: Gustavo Gregorutti 


\section{ABSTRACT OF GRADUATE STUDENT RESEARCH}

Dissertation

Andrews University

School of Education

Title: THE IMPACT OF STUDENT SELF-DISCIPLINE AND PARENTAL INVOLVEMENT IN STUDENTS' ACADEMIC ACTIVITIES ON STUDENT ACADEMIC PERFORMANCE.

Name of researcher: Susan N. Mbauka

Name and degree of faculty chair: Gustavo Gregorutti, Ph.D

Date completed: December 2017

\section{Purpose}

The purpose of this study was to investigate the impact of student's self-discipline and parental involvement on academic performance. The study sought to determine whether student's self-discipline and parental involvement in student's academic activities have any impact on student's Iowa Test of Basic Skills (ITBS) scores or on their GPA.

\section{Method}

This is a quantitative, cross-sectional study in which multiple regressions were used to investigate the relationship(s) between student self-discipline and parental involvement with student's ITBS scores and GPA. Due to challenges of collecting 
sufficient data, the study was done in two phases: a preliminary study involving 16 students in schools in the Texas Conference of the Seventh day-Adventists and later a primary study which utilized archived data from the CognitiveGenesis (CG) study. The data used in the primary study was collected from all students in Seventh-day Adventist schools in the North American Division (NAD), in grades 3-9 and 11 (Thayer \& Kido, 2012). The present study utilized data from 5,144 grades 6 and 7 students. In order to collect data for the preliminary study, teachers responded to Self-Control Rating Scale (SCRS) questionnaire to rate their students' level of self-discipline (Kendall \& Wilcox, 1979). Additionally, parents responded to Parent And School Survey (PASS), an instrument designed to measure parental involvement in their children's education (Ringenberg, Funk, Mullen, Wilford \& Kramer, 2005).

\section{Results}

Results indicated that student's self-discipline and parental involvement are significantly correlated with student's ITBS scores and GPA. Yet, some variables showed stronger correlation with the dependent variables than others. Student self-discipline had a higher correlation with GPA than ITBS scores. On the other hand, parental involvement showed a higher correlation with ITBS than GPA. Of all the scales of self-discipline, student's diligence presented the highest correlation with ITBS scores while parenting had the strongest correlation with ITBS scores among all the parental involvement scales.

Student's diligence, parenting and volunteering have a significant positive correlation with ITBS at $p<.001$ each. However, doing chores and distractions were negatively correlated with ITBS. 


\section{Conclusion}

The findings of this study revealed that student self-discipline and parental involvement are crucial factors in academic performance. Among the subscales of selfdiscipline, diligence showed the highest positive correlation with academic performance while distractions showed the highest negative correlation with academic performance. Parental involvement, too, was highly correlated with GPA and ITBS performance. Combined, student self-discipline and parental involvement revealed significant impact on academic performance. Boys showed to be more prone to distractions, hence portraying less self-discipline than girls. Findings indicated that in order to improve GPA and ITBS performance, parents need to participate actively in the academic activities of their children including communicating with the school, parenting, volunteering, decision making, facilitating learning at home, and collaborating with the community to put resources together to support the school. 
Andrews University

School of Education

THE IMPACT OF STUDENT SELF-DISCIPLINE AND PARENTAL INVOLVEMENT IN STUDENTS' ACADEMIC ACTIVITIES ON STUDENT ACADEMIC PERFORMANCE

\author{
A Dissertation \\ Presented in Partial Fulfillment \\ of the Requirement for the Degree \\ Doctor of Philosophy
}

by

Susan N. Mbaluka

December 2017 
(C) Copyright by Susan N. Mbaluka 2017 All Rights Reserved 


\title{
THE IMPACT OF STUDENT SELF-DISCIPLINE AND PARENTAL INVOLVEMENT IN STUDENTS' ACADEMIC ACTIVITIES ON STUDENT ACADEMIC PERFORMANCE
}

\author{
A dissertation \\ presented in partial fulfillment \\ of the requirement for the degree \\ Doctor of Philosophy
}

by

Susan N. Mbaluka

\section{APPROVAL BY THE COMMITTEE:}

Chair: Gustavo Gregorutti

Member: Jay Brand

Member: Bordes Saturne
Dean, School of Education

Robson Marinho

External: Ruth Horton

Date approved 


\section{DEDICATION}

This dissertation is dedicated:

To God. Father, You are faithful. Through the PhD program, You taught me how to depend on You. You taught me endurance, living by faith, and You taught me humility.

To my loving husband, David Mbaluka. You are a man enough to support your wife to get a PhD. I thank God for you.

To Beatrice Lulu Mbaluka, my daughter, and my cheerleader. You always told me that God would see me through.

To Wisdom Mbaluka, my son. You perpetually pray for the family and for others. You never ceased to encourage and to challenge me.

To West Houston SDA Church- I learned a lot about leadership from the opportunity you gave you gave me to lead various ministries. To sit in church and school board meetings was a great experience in my ministry and career development. 


\section{TABLE OF CONTENTS}

LIST OF TABLES ............................................................................... vii

LIST OF ABBREVIATIONS ..................................................................... ix

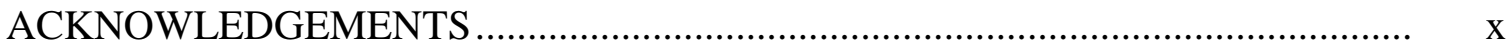

\section{Chapter}

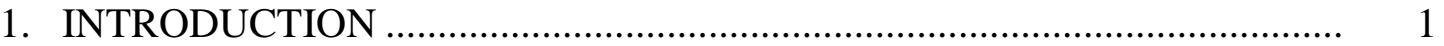

Statement of the Problem............................................................................

Purpose of the Study ............................................................................ 4

Research Questions .............................................................................. 5

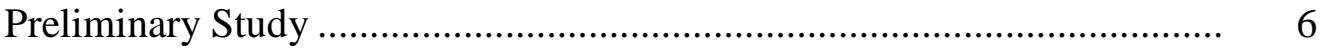

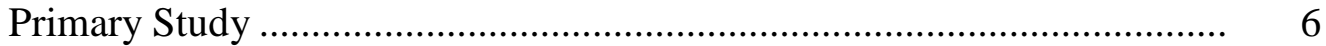

Rationale for the Study: Preliminary and the Primary ................................. 7

Conceptual Framework for the Study: Preliminary and the Primary ......... 8

Significance of the Study .................................................................... $\quad 10$

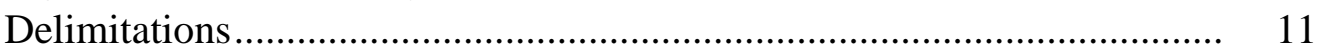

Preliminary Study …………………………………………....... 11

Primary Study ....................................................................... 11

Methodology …………................................................................... 11

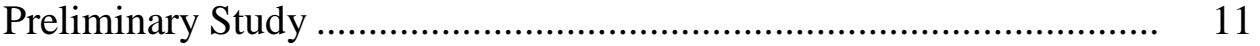

Primary Study ....................................................................... 12

Definition of Terms ............................................................................. 13

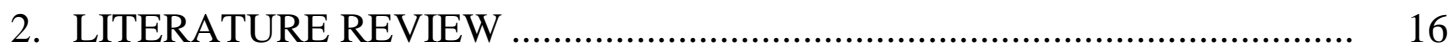

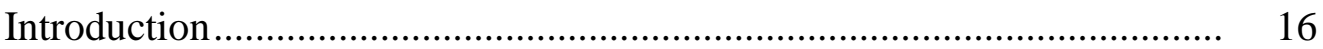

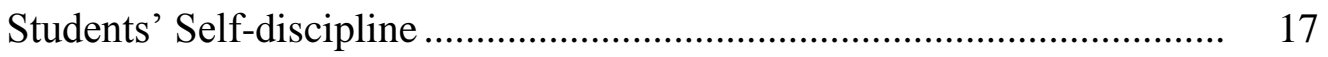

Parental Involvement ……………….................................................... 23

Academic Performance ........................................................................ $\quad 29$

Student Demographics ........................................................................... 33

Students' Ethnicity ……………………………………................ 33

Student Gender........................................................................... 33

Student Age and Grade Level ......................................................... 34

Summary ................................................................................ 34 


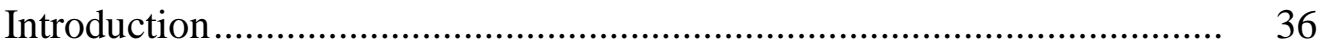

Population ............................................................................. 38

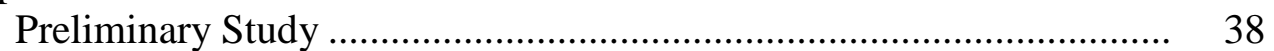

Primary Study ................................................................................ 40

Sample

Preliminary Study …………………………………………........ 40

Primary Study ....................................................................... 42

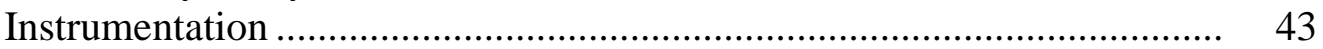

Preliminary Study ..................................................................... 43

Primary Study ........................................................................... 44

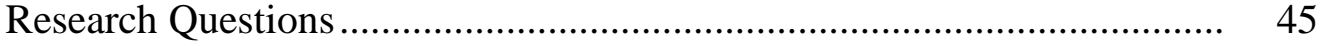

Preliminary Study ..................................................................... 45

Primary Study ......................................................................... 45

Null Hypotheses............................................................................. 46

Preliminary Study ………………………………………….... 46

Primary Study ........................................................................ 47

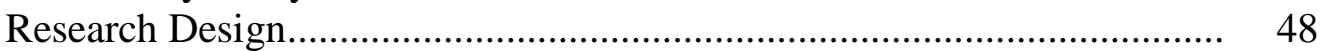

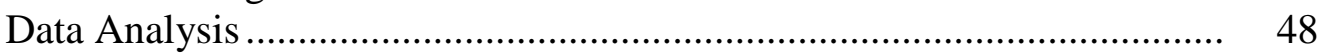

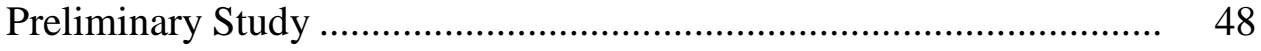

Primary Study ……………………………………………...... 49

Control Variables .............................................................................. 49

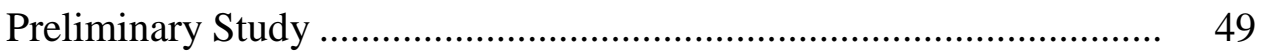

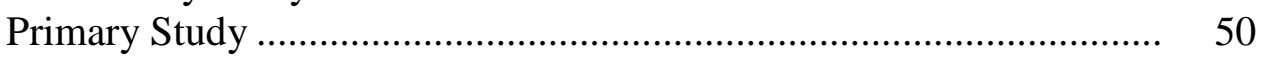

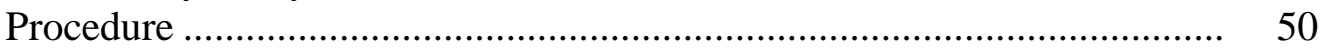

Preliminary Study ................................................................. 50

Primary Study ...................................................................... 52

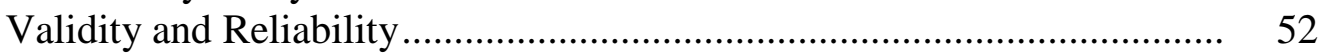

Preliminary Study .................................................................... 52

Self-Control Rating Scale .......................................................... 52

Parent And School Survey .......................................................... 53

Primary Study ..................................................................... 55

Ethical Considerations …................................................................. 59

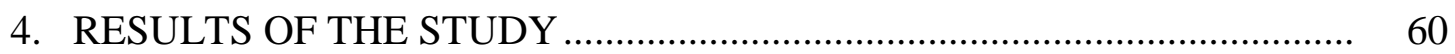

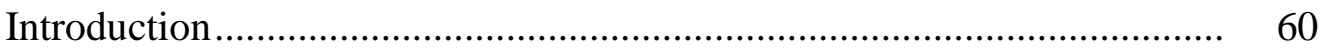

Preliminary Study ........................................................................... 61

Demographic Descriptive Statistics................................................... 61

Demographic Descriptive Statistics ......................................................... 69

Primary (Supplemental) Study ......................................................... 69

Results from Questionnaires ................................................................ 73

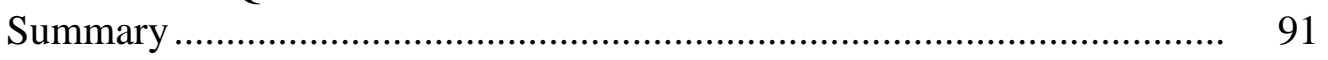


5. DISCUSSION AND CONCLUSION

Summary of the Study ................................................................... 93

Preliminary Study Research Questions................................................ 95

Primary Study Research Questions..................................................... 95

Conclusion and Discussion ................................................................. 96

Student Self-Discipline and Academic Performance............................. 96

Parental Involvement and Academic Performance.................................. 101

Combined Effects of Student Self-discipline and Parental Involvement on GPA and ITBS ...................................................................... 108

Impact of Demographic Variables on the Relationship Between

Student Self-discipline or Parental Involvement and Student's

ITBS Performance ................................................................. 110

Implications.......................................................................... 113

Conclusions ......................................................................... 115

Suggested Further Research.......................................................... 116

Appendix

A. CORRELATIONS AND REGRESSIONS OUTPUTS ............................. 118

B. IRB \& INSTITUTION APPROVAL LETTERS ...................................... 130

C. SURVEY INSTRUMENTS ............................................................ 143

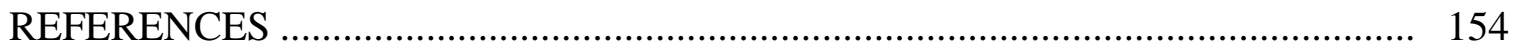

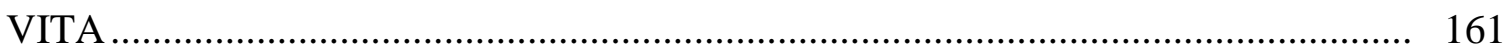




\section{LIST OF TABLES}

1. Self-Control Rating Scale (SCRS) _................................................................. 54

2. Parent And School Survey (PASS) …………………..................................... 56

3. Reliability Analysis of CG Student Survey Scales .............................................. 58

4. Reliability Analysis of CG Parent Survey Scales ................................................ 58

5. Student Subjects' Demographic Frequencies …………………………............. 63

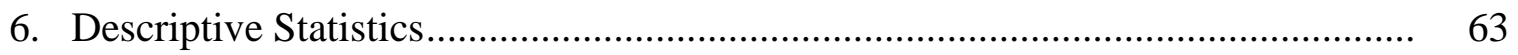

7. Correlation Between Self-Discipline and GPA and ITBS NCE ........................... 65

8. Correlations of Parental Involvement Variables with GPA and ITBS NCE ......... 67

9. Self-discipline and Parental Involvement Variables Together ............................... 68

10. Grade 6 Descriptive Statistics ....................................................................... 70

11. Grade 7 Descriptive Statistics ............................................................................. 71

12. Grade 6 Control Variables ............................................................................... 72

13. Grade 7 Control Variables ................................................................................ 73

14. Grade 6 Model Summary for Self-discipline Scales............................................... 75

15. Grade 6: Contribution of Self-Discipline Variables .............................................. 76

16. Grade 7: Contribution Self-discipline Variables...................................................... 76

17. Grade 7 Model Summary for Self-Discipline Scales............................................. 78

18. Grade 6 Model Summary for Parental Involvement Scales................................... 80

19. Grade 6: Contribution of Parental Involvement Scales ......................................... 80

20. Grade 7: Contribution of Parental Involvement Scales ......................................... 82 
21. Grade 7 Model Summary for Parental Involvement Scales............................... 83

22. Grade 6 Self-discipline and Parental Involvement Variables Combined .............. 85

23. Grade 6: Contribution of All Independent Variables Together ........................... 86

24. Grade 7: Contribution of All Independent Variables Together .......................... 86

25. Grade 7 Self-Discipline and Parental Involvement Scales Combined.................. 87

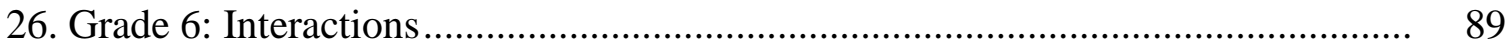

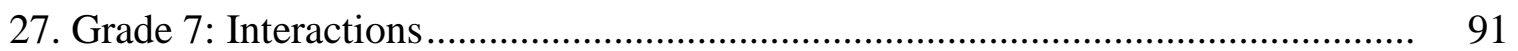




\section{LIST OF ABBREVIATIONS}

\begin{tabular}{|c|c|}
\hline GPA & Grade Point Average \\
\hline $\mathrm{CG}$ & CognitiveGenesis \\
\hline ESSA & Every Student Succeed Act \\
\hline ICC & Intraclass Correlation Coeffiients \\
\hline IQ & Intelligence Quotient \\
\hline IRB & Internal Review Board \\
\hline ITBS & Iowa Test of Basic Skills \\
\hline NAD & North American Division \\
\hline NAEP & National Assessment of Educational Progress \\
\hline NCLB & No Child Left Behind \\
\hline NPR & National Percentile Rank \\
\hline OECD & Organization for Economic Cooperation and Development \\
\hline PASS & Parent and School Survey \\
\hline PISA & Program for International Student Assessment \\
\hline SCRS & Self-Control Rating Scale \\
\hline SDA & Seventh-day Adventist \\
\hline SDT & Self-Determination Theory \\
\hline SES & Socio Economic Status \\
\hline
\end{tabular}




\section{ACKNOWLEDGEMENTS}

"Delight yourself in the LORD, and he will give you the desires of your heart" (Psalm 37:4). This promise, and many others, stayed in my mind throughout my dissertation writing. The words reminded me about the goodness and faithfulness of God, which made me more determined not to leave this dissertation a half-way done.

Many people made it possible for this study to be a success, and I want to thank

them all. My family, thank you for your understanding, for support and encouragement. I could not have done it without you. Dr. Jerome Thayer, thank you for facilitating permission for me to use the CognitiveGenesis data to supplement for my data. You also helped me with data analysis. I am very grateful. When I came to you for help, you had never seen me before, for you were neither my teacher nor were you in my dissertation committee. Thank you for allowing God to use you to bless me.

I am very grateful to my dissertation committee. Dr. Gregorutti, I appreciate the way you give feedback promptly. Thank you. Dr. Jay Brand, you guided and supported me over the years. When it looked almost impossible for me to get enough data for my research you told me, "this is a good study." You encouraged me not to give up. Later, I got data from over 5000 participants, much more than I needed or imagined. Thank you for encouragement. My academic advisor and a committee member, Dr. Saturne, you guided me in portfolio writing and in preparation for comprehensive exam. You always told me, "let's keep moving forward by faith." I have been blessed by your perpetual encouragement and support. Thank you. 
Dr. Janet Ledesma, thank you for teaching me school law and other courses. My first academic advisor and also my teacher, Dr. Covrig, you taught me many leadership courses; you gave me a dozen of books to broaden my knowledge in leadership and in my writing ministry. I made good use of them, and I am very grateful. Dr. Christine Ngei, Esther, and my pastor, Dr. Ashwin Sumasundram, thank you for your prayers and encouragement. You always shared your experiences with me. Dr. Jimmy Kijai, thank you for advising me to use archived data to solve the problem of small data. Mordekai Ongo, thank you for introducing me to Dr. Thayer. Nicole and Hadiya, thank you for formatting my dissertation.

Last and very important, I thank all my participants, students, parents, and educators who allowed me to carry out the study in their schools. Also, I thank Dr. Phillip Kendall and Wilcox, and Dr. Ringenberg, Funk, Mullen, Wilford, and Kramer, for allowing me to use their questionnaires to collect data. Thank you. 


\section{CHAPTER 1}

\section{INTRODUCTION}

Good academic performance can be interpreted as reflecting evidence for learning, while poor performance is usually interpreted as indicating one or more inadequacies in implementation of the school curriculum up to and including failure in school administration and leadership (Shipman, Queen, \& Peel, 2007), or inadequate family support for the importance of education (Epstein, 2008). In this regard, the competency of a school principal is usually evaluated primarily by examining the performance of the students. For example, if students do well in state exams, this shows that the principal is competent in leading the school to achieve its goals. According to Shipman et al. (2007), "the principal's major responsibility and goal is measured by the degree of learning attained by students... on state tests" (p. 62). These authors emphasize the point that it is crucial for students to achieve high performance in state exams.

American students in K-12 achieve low test scores in Program for International Student Assessment (PISA) (Alliance for Excellent Education, 2008), a performance which is not only low, but also falls below that of students from many other countries, including Canada, United Kingdom, Australia, and New Zealand (Yu, Kaprolet, Jannasch-Pennell, \& DiGang, 2012). In order to investigate the cause of this less than outstanding academic performance of American students, a study (Stevenson, Stigler, Lee, Lucker, Kitamura, \& Hsu, 1985) sought to determine whether there were any 
differences based on country of origin in cognitive abilities among Japanese, Chinese, and American children and also to establish whether any possible differences in scores on cognitive tasks such as reading existed for learners from these three cultures. Apparently, results showed essential similarities among the young people of the three cultures in levels, variability, and structure of cognitive abilities. Yet, in spite of similarities in cognitive abilities among American, Japanese and Chinese both Chinese and Japanese students continue to outperform American students in PISA, specifically in science, reading and mathematics.

The problem of poor academic performance for most American students in K-12 has persisted over several decades (Stevenson et al., 1985; Yu et al., 2015). A recent report on PISA results showed consistency in low performance in American students in the international test. The Organization for Economic Cooperation and Development (OECD) report shows that in the 2015 PISA test results, United States was ranked number 25 in the list of countries that participate in PISA (OECD, 2016).

Why are American students outperformed by students from other cultures, such as Chinese, or Japanese? An early study, Stevenson et al. (1985), found that the high academic performance of the Japanese and Chinese children is not due to any superior intellectual abilities, but is shown to be as a result of parental and teacher efforts. These findings are consistent with Epstein (2008) who posits that when parents are involved in the academic activities of their children, the children achieve high academic success.

American children do not only portray problems in academic performance when compared to children from other countries, but also among themselves. Several studies have indicated a far-reaching need to improve performance in K-12 (Allred, 2008; 
Murnane, 2007). Continuous assessments portray a need to equip American students with skills and knowledge to prepare them for college education and pursuit of careers. Murnane (2007) continues to say that "trends among adolescents continue to be discouraging in terms of career and college readiness based on National Assessment of Educational Progress (NAEP) achievement reports and high school graduation rate data" (p. 136). Apparently, the problem of poor academic performance in K-12 affects such important areas such as career development and college readiness. Academic achievement reports show that only one-third of eighth grade students rank above proficiency for mathematics, reading, writing, and science. Also, a big gap in performance persists with Hispanic and African American students attaining not as good scores as the other groups (Radcliffe \& Bos, 2013).

Nonetheless, while most students in public schools in America achieve low academic performance in standardized test, students in Seventh-day Adventist (SDA) schools in North America does not follow the general norm of what happens across the country. Students in SDA schools in North America are shown to be outperforming their peers. Findings of a study done by Thayer and Kido (2012) showed that grades nine and 11 students in SDA high schools in North America achieved far better results in standardized exams, especially in the Iowa tests.

Why does the problem of non-outstanding academic performance persist among American students in K-12? In addition to Epstein's (2008) emphasis on the importance of parental involvement in academic performance, Duckworth and Seligman (2006) posit that student's self-discipline plays a major role student's academic achievement. 
Could student self-discipline and parental involvement explain the reason why students in schools in North American Division (NAD) of the SDA out perform their peers in public schools? The present study was conducted to investigate the impact of student's self-discipline and parental involvement on academic performance.

\section{Statement of the Problem}

Academic performance of K-12 students in North America is a major problem. The majority of student in North America produce undistinguished results in every international assessment of academic proficiency (Alliance for Excellent Education, 2008). Compared to students from other countries who participate in the PISA, US students' performance falls below that of many countries with similar cultural makeup, such as Canada, United Kingdom, Australia, and New Zealand (Yu et al., 2012). However, the while the majority of students in public schools in North America achieve low academic performance in standardized tests, students attending SDA schools in North America outperform their peers in public schools (Thayer \& Kiddo, 2012). What makes students in Adventist schools in NAD outperform their peers in public schools? The present study was conducted to investigate whether student self-discipline and parental involvement can help to solve the problem of non-outstanding academic performance in K-12.

\section{Purpose of the Study}

The purpose of this study was to investigate the impact of student's self-discipline and parental involvement on academic performance. Specifically, the study investigated whether student's self-discipline levels and parental involvement in student's academic 
activities are associated with student's Iowa Test of Basic Skills (ITBS) scores or their grade point average (GPA).

\section{Research Questions}

Originally, this study was planned to be conducted in schools in Texas

Conference of the SDA. However, the researcher did not get enough participants from the schools in that conference. Even after one year of attempting to recruit a sufficient sample size, only 25 subjects from three schools had chosen to participate. Hence, in order to increase statistical power, the researcher decided to use archived data from the CognitiveGenesis (CG) study of SDA. The data from this national sample included measures for all variables crucial to this investigation except student GPA. Nonetheless, because the goals and rationale for the CG study did not originally target the concerns of the present research investigation, only measures of variables defined within CG as closely as possible to the operational definitions required for this study could be used.

Thus, in order to test the research hypotheses and to answer the research questions as thoroughly as possible, the researcher decided to keep and analyze the initial data from the Texas Conference schools in the overall study. But the two data sets could not be combined because the initial study, from Texas Conference schools, used GPA and ITBS to measure academic performance while the CG study used ITBS only. Also, in the initial study, teachers' perceptions were used to evaluate student self-discipline while in the CG data, students themselves were surveyed about their own self-discipline. Hence, this study was conducted in two phases: a preliminary that involved perceptions from teachers about their students' self-discipline and analysis of GPA and ITBS, and a primary study that measured students self-discipline and analyzed ITBS. So, the preliminary study 
refers to the initial study which was conducted in the schools in the Texas Conference of the SDA while the primary study refers to the study which utilized data from the CG. Consequently, each of the two studies had its own research questions, hypotheses and data analysis. Even though the preliminary data was small, the hypotheses were retained in order to enable the researcher to test the research hypotheses with both the preliminary and the primary data. Additionally, the preliminary study hypotheses were retained to evaluate correlations in the preliminary study.

\section{Preliminary Study}

1. Is there a statistically significant relationship between the self-discipline of students in SDA schools, as reported by teachers, and student's GPA or ITBS performance?

2. Is there a statistically significant relationship between parental involvement, as reported by parents, and student's GPA or ITBS performance?

3. Are there combined effects of student self-discipline and parental involvement on student's GPA or ITBS performance? (in other words, do student self-discipline and parental involvement interact in their association with GPA or ITBS scores)?

4. Do ethnicity, gender, age or student grade level have any statistically significant influence on the relationships between student's self-discipline, as reported by teachers, or parental involvement, as reported by parents, and student's GPA or ITBS performance?

\section{Primary Study}

1. Is there a statistically significant relationship between student's self-discipline, as reported by students, and student's performance on the ITBS? 
2. Is there a statistically significant relationship between parental involvement, as reported by parents, and student's performance on the ITBS?

3. Are there combined effects of student self-discipline and parental involvement on student's performance on ITBS? (In other words, do student self-discipline and parental involvement interact in their association with ITBS scores)?

4. Do ethnicity, gender, grade level, student's cognitive ability, and parent level of education have a statistically significant effect on the relationship between student's selfdiscipline, as reported by student, or parental involvement, as reported by parents, and student's performance on the ITBS?

\section{Rationale for the Study: Preliminary and the Primary}

The rationale for this study arises from the need to find out how poor academic performance of students in K-12 in North America can be improved. Research findings show that US students' performance falls below that of many countries with similar cultural makeup (Yu et al., 2012). However, literature records that students in Adventist schools perform much better, academically, than their peers in public schools. Although extensive research has been conducted on students' academic performance, few, if any, have addressed whether student's self-discipline and parental involvement play a part in helping the students in Adventist schools to outperform their peers in public schools. This study sought to provide information about whether student's self-discipline and parental involvement play a part in equipping students in Adventist school in NAD of the SDA to outperform their peers in the public schools. By providing this information, schools that are performing poorly may use it to improve students' academic performance. 


\section{Conceptual Framework for the Study: Preliminary and the Primary}

The conceptual framework guiding this study is based on self-determination theory (SDT) and scholarly culture theory. Self-determination theory derives from general theories of motivation and is associated with students' learning and academic performance (Edvalda, Miranda, Carmo, \& Roberto, 2013). The SDT introduced by Deci and Ryan (1985) distinguishes between intrinsic and extrinsic motivation. Intrinsic motivation moves people to perform activities because they find them interesting, and they find satisfaction in performing them. External motivation, on the other hand, depends on an external reward (Deci \& Ryan, 2000). Past research indicates that intrinsic motivation is the most beneficial type of motivation for students' achievement (Taylor et al., 2014).

Self-determination theory fits the investigation of students' self-discipline and its impact on academic performance as portrayed in GPA and standardized exams such as ITBS. Past studies show that students' self-discipline requires self-determination and intrinsic motivation to focus on school related activities until academic goals are achieved (Duckworth \& Seligman, 2005). Duckworth and Seligman continue to say that students' level of self-discipline predicts their final grades (GPA) better than does their measured Intelligence Quotient (IQ). Students need to involve themselves with activities which improve their cognitive powers such as going for extra coaching and watching educative programs, which assist in academic success (Nachiappan, Marimuthu, Andi, \& Veeran, 2012). Persistence in school related activities requires more intrinsic than external motivation. Hence, SDT is appropriate for this study because if the theory that intrinsic motivation enhances students' academic performance is true, then students' self- 
discipline should impact students' GPAs and their performance on the standardized exam, ITBS, positively.

Further, the principles of SDT state that students' motivation for learning can only be inferred by observing or by self-reporting (Guimarães \& Bzunec, 2008, as cited Edvalda et al., 2013). In this study, teachers will evaluate (measure) students' selfdiscipline based on their observation of the students, which they will report through questionnaires.

The second theory that guides this study is scholarly culture, which was introduced by Spaeth in 1976 (as cited in Evans, Kelley \& Sikora, 2014). The basic aspect of scholarly culture theory is that, "the number of books in the family home, exerts a strong influence on academic performance in ways consistent with the cognitive skill hypothesis" (Evans et al., 2014, p. 1) This theory fits the parental involvement in their children's education aspect for it holds that,

reading provides cognitive skill that enhance educational performance. A home with books as an integral part of the way of life encourages children to read for pleasure and encourages discussion among family members about what they read, thereby providing children with information, vocabulary, imaginative richness, wide horizons, and skills for discovery and play. (Bus \& Ijzendoorn, 1995; Dronkers, 1992; Persson, 1992; Price, 1992, as cited in Evans et al., 2014, p. 3)

The scholarly culture theory is well chronicled by Epstein's (2008) model of parental involvement, which states that parental involvement in their children's academic activities impacts students' academic performance positively. Epstein states that when families are involved in school activities, "more students earn higher grades in English and math, improve their reading and writing skills, complete more course credits, set higher aspirations, have better attendance, come to class more prepared to learn, and have fewer behavioral problems" (p. 10). Apparently, according to Epstein, parents' 
involvement takes more than helping children with homework. It involves such activities as facilitating learning at home, guidance and making decisions that help the children academically.

The scholarly culture theory talks about the impact exerted by books, family discussions and the learning of children in education. Clearly, this theory fits this study as far as parents' involvement in their children's educational activities is concerned. Thus, according to scholarly culture theory, students' GPAs and standardized exams such as ITBS should be positively impacted by parental involvement. The basic conceptual argument that guides this study is that students' self-discipline and parental involvement impacts students' academic performance positively.

\section{Significance of the Study}

This study was conducted to make a contribution toward solving the problem of low academic performance among American students in K-12. The study may inform educators, parents, and policy makers about the impact of student self-discipline and parental involvement on academic performance. Although ways of achieving educational success have been studied by many researchers, poor academic performance persists among students in K-12 schools in North America (Alliance for Excellent Education, 2008; Yu et al., 2012). The academic performance of most US students falls below that of students from many other countries with similar cultural makeup (Heitin, 2013; Yu et al., 2012). Various studies indicate that improving student's self-discipline and parental involvement may help to solve the problem of poor academic performance (Duckworth \& Seligman, 2006; Epstein 2008). 


\section{Delimitations}

\section{Preliminary Study}

The first delimitation is that this study involved only parents, teachers and students in grades six through 12 in SDA schools in the Texas Conference of the SDA Church. Second, 15 schools out of 30 were chosen to participate. Third, in this study socioeconomic status (SES) was not investigated among other demographic variables because most Adventists schools do not collect SES data from parents. Forth, student's self-discipline was measured through the perception of teachers.

\section{Primary Study}

In this study, researcher tested Epstein's model of parental involvement. One of the delimitations is that two of the six factors that make up parental involvement in Epstein's model (2008), decision making and collaboration with community, were not analyzed because the CG data do not have information on the two factors. So, only four factors, out of six, were analyzed. Two, in the primary study, only ITBS was to measure academic performance unlike in the preliminary study where both GPA and ITBS were analyzed. Three, the CG data which was used in the primary study had a few items to measure some variables.

\section{Methodology}

\section{Preliminary Study}

This is a correlational, cross-sectional study set to investigate the impact of student's self-discipline and parental involvement on academic performance. The study was conducted in schools in NAD of the SDA. First a preliminary study was done in 
Adventist schools in Texas Conference of the SDA. Students in grades six through 12, their parents, and the teachers who taught the sampled students were requested to participate in the study. At first fifty percent of the 30 Adventist schools in Texas Conference were sampled to participate in the study. So, fifteen schools were chosen to participate. All the teachers teaching in grades six through 12 in the 15 selected schools were requested to respond to questionnaires to give their perceptions on the students' self-discipline. Parents of the sampled students were requested to respond to questionnaires to assess their parental involvement in educational activities of their children. But when most of the sampled schools chose not to participate, research invited all the Adventist schools in the Texas Conference to participate.

In addition, secondary data was drawn from analysis of the ITBS, and students'

GPA. Researcher obtained permission from parents to access students' academic records. Parents were promised confidentiality within members of the research team. The collected data were analyzed to check if there is any relationship between students' selfdiscipline and parents' involvement and academic performance. However, research did not get enough participants from Texas Conference Schools in spite of inviting all those willing to participate. As a result, researcher used archived data from CG in order to increase statistical power.

\section{Primary Study}

Later a more comprehensive cross-sectional, representative study was conducted in schools in North American of the SDA schools. The study focused on students in grades six through eight and their parents. Additionally, ITBS scores were analyzed to 
investigate the impact of student self-discipline and parental involvement on academic performance. The details of the methods are found in Chapter 3.

\section{Definition of Terms}

Academic performance: refers to the level at which students demonstrate understanding of subject matter and problem-solving. In this study, academic performance was measured through analysis of students' GPA and ITBS scores Academic success: refers to academic performance which includes progressing to the next grade level, passing exams and standardized tests (Finn \& Rock, 1997). In this study, academic success refers to attaining ' $A$ ' or 'B' in GPA or above average (75 99\%) national percentile rank (NPR) in ITBS scores.

Communication: refers to exchanging information between parents and the school where one's child attends and between parents and children.

Decision making: refers to taking a stand on the child's academic activities.

Diligence: refers to persistence in working to achieve the set goals.

Distractions: refers to spending more than two hours a day watching TV, talking with friends on the phone or by computer, playing on the computer, or listening to music for fun.

Facilitating learning at home: refers to setting study time at home, providing books and other resources.

GPA: Refers to grade point average. Students' current GPA data were recorded from school academic records, and it was measured through analysis of the grades. Grades 'A' and ' $\mathrm{B}$ ' showed high academic performance, grade ' $\mathrm{C}$ ' average while ' $\mathrm{D}$ ', ' $\mathrm{E}$ ' and ' $\mathrm{F}$ ' indicated poor academic performance. 
ITBS: Iowa Test of Basic Skill is a standardized national exam which is administered to show students' achievement in Language Arts, Reading, Math, Science and Social Studies (Bright Edu. Para. 1). There are three levels at which the ITBS is measured: above average (75-99\%), low average to high average (25-74\%), below average (124\%) (Berea, NPR). In this study, the student's Normal Curve Equivalent was used to measure academic performance. Seventy-five to $99 \%$ will indicate high academic performance, 25 - 74 average, one to 24 poor academic performance.

North American Division of the Seventh-day Adventist schools: refers to the schools that belong to the SDA Church within the NAD. These provided the population and sample for this study.

Parent And School Survey (PASS): is a questionnaire designed to measure parental involvement in their children's education, (Ringenberg, Funk, Mullen, Wilford, \& Kramer, 2005), which was administered to parents in the preliminary study to measure their involvement in their children's education.

Parental involvement: Refers to communicating, volunteering especially at the school where one's children are attending, facilitating learning at home, parenting, decision making, and collaborating with community (Epstein, 2008).

Poor Academic Performance: In this study, poor academic performance refers to attaining a grade below ' $\mathrm{C}$ ' in GPA or an NCE of 1-24\% in the ITBS scores. Self-discipline: The English Oxford Living Dictionaries (1989) defines self-discipline as "the ability to control one's feelings and overcome one's weaknesses; the ability to pursue what one thinks is right despite temptations to abandon" (noun, para. 1) 
In this study self-discipline refers to focusing, working diligently on school work and resisting distractions in order to achieve academic success.

Self-Control Rating Scale (SCRS): This is a valid, well established and reliable instrument constructed to measure students' level of self-discipline using a scale from 1 to 7 (Kendall \& Wilcox, 1979). Teachers' responses to this questionnaire were used to measure students' self-discipline.

Taking responsibility: refers to acknowledging that one is responsible for one's academic performance.

Texas Conference of the Seventh-day Adventist schools: refers to the schools that belong to the SDA Church within the Texas Conference, which covers two thirds of the state of Texas. These provided the population and sample for the preliminary study. Volunteering: refers to participating in school activities in the school where one's child is attending. 


\section{CHAPTER 2}

\section{LITERATURE REVIEW}

\section{Introduction}

The literature reviewed in this chapter focuses on previous studies on student's self-discipline, parental involvement, academic performance and student demographics. The section on students' self-discipline was discussed first because it presents one of the main ideas involving this study.

The second section of this chapter focuses on parental involvement. The impact of parental involvement in students' academic performance was discussed in the second section because it is one of the independent variables of this study. Research shows that parents' involvement in the education of their children produces positive results in academic performance (Epstein, 2008; Hill \& Taylor, 2004). Parental involvement refers to communicating, volunteering at school where a parent's child is going to school, facilitating learning at home, parenting, making decisions and collaborating with the community for the benefit of the children (Epstein, 2008). Various studies report significant impact of students' self-discipline and parents' involvement on students' academic performance (Duckworth \& Seligman, 2005, 2006).

The third section of this chapter presents academic performance, which is an important element of this study as the dependent variable. Academic performance refers 
to progressing to the next grade level, and passing standardized tests (Finn \& Rock, 1997).

\section{Students' Self-discipline}

Student's self-discipline has shown to have a significant impact on academic performance (Anila, 2016; Duckworth \& Seligman 2005, 2006; Washull, 2005).

Duckworth and Seligman (2006) did two longitudinal studies to investigate the impact of self-discipline on academic achievements. In the two studies, self-discipline and selfcontrol were used interchangeably, and were both defined as "the ability to suppress prepotent responses in the service of a higher goal and further specifying that such a choice is not automatic but rather requires conscious effort" (p. 199). In order to suppress innate responses to focus on a desired goal calls for self-discipline, which students need to exercise throughout their academic years.

Duckworth and Seligman (2006) study one involved 140 eighth grade students from diverse socioeconomic and ethnic backgrounds. The authors collected self-reports, parent, and teacher questionnaires in addition to delaying gratification data. A semester later, they recorded report card grades, school attendance and standardized test scores. Results showed that girls were more disciplined than boys. Also, girls achieved better grades than boys in Algebra 1, English, and social studies. They reported that "Effect size ranged from d_.48 for Algebra II to d_.70 for English, which is significant. Girls also outperformed boys on the standardized achievement test (d_.30), but consistent with our prediction, this advantage was half that for overall GPA (d_.66) and not statistically significant" (p. 201). This study demonstrated the importance of students' self-discipline in academic performance. 
In the second study, Duckworth and Seligman (2006) replicated the first research design with the following cohort of students in the same middle school. Participants were 164 eighth grade students. The authors added IQ test to compare the relationship between aptitude and achievement tests, gender and self-discipline, and report card grades. Intelligence quotient scores were recorded. Results indicated that "girls earned significantly higher final grades in Algebra II, English, and social studies than did boys. Girls also earned higher final grades in Algebra I, though this difference failed to reach statistical significance" (p. 203). In both study one and study two Duckworth and Seligman (2006) report that girls finished the school year with much stronger grades than boys. Yet girls' IQ was lower than that of boys according to results from standardized tests.

According to the results, girls outperformed boys in the subjects, math included. Even though girls' IQ was lower than that of boys, as portrayed by girls' lower score in some standardized tests such as SAT, they obtain higher GPAs than boys, which portrayed diligence in studying for exams, completing homework and long-term projects on time, and active positive contribution in class (Duckworth and Seligman, 2006). The study demonstrated the importance of students' self-discipline in academic performance.

Further, in two longitudinal studies which involved 1,364 middle school students at the National Institute of Child Health and Human Development, Duckworth, Quinn and Tsukayama (2011) investigated the role played by self-control and the role played by IQ in academic performance. In the study "self-control refers to the voluntary regulation of attention, emotion, and behavior in the service of personally valued goals and standards" (p. 2). How can students achieve academic goals without focusing and working on academic activities? 
In the study, Duckworth et al. (2011) tested the following two hypotheses, among others: "Self-control is a better predictor than IQ of improvements in report card grades over time," and "IQ is a better predictor than self-control of improvements in standardized achievement test scores over time" (p.3). The two studies confirmed both hypotheses. In both studies, results indicated that self-discipline was a better predictor of GPA than was IQ. It follows that self-discipline impacts student's academic success, especially in GPA.

Findings from various studies indicate that highly self-controlled people achieve better grades than people with less self-control. "Advocates of self-discipline have long speculated that it will produce better performance... The results are consistent with the view that high self-control fosters strong academic performance" (Tangney, Baumeister, \& Boone, 2004, p. 311). Without self-control a student will engage in any activities that feel more exciting compared to studying diligently for long hours.

On the part of a student, self-discipline involves focusing on activities that are helpful in attaining academic success, such as completing school assignments on time, reviewing notes, listening to teachers in class instead of engaging in tendencies that destruct from accomplishing academic assignments. For most middle and high school students, playing games, watching entertainment programs on television or texting friends is more exciting than solving math problems or studying history chapters to complete class assignments. Yet, students need to spend more time on school work than they do on entertainments in order to excel in school (Duckworth \& Seligman, 2006).

Self-regulation works closely together with self-discipline in academic achievement. Self-regulation involves engaging oneself in school related activities such 
as reviewing notes, going for extra coaching, doing assignments, studying and watching educative programs instead of going for entertainment Zimmerman and Ramdass (2011). Zimmerman and Ramdass investigated the relationship between homework and selfregulation, which is defined as "proactive process whereby individuals consistently organize and manage their thoughts, emotions, behaviors, and environment in order to attain academic goals" (p.198). Results indicated that students needed to learn how to set goals, how to choose the right learning strategies, and the art of monitoring their performance. Also, results showed the need for students to learn the habit of thinking about the learning outcomes over a long period of time for them to become selfregulated.

Self-regulation skills enhance learning. (Eilam, Zeidner, \& Aharon, 2009; Zimmerman \& Ramdass, 2011). To regulate oneself and to focus on school work until academic goals are achieved requires self-discipline. A study, Zimmerman and Kitsantas (2014) indicated that students who exercise both self-discipline and self-regulation achieve higher test scores than when either self-discipline or self-regulation is applied. Hence, in this study self-discipline involves self-regulation. Zimmerman and Kitsantas (2014) say that self-regulated students are confident, diligent and productive. They are self-motivated to learn, which propels them to go out of their way to seek information. Also, self-regulated students know when they do not understand something, and they seek help. The learners focus their thoughts, feelings, and actions to school work so that they may achieve their academic success (Bembenutty, 2011; Zimmerman, 1990).

From self-regulation children learn to be caring, purposeful and diligent. The qualities that make up self-regulation involve such abilities as delaying gratification, 
controlling impulses, paying attention and staying on task (Bodrova \& Leong, 2006; Han \& Kempl, 2006, as cited in Wentzel, 1993). These are the same traits that are portrayed by self-disciplined students.

Focusing on academic activities requires self-discipline in order to avoid habits such as spending too many hours on the computer especially when the student is not using the computer to perform school related activities. A study, Inal, Kelleci, and Canbulat (2012) that involved 1100 high school students randomly chosen from four state schools sought to investigate the impact of computer use and the internet on the high school students. Results indicated that most students who earned a GPA above three had computers at home, but they spent less than two hours on the computer. To stay away from a computer to study takes self-discipline, a goal to achieve and determination to pursue the goal. Also, restricting the time spent on computer to only two hours in a day portrays high level of self-discipline. Inal et al. (2012) continue to say:

In some studies, it was reported that as the period of internet use increased, emotional and behavioral problems such as solitude, social isolation and aggression were more widely observed in children and teenagers, their general health levels decreased, and percentage of finding depressive symptoms increased. Prolonged internet use not only causes disorders in interpersonal relations, but adversely affects performance at school as well. (p. 1649)

It is evident that lack of self-discipline to control oneself in matters such using the internet does not only cause academic problems but is also associated with poor health and depressive symptoms.

Self-discipline impacts such school related activities as time management, reading and note-taking (Fazal, Hussein, Majoka, \& Masood, 2012). It is no wonder that less selfdisciplined students achieve low academic achievements compared to highly disciplined students. 
Regardless of its importance in academic performance, self-discipline is not without critics. A study, Zimmerman and Kitsantas (2014) that used

a multi-source, multi-measure research design involving 507 high school students and their teachers, compared prediction of these students' academic achievement by a composite of students' and teachers' measures of students' self-regulation (SR) with a composite of students' and teachers' measures of students' self-discipline (SD). (abstract)

Zimmerman and Kitsantas (2014) posit that earlier researchers, such as

Duckworth and Seligman (2005), who investigated the impact of students' self-discipline on academic performance focused on overcoming performance problems. Such studies emphasize Performance processes, which are designed to guide students to complete a task optimally. According to Zimmerman and Kitsantas (2014), students achieve better academic results when they focus on learning processes which are set up to help learners to attain the ability to improve their academic skills.

Nevertheless, the results of the hierarchical regression analyses of the study, Zimmerman and Kitsantas (2014), showed that the self-discipline and self-regulated composites were moderately correlated $(r=.54)$. Results indicated that the variance in GPA which was predicted by self-discipline composite was much smaller that the variance predicted by self-regulation. Nonetheless, combined, GPA and self-regulation showed a stronger prediction of academic performance that either of them alone.

The fact that combined, self-discipline and self-regulation earned students higher GPA than when self-regulation was used alone shows that self-discipline is a crucial ingredient in academic performance. Also, high academic performance indicates students' mastery of content; hence learning. At this time when accountability is much emphasized, it is crucial for students to perform highly in tests and examinations because 
that is one of the major indications that students actually learned. Various studies have shown that students may have high IQ, but if they do not exercise self-discipline they do not attain high academic performance. Self-discipline enables students to focus on academic studies instead of choosing other competing activities, such as entertainments (Chamopro-Premuzic \& Furnham, 2003; Duckworth \& Seligman, 2005).

\section{Parental Involvement}

Parental involvement refers to communicating, volunteering especially at the school where one's children are attending, facilitating learning at home, guidance, decision making, and collaborating with community (Epstein, 2008).

Parents' involvement encourages two-way communication between home and school. These enable parents to stay informed about the progress of their children. Open communication between school and home provides parents with information which they need to assist teachers. When teachers and parents work together students' self-discipline is strengthened, which in return, aids in high academic success. Also, volunteering is encouraged so that parents and guardians can get a chance to be trained on educational activities that equip them to participate in school activities. The benefits of training parents and other volunteers include equipping them to talk to students on important topics such as careers (Epstein, 2008).

In addition, when parents are involved in the learning of their children, they facilitate learning at home (Cabus \& Aries, 2017). This is very crucial especially for students who need extended time to meet educational goals. The factor of decision making includes involving parents in developing mission statements and improving school policies which affect students and families. Also, there is need for collaboration 
among families, school and communities. Collaboration with the community calls for the whole community to get involved in order to support the school by utilizing all resources at their disposal (Epstein, 2008). With this kind of involvement, students receie the help and assistance they need to achieve academic success.

Parental support takes more than guiding children to complete homework. Research revealed two types of parental involvement. One type is school-focused, which takes place when parents participate in school activities. The second type of involvement is student-focused, which happens when parents focus on assisting their children in ways that lead to high academic performance (Barge \& Loges, 2003; Hill \& Taylor, 2004; Shute, Hansen, Underwood, \& Razzouk, 2011; Wang \& Cai, 2017).

Sheldon and Epstein (2005) investigated the effects of school, family and community partnership on students in elementary, middle and high schools. Results met the researchers' expectations that "subject specific, family-involvement activities will likely affect student outcomes in the targeted curricular subject. Many students in elementary schools achieved As and Bs on their report cards in mathematics" (p. 200). It seems as though when parents get interested in the learning of their children and participate in learning activities, it gives their children more motivation to learn. What about teachers? Do they pay more attention to those children whose parents are keenly monitoring what their children are doing at school?

Parental involvement in education is also associated with improved social behavior, social competency, and better all-around behavior at home and school. Hill and Craft (2003) did a study on 103 kindergarten children and their mothers. The families were from diverse socioeconomic background. The study sought to find out both the 
impact of parent school-focused involvement, and parent student-focused involvement. Results showed improved performance in math for African-American children. EuroAmerican children performed better in academics than African American children. "Social competence mediated the relation between home involvement and math performance for Euro-Americans" (p. 80). This study demonstrated that the more parents get involved in helping their children, the better the children's grades become.

Parental student-focused involvement requires the presence and the assistance of the parent to the child at home (Boersma \& Chapman,1983, as cited in Mark, 2012; Lenka \& Kant, 2012). Families play a key role in improving behavior and in providing engagement. Unfortunately, many parents or guardians of children who have discipline issues stay away from school instead of availing themselves and giving the school the needed support. Eradicating behavioral issues in students will improve students' selfdiscipline thus improving academic performance (Friescen \& Osher 1996). It is very ironical that parents whose children need their support most, in order to improve their self-discipline, are the ones who hardly cooperate with teachers or get out of their way to support their children's educational activities.

While many studies have shown that parents' involvement in their children's education lead to high academic performance, (Barge \& Loges, 2003; Hill \& Taylor, 2004; Wang \& Cai, 2017), it is not all types of parents' involvement that yield high academic achievement for all children. A study, (Hill \& Tyson, 2009) investigated the type of parental involvement that lead to high academic achievement during the adolescent years. Results showed that academic socialization was the highest positively correlated with academic performance during the middle school years. 
Academic socialization includes the types of strategies that will scaffold adolescents' burgeoning autonomy, independence, and cognitive abilities. In addition, this type of involvement represents developmentally appropriate strategies of involvement, as it fosters and builds upon the development of internalized motivation for achievement, focuses on future plans, provides a link between school work and future goals and aspirations, and is consistent with the needs of middle school students. (Hill \& Tyson, 2009, p. 758)

Traits such as involvement, focusing on school work and setting of future goals require self-discipline. Students' self-discipline in middle and high school continues to impact their academic performance into college/university, especially during the first year. A study by Allen, Robbins, and Casillas (2008) that involved undergraduate students showed that students' GPA during the first year of college correlates with high school GPA and ACT. It makes sense to say that students' self-discipline impacts their academic performance not only during middle and high school years, but also during college/university years.

Many projects in education require setting long-term goals and working on them with determination and consistency. By the time students reach middle and high school, they realize that academic activities are crucial in attaining high academic success, but they need hard work. That is why self-discipline has been found to be an accurate predictor of academic achievement among adolescents, independently of IQ (Duckworth \& Seligman 2005; Duckworth, Quinn et al., 2011).

Learning processes are required for students to acquire capabilities and improve their academic skills (Rodríguez et al., 2017; Zimmerman \& Kitsantas, 2014). Yet, in this digital age where gratification is achieved instantly, persisting on academic activity until a skill is mastered has become a lost art. Students need not only to be taught academic lessons, but also the life skill of self-discipline (Konrad, 2014). 
By the time children get to middle school, they need to have developed selfdiscipline and enough skills to work on their academic activities independently (Englund, Luckner, \& Whaley, 2004). Students need to learn to control themselves in order to attain their academic goals (Duckworth \& Seligman, 2006). Parents' involvement in the academic activities of their children is needed both at home and at school.

The performance of school administrators and teachers is usually judged from the academic performance of their students. "The principal's major responsibility and goal is measured by the degree of learning attained by the students...on state tests" (Shipman et al., p. 62, 2007). However, while policy makers and the government hold school principals and teachers accountable for the learning and high academic performance of their students, results from various studies show that students and their parents have a key role to play to ensure excellent academic achievement. One major factor in students' academic performance is the student's self-discipline, which according to Waschull (2005), impacts all areas of academic performance. Additionally, research has shown that parental support impacts students' academic performance (Epstein, 2008).

Even though there seems to be no studies that combine students' self-discipline and parents' involvement on students' academic performance, various studies show that students' self-discipline improve academic performance (Duckworth \& Seligman, 2005, 2006). Other studies indicate that parents' involvement aid students' academic success (Epstein, 2008). Also, various studies indicate that cooperation between parents and teachers boosts students' academic performance. (Burke, 1998; Chavkin, 1994; Epstein, 2008; Friescen \& Osher 1996, Hara \& Burke, 1998).

On the other hand, whereas various studies have shown that self-discipline results 
in high academic performance, lack or self-discipline predicts poor grades. Myers, Milne, Baker, and Ginsburg (1987) did a survey to find out the relationship between student misbehavior and academic performance and the impact of family structure together with mother's employment on the children's misbehavior and school performance. The findings showed that misbehavior (lack of self-discipline) has negative impact on school grades.

It is clear that self-discipline is necessary in academic performance. How do student develop self-discipline? It appears that more children from single parents have more self-discipline issues than most children from two parents. Most single parents are said to work long hours to provide for the family's financial needs. This shows that parental involvement in the learning of their children is crucial to aid in learning selfdiscipline and also in academic performance and educational success. It is very helpful for parents to create an environment conducive for doing school work at home.

Tocci and Engelhard, 1991, as cited in Guner (2012) posit that when parents are involved in educational activities of their children, the learners earn better grades than when parents are uninvolved. For instance, parental support and encouragement boosts children's confidence in mathematics. Involvement includes parents helping children with homework, supervision and encouragement, which have been found to boosts selfdiscipline and academic performance.

The importance of parents' involvement in the learning of their children cannot be over emphasized. A study, Plomin (1989) estimated that the relative effects of genes and environment are about equal. The study reports that the influence of hereditary factors is about 60\% (as cited in Fritzberg, 2001). 
If environment influences account for roughly one-half of any given individual's intelligence ... then we cannot assume that any individual's educational and occupational performance is a simple reflection of the opportunities she has been given... A 40-50\% degree of environmental influence is easily large enough to explain group differences between blacks and whites. (Fritzberg, 2001, p. 125)

It appears that enviromental situations make a big difference between academic succuss and failure. Parental involvement such as providing children with a conducive area for study and visiting school where one's children are learning to find out what is expected of the children is important in giving children the necessary parental support. Also, students need to cooperate with teachers and do their school work. IQ alone does not afford a student a high GPA (Duckworth \& Seligman, 2006). It is evident that both parental involvement and a studetnts' self-discipline is necessary for high academic performance.

\section{Academic Performance}

Several studies show that American students' PISA falls below that of students from many countries including Canada, United Kingdom, Australia, and New Zealand. (Yu et al., 2012). A study, Stevenson et al. (1985), that sought to determine whether there are any

differences in cognitive abilities of Japanese, Chinese, and American children and to investigate the possible differential relation of scores on cognitive tasks to reading by children of the 3 cultures. Similarity was found among children of the 3 cultures in levels, variability, and structure of cognitive abilities. Chinese children surpassed Japanese and American children in reading scores; both Chinese and Japanese children obtained higher scores in mathematics than the American children. (p. 718)

Stevenson et al. (1985), state that the findings of this study suggest that the high academic performance of the Japanese and Chinese children is not due to any superior 
intellectual abilities but is shown to be as a result of parental and teacher efforts. This demonstrates that academic success takes more than IQ.

What are the home and school experiences that enable Chinese and Japanese children to outperform American children? American children spend the least time on academic activities compared to Chinese and Japanese children. According to Stigler et al. (1987), while first grade American children spent 69.8\%, Chinese, and Japanese children spent " $85.1 \%$, and $79.2 \%$ of the time respectively, engaged in in academic activities. At the fifth grade, the corresponding percentages were $64.5 \%, 91.5 \%$, and 87 . 4\%" (p. 1276). These differences of time the children had on academic performances were evidently portrayed in their academic performance.

American children are not innately less intelligent than Chinese or Japanese children. The difference is in the focus and the effort that Japanese, Chinese and American children put in their academic work (Stevenson et al., 1985). Various studies have shown that the more time students spent on academic activities, whether at school or at home, the better their academic performance. Academic achievement requires, among other things, students' self-discipline, and self-regulation. (Duckworth, Quinn et al., 2011; Duckworth \& Seligman, 2005; Stigler et al., 1987; Zimmerman \& Kitsantas, 2014). Academic performance issues for American students K-12 do not only feature in international tests. Within North American schools, there is a broad concern and a need to improve academic performance (Bryant et al., 2008; Murnane, 2007). Also, among the American children, there are major inequalities in academic achievement. The difference between those who achieve academic success and those who do not has been widely 
researched. Some of the reasons given for variations on performance involve IQ and environmental factors.

Sowell (1977) demonstrated the importance of both IQ and environment in academic achievement. Sowell states that almost all the southern and eastern European ethnic groups that immigrated to America earlier this century lagged behind white natives in IQ scores until they assimilated into the dominant culture. Some of the environmental issues that inhibit students from achieving success in school involve lack of supervision of children, especailly those from poor single parents who work long hours to provide for the family (Murnane, 2007). Absent parents cannot teach their children self-discipline that students need to excel in academics activities

In pursuit of academic success for all students in North America, the federal government came up with the No Child Left Behind (NCLB) Act of 2001. But the Act put many educators in a dilemma. Many teachers and school administrators operate under much pressure to prepare their students to perform well in standardized math and reading tests. The emphasis in these two subjects is done at the expense of other subjects, such as civics, creative thinking, social and emotional. "Students need more than just reading and math skills for a successful, engaged life" (Allred, 2008, p.26). Alone, policies cannot fix the problems of poor academic performance. In spite of the federal government's intervation through NCLB, academic achievement continues to be a problem in $\mathrm{K}-12$ (Bryant et al., 2008; Murnane, 2007). One of the key factors lacking in the students who do not achieve academic success is self-discipline (Duckworth \& Seligman, 2005, 2006). Students need to be taught self-discipline and self-regulation. 
According to Ramdass and Zimmerman (2011), self-regulation habits do not get formed over- night. It takes practice. "It is important to continue with training studies at all grade levels so that students can become aware of the relationship between homework activities and these self-regulation processes such as goals, self-efficacy, self-reflection, time management, and delay of gratification" (p. 194). Just like self-regulation, selfdiscipline requires continued training throughout all grade levels. Students need to understand that success in education requires setting goals and working hard to attain them (Duckworth \& Seligman, 2006).

A study, (Brigman \& Campbell, 2003) that sought to find out whether counselorled interventions could lead to improved cognitive, social, self-management skills and academic performance involved 180 elementary and high school students as participants. Results showed that seven out of ten students improved behavior in eight months. As a result, students improved academic achievement by twenty two percent. It is no surprise that students in this study improved their grades significantly because their behavior improved. The results indicate that they improved cognitive, social, and selfmanagement. Self-management could be used interchangeably with self-regulation. These traits indicate self-discipline. Various studies have shown that once self-discipline is in place, academic success is achieved (Duckworth \& Seligman, 2005; Zimmerman \& Kitsantas, 2014).

While it is crucial for parents to assist their children through guidance and assistance in academic work, research indicates that majority of parents want their children to succeed in school, but they do not know how to help their children to achieve academic success (Epstein, 1986). Equipping parents to assist their children can be 
helpful in improving academic performance. Thus, encouraging parents to team up with teachers is necessary for parents to know what teachers expect of their children and to learn how to help the children to meet their academic needs.

Research findings indicate that it is crucial for children to engage in activities that foster academic enhancement even when they are at home. It is the responsibility of parents and teachers to ensure that children are in a conducive learning environment both at school and at home (Hara \& Burke, 1998). For example, students should spend limited time on the internet. Young people should be given more time to interact instead of spending long periods of time on the computer. Such care will lead to better educational improvement. When the time spent on computer use is kept under control, students achieve high grades in school (Inal et al., 2012).

\section{Student Demographics}

\section{Students' Ethnicity}

Research indicates major differences in academic performance along racial lines. White are shown to lead while minority groups underperform in all subjects (Altbach, Berhdahl, \& Gumport, 2011; Fritzberg, 2001; McGee, 2004).

\section{Student Gender}

Past studies have shown significant differences in academic performance between genders. In standardized test, boys are shown to outperform girls. However, girls achieve higher GPAs than boys (Duckworth \& Seligman, 2005, 2006). But Zimmerman and Kitsantas (2014) posit that there was no difference in academic achievement based on gender. 


\section{Student Age and Grade Level}

Students' learning activities and tests are planned according to the students' age and grade. (Snowman, McCown, \& Biehler, 2012). Intelligence levels of older children are shown to be higher than the intelligence levels of the younger children (Bower, 2007; Kluger \& Cray, 2007). Past studies show a significant relationship between students’ demographic variables and academic performance. For that reason, the present study will control for the impact of students' ethnicity, gender, and age on academic performance.

\section{Summary}

This literature review was conducted in order to better understand the role of students' self-discipline and parental involvement on academic performance. In the United States of America, academic performance is portrayed as a major concern especially among educators due to poor academic performance in K-12 (Alliance for Excellent Education, 2008). Past research indicates that student's self-discipline predicted academic performance better than IQ (Duckworth \& Seligman, 2005). According to Waschull (2005), student's self-discipline impacts all areas of academic performance. Frameworks such as SDT is suggested in search to understand students learning and academic performance (Edvalda et al., 2013).

The impact of parental involvement in academic activities of their children was also reviewed. Findings from various studies indicated that parental involvement results in high educational achievements (Epstein, 2008; Hara \& Burke, 1998; Kohl, Lengua, \& McMahon, 2000). Scholarly culture theory is suggested by Evans et al. (2014), as one of the strong influences on academic performance. Also, literature review indicated major differences in academic performance based on ethnicity, gender, age and grade level. 
The role of student self-discipline combined with parental involvement was reviewed as well. Literature seems to have almost no studies that investigated the impact of student's self-discipline combined with parental involvement on academic performance, a gap that the present study may fill. In addition, while literature portrays an undistinguished academic performance of students in public schools in America (Yu et al., 2012), Adventist schools in North America are portrayed to outperform their peers in the public schools (Thayer \& Kiddo, 2010). But literature does not offer explanation as to how students in the Adventist schools are able to achieve academic success. The present study investigated whether student self-discipline and parental involvement play a part in enabling high academic performance in the Adventist schools. This literature review reflects the theoretical framework, self-determination and scholarly culture, which guided the current study. The next chapter presents details on how this study was conducted. 


\section{CHAPTER 3}

\section{METHODOLOGY}

\section{Introduction}

This quantitative study was conducted to investigate the impact of student selfdiscipline and parental involvement in their children's academic experiences on student academic performance. Initially, the researcher planned to conduct this study within schools in the Texas Conference of SDAs. Also, originally, the researcher planned to measure academic performance by analyzing student's GPA and ITBS test scores. However, researcher did not obtain enough participants from the schools in Texas Conference, due at least partly to local and regional educational leaders denying permission for conducting the research. Even after one year of attempting to recruit a sufficient sample size, only 25 subjects from three schools had chosen to participate. Hence, in order to increase statistical power, the researcher decided to supplement this small, original sample with archived data from the CG study, which collected data from all students in SDA schools in North America, in grades three through nine and 11.

The present study utilized data from grades six and seven. The data from CG sample included measures for all variables crucial to this investigation except student GPA. For that reason, GPA was not analyzed in the supplemental, primary study because the CG did not have the data. But in the preliminary study, both GPA and ITBS were analyzed. Therefore, since the goals and rationale for the CG study did not originally 
target the concerns of the present research investigation, only measures of variables within $\mathrm{CG}$ defined as closely as possible to the operational definitions required for this study could be used.

Nonetheless, from its inception, this study intended to investigate the impact of student's self-discipline and parental involvement on student academic performance. Academic performance was originally meant to be measured through GPA and ITBS. But the CG database did not include GPA, while the preliminary study had both GPA and ITBS. Thus, in order to test the research hypotheses and to answer the research questions as thoroughly as possible, the researcher decided to keep and analyze the initial data from the Texas Conference schools in the overall study. However, the two data sets could not be combined because the initial study, in Texas Conference, used GPA and ITBS while the CG study used ITBS only. Also, while the initial study in Texas Conference schools used teachers' perceptions to evaluate student self-discipline, in the CG data, students themselves reported about their own self-discipline. Hence, this study was conducted in two phases: a preliminary (the 'original') and a primary (the 'supplemental') study. The preliminary study refers to the initial study conducted in the schools in the Texas Conference of SDAs, while the primary study refers to the study which utilized data from CG.

Another advantage of keeping the initial data, the preliminary study, is that the smaller sample more closely matched the original intent of this study and may serve as a platform for further research. Yet the CG data, based on a nationwide sample, provided higher statistical power to test the primary hypotheses and featured demonstrated 
reliability for its measures of student self-discipline and parental involvement (Thayer \& Kido, 2012).

Furthermore, in addition to investigating the impact of student self-discipline, this study was designed to test Epstein's (2008) model of parental involvement, which involves the following six constructs: parent-school communication, parenting, volunteering, learning at home, decision making, and collaborating with community. In the preliminary study, all these six constructs were measured and analyzed, but in the primary (supplemental) study only the first four constructs (parent-school communication, parenting, volunteering, learning at home) were analyzed. 'Decision making' and 'collaborating with community' were not evaluated in the primary study, because the CG data did include enough data to analyze these two factors.

So, each of the two studies, the preliminary and the primary, addressed its own research questions, hypotheses, and data analysis, although as much conceptual and methodological overlap as possible was maintained.

\section{Population}

\section{Preliminary Study}

The population for the preliminary study was the middle and high school students in grades six through 12 in the schools of the Texas Conference of the SDA Church, their teachers and their parents. The total number of students in grades six to 12 in all the Adventist schools in Texas Conference was 1,290. The following are the numbers in each class: sixth grade: 213 ; seventh grade: 215 ; eighth grade: 224 ; ninth grade: $153 ; 10^{\text {th }}$ grade: $167 ; 11^{\text {th }}$ grade: $161 ; 12^{\text {th }}$ grade: 157 . A total of 1,290 students make $100 \%$ of the 
population. In addition, the total number of teachers who taught grades six to 12 in the schools of the Texas Conference of the SDAs was 180.

In the preliminary study, the researcher chose to measure student self-discipline by surveying teachers' perception on their students' self-discipline because research such as Combs (2001) shows that grown-ups who interact with students closely can adequately be surveyed about the student's self-discipline. Combs posits that "behavior is the product of personal meaning. Children are naturally sensitive to the feelings and attitudes of the grown-ups around them" (p. 260). The study concluded that a person, such as teacher, can accurately perceive the attitudes of students, their feelings and beliefs by way of observing, deduction, performance and correction.

Another study, Shimada, Moriyama and Matsuura (2006) investigated student's attitude toward self-discipline in students in grades 10-12. Results showed that it takes students a long time for them to quite understand their own self-discipline. The researchers posit that "the closer the students get to graduation, the more conscious they become of self-discipline" (p. 51).

These studies suggest that it is quite appropriate to measure student self-discipline through surveying the perceptions of their teachers, especially if the students are in grades six through 12 .

Yet other studies measured student self-discipline by surveying the students themselves, and the results were quite adequate in investigating the impact of student self-discipline on academic performance (Duckworth \& Seligman, 2006; Thayer \& Kido, 2012). For that reason, the current student employed both methods. While in the 
preliminary study the researcher surveyed teachers' perceptions on student selfdiscipline, in the primary study the students themselves were surveyed.

\section{Primary Study}

The subjects for the primary study were students in grades six and seven in SDA schools in North America, in 2006/2007 and in 2007/2008. All students in grades six and seven were invited to participate in the study. But only subjects who responded to all research questions were used in this study. A total of 2457 grade six students participated while 2687 grade seven students participated. Both grade six and seven participants combined were a total of 5,144, and their parents. Selection of subjects was based on the CG data collection procedure outlined in Thayer and Kido (2012).

\section{Sample}

\section{Preliminary Study}

As shown in the population section above, it is clear that Adventist schools in the Texas Conference had relatively fewer students and teachers. Consequently, in order to select a sufficient sample size adequate to predict population parameters with $95 \%$ confidence intervals, this study chose 15 schools out of 31 , which is 0.50 of the population.

The following is a detailed description of the sampling procedure for the preliminary study. Researcher used random sampling to choose $50 \%$ of the 31 schools in Texas Conference of SDAs, which gave researcher 15 schools to sample for the study. One school was not included in the sampling because it did not have a middle or high school. All students in grades six through 12 in the 15 chosen Adventist schools in Texas 
Conference, 645 students, were sampled to participate in the study. So, the sampled students' GPA and ITBS scores were analyzed by the researcher to determine the students' academic performance. Additionally, two of the teachers who taught the sampled students were requested to fill out questionnaires, SCRS, to indicate the teachers' perceptions of the sampled students' level of self-discipline. Also, one of the parents of the sampled students was requested to respond to PASS questionnaire to rate their parental involvement in the academic activities of their children. The evaluation of one parent of guardian was deemed enough.

Grades six through 12 were chosen to participate in the study because beginning in middle school, students perform school academic work independently. While parental involvement has been shown to be highly correlated with achievement, helping with homework is negatively correlated with academic achievement. At the middle school level, students are supposed to have developed skills to help them handle school work independently (Hill \& Tyson, 2009). Therefore, it is important to draw a sample from middle to high school (grades six through 12) to find out whether their self-discipline is correlated with their academic performance.

Because the researcher selected $50 \%$ out of 30 schools randomly, some of the schools could be quite dispersed. That means it would not be feasible to collect data physically. So, the teachers' and the parents' questionnaires were mailed to the schools. The raw Likert-scales data from teachers' responses was used to measure students' selfdiscipline. Then correlations between students' self-discipline and GPA, and student's self-discipline and ITBS were calculated using Pearson $r$ and multiple regressions to test 
specific implications of the research questions and hypotheses. Details on this process are given in Chapter 4, data analysis and results.

Moreover, the raw Likert-scales data from parents' responses were used to measure parents' involvement. Later, correlations between parents' involvement and GPA, and parents' involvement and ITBS were determined. Details on this process are given in Chapter 4, data analysis.

Some of the parents who were invited chose not to participate in this study. So, researcher included all parents and students who were willing to participate. Creswell (2012) states that sometimes it is not possible to use probability sampling. In such cases, researchers may use nonprobability sampling, whereby participants are chosen because they are available, and they have characteristics that the researcher wants to study. "In some situations, you may need to involve participants who volunteer and who agree to be studied" (p. 145). In this study, researcher invited all students in grades six through 12, their teachers and their parents to participate in this study.

\section{Primary Study}

In order for the results from this research to be generalizable, researcher used data from the CG data base, which involved a much more representative sample of subjects reflecting the whole NAD instead of focusing on just one conference. Another reason why the researcher used data from the CG is that researcher experienced intense difficulties in data collection during the preliminary study. In spite of face-to-face appeals to school boards and administrators, using mailings, and online procedures of data collection, researcher was able to get only 25 participants during a period of more than one year. However, the CG data base provided more comprehensive data that enabled the 
researcher to investigate the impact of student's self-discipline and parental involvement on student academic performance using more statistical power to test the null hypotheses.

\section{Instrumentation}

Preliminary Study

Teachers responded to SCRS, a 33-item questionnaire, with closed-ended questions, which asked the educators to rate their students' level of self-discipline using a scale from 1 to 7 . Four represented an average level of self-discipline while 7 represented the most impulsive and 1 the most controlled student. The questionnaire was adopted from Kendall and Wilcox (1979). "The items tap the ability to inhibit behavior, follow rules, and control impulse reactions" (Duckworth \& Seligman, 2006, p. 940). In addition, GPAs and standardized test scores of the ITBS were accepted as reflecting the academic performance of the students.

In addition, parents responded to PASS, which was an instrument designed to measure parental involvement in their children's education using a scale of $1-5$. The questionnaire was adopted from Ringenberg et al. (2005). The instrument was based on Epstein's six-construct framework: communicating; volunteering, especially at the school where one's children are attending; parenting, facilitating learning at home, decision making, and collaborating with community (Epstein, 2008). Every four items of the instrument were devoted to each of Epstein's six constructs.

Each item included a five point Likert scale, ranging from 1 to 5, with responses labeled "strongly agree," "agree," "partially agree/partially disagree," "disagree,” and “strongly disagree." Items 6, 8, 16, 17, 18, 20 are reverse ordered; so "strongly disagree" 
is the most positive response (Ringenberg et al., 2005). During data analysis, these items were reversed. Demographic variables were collected from school records.

\section{Primary Study}

In the primary study, grades six and seven students responded to the CG student survey. The reliability of the CG surveys was previously calculated, and results show high measures as shown in the CG study (Thayer \& Kido, 2012). The reliability coefficient for grade six questionnaires yielded an alpha of 0.95 and for grade seven, 0.94. (Lohman \& Hagen, 2002). For the current study, eight questions from the CG student survey were used to measure student self-discipline. The reliability of each item was determined. The Cronbach's Alpha for self-discipline scales showed a range from .529 to 665 .

In addition, to measure parental involvement in the current study, 12 closed ended questions from CG Parent Survey were used. The alpha of the 12 scales used to in this study range from .420 to .821 , which was good. The items derived from the CG surveys for both self-discipline and parental involvement were strong, but some of the question could only get a few items that could be used in the current study. Hence, the reason for the range of the Cronbach's Alpha from .529 to 665 for self-discipline and .420 to .821 for parental involvement. According to Thayer and Kido (2012), the CG surveys enabled the researchers to gather information from over 30,000 participants a year for three years. "Survey information was collected for the first 3 years from all students, their parents, teachers, and school administrators (Thayer \& Kido, 2012, p. 102). 


\section{Research Questions}

Preliminary Study

The following questions guided analysis of the initial sample:

1. Is there a statistically significant relationship between the self-discipline of students in SDA schools, as reported by teachers, and student's GPA or ITBS performance?

2. Is there a statistically significant relationship between parental involvement, as reported by parents, and student's GPA or ITBS performance?

3. Are there combined effects of student self-discipline and parental involvement on student's GPA or ITBS performance (in other words, do student self-discipline and parental involvement interact in their association with GPA or ITBS scores)?

4. Do ethnicity, gender, age or grade level have any statistically significant influence on the relationships between student's self-discipline, as reported by teachers, or parental involvement, as reported by parents, and student's GPA or ITBS performance?

In the primary, supplemental study, students were surveyed on their selfdiscipline, unlike in the initial, preliminary study where teachers' perceptions were used to evaluate students' self-discipline. The researcher made this change because the CG data, used in the primary study, have demonstrated reliability for evaluating student's self-discipline. (Thayer \& Kido, 2012).

\section{Primary Study}

1. Is there a statistically significant relationship between the self-discipline of students in SDA schools, as reported by students, and student's ITBS performance? 
2. Is there a statistically significant relationship between parental involvement, as reported by parents, and student's ITBS performance.

3. Are there combined effects of student self-discipline and parental involvement on student's ITBS performance? (ie, do student self-discipline and parental involvement interact in their association with ITBS scores)?

4. Do ethnicity, gender, grade level, student's cognitive ability, or parent level of education have any statistically significant influence on the relationships between student's self-discipline, as reported by students, or parental involvement, as reported by parents, and student's TBS performance?

\section{Null Hypotheses}

Even though the preliminary data was small, the hypotheses were retained in order to enable the researcher to test the research hypotheses both with the preliminary and the primary data in order to identify any trends. Additionally, the hypotheses in the preliminary study were used to evaluate correlations of variables in the study.

\section{Preliminary Study}

1. There is no statistically significant relationship between the self-discipline of students in SDA schools, as reported by teachers, and student's GPA or ITBS performance.

2. There is no statistically significant relationship between parental involvement, as reported by parents, and student's GPA or ITBS performance.

3. There are no statistically significant combined effects of student self-discipline and parental involvement on student's GPA or ITBS performance (Specifically, there is 
no interaction between student self-discipline and parental involvement in their association with GPA or ITBS scores).

4. Ethnicity, gender, age or grade level have no statistically significant influence on the relationships between student's self-discipline, as reported by teachers, or parental involvement, as reported by parents, and student's GPA or ITBS performance.

\section{Primary Study}

1. There is no statistically significant relationship between the self-discipline of students in SDA schools, as reported by students, and ITBS performance.

2. There is no statistically significant relationship between parental involvement, as reported by parents, and student's ITBS performance.

3. There are no statistically significant combined effects of student self-discipline and parental involvement on student's ITBS performance (i.e., there is no interaction between student self-discipline and parental involvement in their association with students' ITBS scores).

4. Ethnicity, gender, grade level, student's cognitive ability, or parent level of education do not have a statistically significant effect on the relationship between student's self-discipline, as reported by students, or parental involvement, as reported by parents, and students' ITBS performance.

Parental involvement was measured directly by surveying the parents instead of measuring teachers' perceptions of parental involvement because parents' involvement in the education of their children does not only happen in school. Epstein (2008) states that when parents are involved in the learning of their children, they facilitate learning at home. For example, they help their young children to complete school work and also 
create a conducive environment for their children to study while at home. Hence, it may be adequate to survey parents about their involvement in the education of their own children.

\section{Research Design}

This is a quantitative, correlational, cross-sectional study, in which Pearson's $r$ and multiple regression were used to investigate the relationship(s) between student selfdiscipline and parental involvement with student academic performance. The details of the research design, such as data collection, analysis and reporting are discussed in this chapter. "Research designs are the specific procedures involved in the research process: data collection, data analysis, and report writing" (Creswell, 2012, p. 20). The study utilized research questions and hypotheses suitable in quantitative research.

\section{Data Analysis}

\section{Preliminary Study}

Pearson $r$ and multiple regression analysis were used to assess the nature and the strength of the relationships between student self-discipline, parental involvement and students' ITBS scores and GPA. The value of coefficient of determination on academic performance showed the variation in academic performance

An alpha level of 0.05 was used to determine statistical significance of pertinent relationships among the variables, because in this study, the consequence of rejecting a true null hypothesis does not warrant a smaller confidence level. The Statistical Package for the Social Sciences was used to analyze data. 


\section{Primary Study}

Multiple Regression Analysis was used to test whether there were any statistically significant relationships between:

1. the self-discipline of students in SDA schools, as reported by students, and ITBS performance.

2. parental involvement, as reported by parents, and student's ITBS performance.

Multiple Regression Analysis was used to determine whether:

3. there were any statistically significant combined effects of student selfdiscipline and parental involvement on student's ITBS performance.

4. ethnicity, gender, grade level, student's cognitive ability, or parent level of education have any statistically significant effect on the relationship between student's self-discipline, as reported by students, or parental involvement, as reported by parents, and students' ITBS performance.

\section{Control Variables}

\section{Preliminary Study}

Past studies show a significant relationship between student's demographic variables and academic performance. For that reason, researcher planned to analyze these variables to determine whether they had any effect on the relationship between student' self-discipline or parental involvement and GPA or ITBS. However, due to the small sample of the preliminary study, researcher did not analyze the demographic variables in the preliminary study. The analysis was done in the primary study. 


\section{Primary Study}

Ethnicity, gender, grade level, cognitive ability and parent education level were evaluated as control variables in this study and were analyzed to ascertain whether any of these variables had an effect on the relationship between student's self-discipline, as reported by students, and performance on the ITBS.

Also, this study assessed whether any of these control variables had any effect on the relationship between parental involvement, as reported by parents, and student's performance on the ITBS.

Similarly, researcher investigated whether there was any relationship between student's self-discipline, as reported students, and scores on the ITBS based on the control variables and whether there was a relationship between parental involvement, as reported by parents, and ITBS scores based on the control variables.

\section{Procedure}

\section{Preliminary Study}

The researcher sent an application to Internal Review Board (IRB) requesting for approval to conduct the study. Additionally, researcher sent another request to the superintendent of the Adventist schools in the Texas Conference to request permission to conduct the research in the Adventist schools in the Texas Conference. After researcher received approval from IRB and permission to conduct the study from the superintendent, researcher obtained written consent from teachers and parents of students who participated in the study. Only students who participated in the study. The teachers gave their consent before filling out the questionnaires, and students and parents were requested to give permission to the researcher to access the students' academic records, 
GPA and ITBS. A consent form was sent to the three groups: teachers, parents and students. Researcher explained the purpose of the study to the participants and to parents through letters. Participants were given two weeks to sign the consent forms. After receiving the consent forms, researcher sent the survey to teachers to fill. At the same time, the researcher requested the school principals to email students' GPA and ITBS scores to the researcher for analysis.

In addition, parents' questionnaires were mailed to the school principals, who were requested to pass them to teachers to distribute to all students who were sampled to participate in the study. The sampled students were requested to take the parents' questionnaires to their parents to fill out. Clear instructions and request letters were enclosed for parents. After parents completed their questionnaires, students were requested to take them to their teachers. Teachers were requested to pass the completed questionnaires to their principal, who mailed them to the researcher. Students' demographic data were taken from school records.

In order to maintain confidentiality of participants, researcher made two correspondence tables to organize data. One table associated all participants' names with generated alphanumeric identification numbers. The second table associated all identification numbers with all related data sources: GPA, ITBS, parents, teachers, gender, age, ethnicity, and grade level. The use of identification numbers was to enable the researcher to match data with subjects. Researcher did not use both tables at the same time. For all the purposes of organizing and analyzing data, researcher used the created identification numbers. This table was only to be used when it was absolutely necessary to re-organize lost data. 


\section{Primary Study}

Researcher sent a letter to the owners of the CG data and obtained permission to use the CG Data in the present 'primary study'. Also, researcher filled a modification form and sent it to Andrews University IRB office and requested for permission to make modifications on the earlier proposal after which she sought and received approval of the IRB to use the CG data in the primary study.

In the primary study, ITBS was measured as a single score, the Normal Curve Equivalent (NCE) Composite, which is the average of the scores in six subject areas: Reading, Language Arts, Math, Social Studies, Science, and Sources of Information. The NCEComposite is used because it is equally spaced out to reflect an interval scale.

\section{Validity and Reliability}

\section{Preliminary Study}

\section{Self-Control Rating Scale}

The 33-item SCRS features high internal consistency and test-retest reliability. In the current study, the self-discipline scale was computed as the mean of all 33 items that the student answered. The authors of the SCRS questionnaire conducted six reliability checks, three each from the first and second half of the study, resulting in an average overall agreement of 93\%. "Average percentages of agreement for non-occurrences was 99.7\%...The internal reliabilities of the SCRS were .98, as indicated by Cronbach's alpha" (Kendall \& Wilcox, 1979, p. 1023). The reliability numbers show a high level of internal consistency.

The Cronbach's alpha coefficients measure of internal consistency was used to determine whether the instrument was reliable. The Cronbach's alpha is used by having 
respondents choose only one of the alternatives of the scored items such that the total items can be calculated to measure a unique construct (Newman \& McNeil, 1998).

Kendall and Wilcox (1979) state that to evaluate the validity of the SCRS for rating cognitive-behavioral self-control, tests of cognitive impulsivity such as Matching Familiar Figures were included in the following studies: Kagan's (1966) behavioral selfcontrol test, such as Porteus mazes Q score, as well as Porteus' (1955) behavioral observations and delay of gratification. "These validation materials are particularly relevant, since they are often employed as treatment outcome measures with children (e.g., Camp, Blom, Hebert, \& Van Doominck, 1977; Douglas et al.,1976; Kendall \& Finch, 1978, p.1021)" (Kendall \& Wilcox, 1979, p. 1021). Item statistics are presented in Table 1.

\section{Parent And School Survey}

Parents filled the PASS to assess parental involvement. The questionnaire is based on Epstein's six-construct framework. Each item includes a five-point Likert scale, ranging from 1 to 5, with responses "strongly agree," "agree," "partially agree/partially disagree," "disagree," and "strongly disagree." Ringenberg et al., (2005) posit that items $6,8,16,17,18,20$ are reverse ordered, so for these items, "strongly disagree" is the most positive response. Therefore, when computing the six parental involvement scales, the six items were reversed.

Test-retest reliability estimates were calculated on the 24 items of the PASS (Ringenberg et al., 2005). Bartko (1991) recommends intraclass correlation coefficients (ICC) be calculated in test-retest evaluations of interval data. This was done on the PASS 
Table 1

Self-Control Rating Scale (SCRS)

Item-Total Statistics

\begin{tabular}{|c|c|c|c|c|}
\hline & $\begin{array}{l}\text { Scale Mean if } \\
\text { Item Deleted }\end{array}$ & $\begin{array}{r}\text { Scale Variance if } \\
\text { Item Deleted }\end{array}$ & $\begin{array}{r}\text { Corrected } \\
\text { Item-Total } \\
\text { Correlation } \\
\end{array}$ & $\begin{array}{r}\text { Cronbach's Alpha if } \\
\text { Item Deleted }\end{array}$ \\
\hline SelfDiscipline1 & 169.3750 & 1687.983 & .771 & .987 \\
\hline SelfDiscipline2 & 169.3750 & 1692.217 & .748 & .987 \\
\hline SelfDiscipline3 & 169.2500 & 1677.533 & .808 & .987 \\
\hline SelfDiscipline4 & 169.1875 & 1688.863 & .824 & .987 \\
\hline SelfDiscipline5 & 169.9063 & 1683.874 & .742 & .987 \\
\hline SelfDiscipline6 & 168.8125 & 1677.729 & .862 & .987 \\
\hline SelfDiscipline7 & 169.1875 & 1659.496 & .934 & .987 \\
\hline SelfDiscipline8 & 169.7813 & 1644.999 & .914 & .987 \\
\hline SelfDiscipline9 & 169.1250 & 1678.917 & .891 & .987 \\
\hline SelfDiscipline 10 & 169.0625 & 1718.629 & .713 & .987 \\
\hline SelfDiscipline11 & 169.1563 & 1692.157 & .789 & .987 \\
\hline SelfDiscipline12 & 168.9063 & 1693.474 & .825 & .987 \\
\hline SelfDiscipline13 & 169.6875 & 1700.129 & .765 & .987 \\
\hline SelfDiscipline14 & 169.8750 & 1660.883 & .914 & .987 \\
\hline SelfDiscipline15 & 168.9688 & 1688.282 & .678 & .988 \\
\hline SelfDiscipline16 & 168.9688 & 1691.116 & .824 & .987 \\
\hline SelfDiscipline17 & 169.7500 & 1643.067 & .934 & .987 \\
\hline SelfDiscipline 18 & 169.5938 & 1643.741 & .958 & .987 \\
\hline SelfDiscipline19 & 169.1563 & 1668.957 & .755 & .987 \\
\hline SelfDiscipline20 & 169.0000 & 1688.700 & .848 & .987 \\
\hline SelfDiscipline21 & 169.5313 & 1665.082 & .922 & .987 \\
\hline SelfDiscipline22 & 169.2813 & 1676.266 & .869 & .987 \\
\hline SelfDiscipline 23 & 168.8438 & 1694.391 & .920 & .987 \\
\hline SelfDiscipline24 & 169.2813 & 1674.432 & .885 & .987 \\
\hline SelfDiscipline25 & 170.0938 & 1642.307 & .907 & .987 \\
\hline
\end{tabular}


Table 1-Continued

\begin{tabular}{lrrrr}
\hline & $\begin{array}{r}\text { Scale Mean if } \\
\text { Item Deleted }\end{array}$ & $\begin{array}{r}\text { Scale Variance if } \\
\text { Item Deleted }\end{array}$ & $\begin{array}{r}\text { Corrected Item- } \\
\text { Total Correlation }\end{array}$ & $\begin{array}{r}\text { Cronbach's } \\
\text { Alph if Item } \\
\text { Deleted }\end{array}$ \\
\hline SelfDiscipline26 & 169.2188 & 1665.466 & .952 & .987 \\
SelfDiscipline27 & 169.2813 & 1647.299 & .884 & .987 \\
SelfDiscipline28 & 169.3125 & 1685.496 & .870 & .987 \\
SelfDiscipline29 & 169.5313 & 1643.049 & .857 & .987 \\
SelfDiscipline30 & 168.7188 & 1699.632 & .801 & .987 \\
SelfDiscipline31 & 169.7500 & 1657.700 & .951 & .987 \\
SelfDiscipline32 & 170.7813 & 1671.499 & .701 & .988 \\
SelfDiscipline33 & 169.2500 & 1712.033 & .755 & .987 \\
\hline
\end{tabular}

(Ringenberg et al., 2005). Cicchetti’s (1994) criteria for ICCs in test-retest situations were as follows: "below $.40=$ poor, .40 to $.59=$ fair, .60 to $.74=$ good, and .75 to $1.00=$ excellent" (Ringenberg et al., 2005, p.128).

Ringenberg et al., (2005) posit that the 24 items focus on "specific behaviors that reflect the corresponding construct rather than providing broad descriptions of the construct. This decision was based on the need for unambiguous and, consequently, reliable items" (p.124). reliability. The Cronbach's Alpha for the 24 items ranges from .823 to .850 , which is quite high (see Table 2 ).

Based on the test-retest results, all the 24 items of the instrument have acceptable reliability.

\section{Primary Study}

The reliability of each question or item used in this study was previously calculated, and results show high measures of reliability and validity. As an instrument, 
Table 2

Parent And School Survey (PASS)

\begin{tabular}{|c|c|c|c|c|}
\hline & & Item-Total Statis & & \\
\hline & $\begin{array}{l}\text { Scale Mean if Item } \\
\text { Deleted }\end{array}$ & $\begin{array}{l}\text { Scale Variance if } \\
\text { Item Deleted }\end{array}$ & $\begin{array}{l}\text { Corrected Item- } \\
\text { Total Correlation }\end{array}$ & $\begin{array}{l}\text { Cronbach's Alpha } \\
\text { if Item Deleted }\end{array}$ \\
\hline ParentalInvolvement1 & 88.53 & 129.695 & .574 & .832 \\
\hline ParentalInvolvement2 & 89.07 & 123.495 & .568 & .829 \\
\hline ParentalInvolvement3 & 88.67 & 134.381 & .330 & .839 \\
\hline ParentalInvolvement4 & 88.47 & 124.838 & .699 & .826 \\
\hline ParentalInvolvement5 & 88.47 & 134.124 & .384 & .838 \\
\hline ParentalInvolvement6 & 89.07 & 136.495 & .097 & .851 \\
\hline ParentalInvolvement7 & 88.60 & 128.686 & .634 & .830 \\
\hline ParentalInvolvement8 & 88.33 & 136.095 & .435 & .838 \\
\hline ParentalInvolvement9 & 90.13 & 134.981 & .132 & .850 \\
\hline ParentalInvolvement 10 & 89.60 & 128.400 & .650 & .829 \\
\hline ParentalInvolvement11 & 89.07 & 131.781 & .285 & .841 \\
\hline ParentalInvolvement 12 & 89.13 & 132.838 & .361 & .838 \\
\hline ParentalInvolvement 13 & 89.20 & 137.457 & .054 & .854 \\
\hline ParentalInvolvement14 & 88.47 & 133.981 & .465 & .836 \\
\hline ParentalInvolvement 15 & 88.60 & 133.543 & .272 & .841 \\
\hline ParentalInvolvement 16 & 89.13 & 128.267 & .432 & .835 \\
\hline ParentalInvolvement 17 & 88.73 & 131.352 & .452 & .835 \\
\hline ParentalInvolvement 18 & 89.27 & 139.067 & .047 & .849 \\
\hline ParentalInvolvement19 & 89.00 & 126.286 & .623 & .828 \\
\hline ParentalInvolvement 20 & 89.20 & 133.457 & .290 & .840 \\
\hline ParentalInvolvement 21 & 89.67 & 129.810 & .404 & .836 \\
\hline ParentalInvolvement 22 & 91.33 & 129.667 & .589 & .831 \\
\hline ParentalInvolvement 23 & 89.87 & 115.267 & 662 & .823 \\
\hline ParentalInvolvement 24 & 89.40 & 121.543 & .665 & .825 \\
\hline
\end{tabular}


the validity and reliability of the CG surveys have been tested as shown in the CG study (Thayer \& Kido, 2012). The reliability coefficient for grade six questionnaires yielded an alpha of 0.95 and for grade seven, 0.94. (Lohman \& Hagen, 2002).

From the CG student survey, eight questions were used to measure student selfdiscipline in the current primary study. The reliability of each item was determined. The Cronbach's Alpha for self-discipline scales showed a range from .529 to 665. Only relevant items were used in this study. So, diligence and taking responsibility had one item each. Hence, it was not possible to determine the reliability of the two scales. But even though the Alpha for the items used to measure self-discipline was average, the alpha for the CG student questionnaire was quite high (0.95) meaning that the questionnaire was reliable to measure self-discipline. The few items that were taken from the CG to measure self-discipline seemed to be the cause of the low alpha. For example, doing chores had only two items, yet the alpha was .53 as shown below suggesting that the scale is good. Results for item statistics are presented in Table 3.

Twelve items were derived from the CG data to measure parental involvement in the current primary study. The item statistics for each of the parental involvement items were calculated. The scales that had more items recorded high reliability. Results are presented in Table 4. The alphas of the scales of parental involvement range from .420 to .821. Parent school communication and volunteering, which have two items each, have an alpha of almost .50 , which shows that the scale is very good. The alpha suggests that the few items in the scales may be the reason for the low alpha. 
Table 3

Reliability Analysis of CG Student Survey Scales

\begin{tabular}{llll}
\hline $\begin{array}{l}\text { Self-Discipline } \\
2006 / 2007\end{array}$ & Scale & $\begin{array}{l}\text { Number of } \\
\text { Items }\end{array}$ & $\begin{array}{l}\text { Cronbach's } \\
\text { Alpha }\end{array}$ \\
\hline & Diligence & 1 & - \\
& $\begin{array}{l}\text { Doing Chores } \\
\text { Taking Responsibility }\end{array}$ & 2 & .529 \\
& Distractions & 4 & - \\
Self-Discipline & & & .663 \\
$2007 / 2008$ & & 1 & \\
& Diligence & 2 & - \\
& Doing Chores & .536 \\
& Taking Responsibility & 1 & - \\
& Distractions & 4 & .652 \\
\hline
\end{tabular}

Note: scales with one item do not show reliability

Table 4

Reliability Analysis of CG Parent Survey Scales

Parental Involvement

2006/2007

Parental Involvement

$\begin{array}{lll}\text { Parent School- } & 2 & .484 \\ \text { Communication } & & \\ \text { Parenting } & 5 & .809 \\ \text { Volunteering } & 2 & .452 \\ \text { Learning at Home } & 3 & .491\end{array}$

2007/2008

$\begin{array}{lll}\text { Parent School } & 2 & .489 \\ \text { Communication } & & .821 \\ \text { Parenting } & 5 & .420 \\ \text { Volunteering } & 2 & .491 \\ \text { Learning at Home } & 3 & \end{array}$




\section{Ethical Considerations}

Before conducting the preliminary study, researcher sought permission from the superintendent of Texas Conference of SDAs. The subjects were respected, and their confidentiality was protected. The aim of conducting the study was explained to the participants in the cover letter which accompany the questionnaire. The consent of the subjects was sought, and they were given the opportunity to decide whether to participate in the study or not. The subjects were coded so that data from the questionnaires were matched with GPA and standardized test scores while maintaining anonymity for the students. Anonymity was maintained beyond the primary investigator. Only group-level aggregated data were distributed. The details of ethical considerations of the primary study are reported in Thayer and Kido (2012). 


\section{CHAPTER 4}

\section{RESULTS OF THE STUDY}

\section{Introduction}

This study investigated the impact of students' self-discipline and parental involvement in their children's academic experiences on the students' academic performance. Initially, the researcher planned to conduct this study within schools in the Texas Conference of SDAs. But researcher could not obtain enough participants. After one year of attempting to recruit an adequate sample, only 25 subjects from three schools had chosen to participate. Hence, in order to increase statistical power, the researcher used archived data from the CG study, which drew data from students in SDA schools in North America, in grades three through nine and 11.

Moreover, in order to test the research hypotheses and to answer the research questions as thoroughly as possible, the researcher decided to keep and analyze the initial data from the Texas Conference schools in the overall study. However, the two data sets could not be combined because the initial study, in Texas Conference schools, used GPA and ITBS while the CG study used ITBS only. Also, in the initial study, teachers' perceptions were used to evaluate student self-discipline while in the CG data, students themselves were surveyed about their own self-discipline. So, this study was conducted in two phases: a preliminary, which was conducted in the schools in the Texas Conference of the SDA and a primary study which utilized data from the CG archives. 
In addition, besides investigating the impact of student self-discipline, this study was set to test Epstein's model of parental involvement, which involves the following six constructs: parent school communication, parenting, volunteering, learning at home, decision making, and collaborating with community (Epstein, 2008). In the preliminary study, all these six constructs were tested and analyzed, but in the primary study only parent school communication, parenting, volunteering, and learning at home were analyzed. Decision making and collaborating with community were not evaluated in the primary study because the CG data did not have enough data to analyze the two factors.

Thus, since each of the two studies, the preliminary and the primary study, had its own research questions, hypotheses, and data analysis, results of each study are presented separately in this chapter. Also, comments to highlight trends, similarities or differences in the two studies are provided throughout this chapter.

Both the preliminary and the primary study consists of two sections. The first section contains descriptive statistics of the subjects including frequencies, means and standard deviations of the subscales of the variables of self- discipline and parental involvement. The second section presents inferential statistics, which include the correlations of student's self-discipline and parental involvement and GPA and ITBS.

\section{Preliminary Study}

Demographic Descriptive Statistics

A total of 26 students in grades six through 12 from three schools in the Texas Conference of SDAs participated in the preliminary study. Nine of the participants did not provide complete information, so their results were dropped from the analyses. Data for 16 participants were analyzed in the preliminary study. After receiving approval from 
the conference superintendent, school principals and parents' informed consent, teachers filled the SCRS questionnaires to assess student's self-discipline. Parents responded to parent questionnaires, PASS to assess their parental involvement in their children's academic activities.

The raw Likert-scales data from teachers' responses were used to measure students' self-discipline. Then correlations between students' self-discipline and GPA, and student's self-discipline and ITBS were calculated.

In addition, the raw Likert-scales data from parents' responses were used to measure parents' involvement. Later, correlations between parents' involvement and GPA, and parents' involvement and ITBS were determined. In the preliminary study, self-discipline was measured as one variable. But parental involvement was measured through six subscales: parent-school communication, parenting, facilitating learning at home, decision making, volunteering, and collaborating with community. Table 5 presents the details of the demographic information of the subjects in the preliminary study. Demographic results show that there were eight females and eight males, three Anglo, one Caucasian, nine Hispanic, and three White. Ages ranged from 11 to 17. Grades six to 11 were represented.

Means and standard deviations were also determined. Results showed that means for the two dependent variables were above average, GPA $(M=3.5694, S D=0.39176)$ and ITBS Composite NCE $(M=60.563, S D=15.4573)$. But self-discipline mean was higher $(M=2.7074, S D=1.2718)$ than the mean for parental involvement $(M=2.1389$, $S D=0.4817)$. Table 6 presents the descriptive statistics. 
Table 5

Student Subjects' Demographic Frequencies

\begin{tabular}{llcc}
\hline Variable & & $\mathbf{N}$ & Percentage \\
Gender & & $\mathrm{N}=16$ & \\
& Female & 8 & 50 \\
Ethnicity & Male & 8 & 50 \\
& & $\mathrm{~N}=16$ & \\
& Anglo & 3 & 18.8 \\
& Caucasian & 1 & 6.3 \\
Age & Hispanic & 9 & 56.3 \\
& White & 3 & 18.8 \\
& & $\mathrm{~N}=16$ & \\
& 11 & 1 & 6.3 \\
& 12 & 6 & 37.5 \\
Grade & 13 & 4 & 25.0 \\
& 14 & 3 & 18.8 \\
& 17 & 2 & 12.5 \\
& 6 & $\mathrm{~N}=16$ & \\
& 7 & 6 & 37.5 \\
& 8 & 4 & 25.0 \\
& 10 & 4 & 25.0 \\
& 11 & 1 & 6.3 \\
& & 1 & 6.3 \\
\hline
\end{tabular}

Table 6

Descriptive Statistics

\begin{tabular}{lllllll}
\hline & & $\mathrm{N}$ & Minimum & Maximum & Mean & Std. Deviation \\
\hline GPA & & 16 & 2.79 & 3.98 & 3.5694 & 0.39176 \\
Iowa NCE & 16 & 33 & 91 & 60.563 & 15.4573 \\
Self-discipline & & 16 & 1 & 5.3 & 2.7074 & 1.2718 \\
Parental Involvement & & 16 & 1.46 & 2.96 & 2.1389 & 0.4817 \\
& & 16 & 1 & 2.75 & 1.8281 & 0.66907 \\
& Parenting & 16 & 1 & 3.25 & 1.75 & 0.677 \\
& Communication & 16 & 3.25 & 2.00 & 0.66458 \\
& Volunteering & 16 & 1 & & & \\
& Learning & & & & & \\
& at Home & 16 & 1.25 & 3.5 & 2.2604 & 0.63163 \\
& Decision & & & & & \\
& Making & 16 & 1.75 & 3.75 & 2.625 & 0.57009 \\
& Collaborating & 16 & 1.25 & 3.25 & 2.625 & 0.73598 \\
\hline
\end{tabular}


Regression analysis was done to give more information on the relationships between student self-discipline and parental involvement and academic performance. Even though the number of participants in the preliminary study was small, results provided information that was used to answer research questions 1,2 and 3 in the preliminary study. Additionally, the results reflected trends about the impact of the relationship between self-discipline and parental involvement and academic performance that were further tested using 2457 subjects in grade six and 2657 subjects in grade seven in the primary study. The preliminary study questions one, two and three answers and the null hypotheses are presented in the following section.

Question 1. Is there a statistically significant relationship between student's selfdiscipline, as reported by teachers, and student's GPA or ITBS performance?

In order to uncover any relevant trends in the preliminary study, which had a small sample size of 16 participants, the level of significance was set at 0.10 . The correlation between self- discipline and GPA was $r=0.720, p<0.01$ which was significant, indicating a statistically significant relationship between self-discipline and GPA. Self-discipline was calculated as a single scale representing all 33 items of student's self-discipline as shown in the student questionnaire, which was computed as the mean of all 33 items that the student answered. Self-discipline and ITBS showed a correlation of $r=0.643, p<.01$ indicating a statistically significant relationship between self-discipline and Iowa test scores. ITBS performance was reflected in a single score, NCE Composite, an average of Reading, Language Arts, Math, Science, and Social Studies. Table 7 presents the results. 
Table 7

Correlation Between Self-Discipline and GPA and ITBS NCE

\begin{tabular}{lcccc}
\hline \multicolumn{1}{c}{ Variable } & \multicolumn{2}{c}{ GPA } & \multicolumn{2}{c}{ ITBS NCE } \\
& $\mathrm{r}$ & $\mathrm{p}$ & $\mathrm{r}$ & $\mathrm{p}$ \\
\hline Self-Discipline & .720 & $.002 * * *$ & .643 & $.007 * * *$ \\
\hline$* * * \mathrm{p}<.001$ & & & &
\end{tabular}

The relationships between self-discipline and GPA and between self-discipline and ITBS performance were further confirmed through scatter plots, which showed a linear relationship between self-discipline and GPA, with $r^{2}$ linear $=0.518$ indicating that $52 \%$ of the variance in GPA is accounted for by student self-discipline. Appendix A includes the significance table.

The relationships between Self-discipline and ITBS NCE was also confirmed through scatter plots, which presented the $r^{2}$ linear $=0.414$ between self-discipline and ITBS NCE, indicating that $41 \%$ of variance in ITBS is explained by student selfdiscipline. Even though the preliminary sample was small, a regression equation showed that self-discipline had a significant association with each of the two dependent variables, ITBS or GPA at $p<.01$. So, the regression equations referred in this summary were with one independent variable, self-discipline, and one dependent variable, ITBS or GPA. Results show that the more self-disciplined a student is, the higher his or her academic success. Additional details are presented in Appendix A.

Null Hypothesis 1: There is no statistically significant relationship between student's self-discipline, as reported by teachers, and student's GPA or ITBS performance. The level of significance was set at 0.10 . Results showed statistically significant relationship between student self-discipline and GPA $(r=0.720, p<0.01)$, a 
relationship which was confirmed by a scatter plot $\left(r^{2}=0.518\right)$. Also, results showed that the relationship between student self-discipline and ITBS was statistically significant $(r=$ 0.643, $p<0.01$ ). A scatter plot confirmed the statistically significant relationship between student self-discipline and ITBS $\left(r^{2}=0.414\right)$. So, we reject the null hypothesis because it states that there is no statistically significant relationship between student's selfdiscipline, as reported by teachers, and student's GPA or ITBS performance.

Question 2: Is there a statistically significant relationship between parental involvement, as reported by parents, and student's GPA or ITBS performance?

The correlations between parental involvement and both GPA and ITBS were calculated using Pearson r. Results showed correlations between parental involvement and GPA of $r=0.636, p<0.01$ and between parental involvement and ITBS NCE test scores of $r=0.727, p<0.01$ which was significant. This latter significant correlation was based on the average scores of all the parental involvement scales (parenting, communicating, volunteering, learning at home, decision making and collaborating), meaning that there was a statistically significant relationship between overall parental involvement and both GPA and ITBS performance. Table 8 presents these results. Among the scales of parental involvement, parenting had the highest correlations and the most significant $\mathrm{p}$ value with GPA, $r=0.723, p<0.01$, and with ITBS NCE, $r=0.727, p$ $<0.01$. The GPA for learning at home was significant $(p<0.05)$ but learning at home and ITBS NCE was not significant. On the other hand, decision making GPA was not significant while ITBS NCE showed significance at $p<0.05$. That suggests that studying at home impacts GPA more than it does ITBS NCE. But decision-making impacts ITBS NCE results more than it does GPA. 
Table 8

Correlations of Parental Involvement Variables with GPA and ITBS NCE

\begin{tabular}{lclll}
\hline \multicolumn{1}{c}{ Variable } & \multicolumn{2}{c}{ GPA } & \multicolumn{2}{l}{ ITBS NCE } \\
\hline & $r^{*}$ & $p$ & $r^{*}$ & $p$ \\
\hline Parental Involvement & .636 & $.008^{* * *}$ & .727 & $.001^{* * *}$ \\
Parenting & .723 & $.002^{* * *}$ & .757 & $.001^{* * *}$ \\
Communicating & .066 & .808 & .248 & .353 \\
Volunteering & .509 & $.044^{* *}$ & .647 & $.007^{* * *}$ \\
Learning at Home & .500 & $.049^{* *}$ & .418 & .107 \\
Decision Making & .349 & .185 & .555 & $.026^{* *}$ \\
Collaborating & .631 & $.009^{* * *}$ & .568 & $.022^{* *}$ \\
\hline
\end{tabular}

$* p<.10, * * p<.05, * * * p<.01$

The relationship between parental involvement and GPA and ITBS performance was also confirmed through scatter plots. Parental involvement and GPA had $r^{2}$ linear $=$ $0.404(41 \%)$ indicating a very strong relationship between GPA and parental involvement. Additionally, scatter plots showed that parental involvement and ITBS performance recorded $r^{2} 0.529(53 \%)$ indicating that the more a parent is involved in the academic activities of the child, the better the child performs academically. More details are given in Appendix A.

Null Hypothesis 2: There is no statistically significant relationship between parental involvement, as reported by parents, and students' GPA or ITBS performance. Given the statistically significant relationship that is portrayed between parental involvement and GPA $(r=0.636, p<0.01)$ and graph $\left(r^{2}=0.404\right)$ and between parental involvement and ITBS $(r=0.727, p<0.001)$ and graph $\left(r^{2}=0.529\right)$, we reject the null hypothesis because results indicate the contrary.

Question 3: Is there statistically significant combined effects of student selfdiscipline and parental involvement on student's GPA or ITBS performance? (ie, do 
student self-discipline and parental involvement interact in their association with GPA or ITBS scores)?

The model summary Table 9 below shows the combined effects of self-discipline and parental involvement on GPA and Iowa NCE performance. The model summary for self- discipline and parental involvement together shows $r^{2}=0.718,(72 \%)$ which was high. Since the level of significance in the preliminary study was set at 0.10 , the sig shown in Table $9(p<0.10)$ was significant. The results indicated that there was a combined effect of self-discipline and parental involvement on GPA and ITBS performance.

Table 9

Self-discipline and Parental Involvement Variables Together

\begin{tabular}{lccccc}
\hline Model & $\mathrm{R}$ & R Square & Adjusted R & $\begin{array}{l}\text { Std. Error of the } \\
\text { Estimate }\end{array}$ & Sig \\
\hline 1 & .848 & .718 & .472 & .28472 & .079 \\
\hline a. & $\begin{array}{l}\text { Predictors: } \text { Constant), Collaborating, Communicating, LearningAtHome, } \\
\text { DecisionMaking, SelfDiscipline, Volunteering,Parenting }\end{array}$
\end{tabular}

Null Hypothesis 3: There is no statistically significant combined effects of student self-discipline and parental involvement on student's GPA or ITBS performance. This null hypothesis was rejected because results from the model summary of self-discipline and parental involvement variables combined was $\left(r^{2}=0.718, p<0.10\right)$ suggesting that there were combined effects of self-discipline and parental involvement on GPA and ITBS performance. 
Question 4: Do ethnicity, gender, age and grade level have any influence on the relationship between student's self-discipline, as reported by teachers, parental involvement, as reported by parents, and student's GPA or ITBS performance?

Due to the small number of participants in the preliminary study, research question 4 in the preliminary study was not answered. The influence of the demographic variables on the relationship between self-discipline and parental involvement and ITBS was analyzed in the primary study.

\section{Demographic Descriptive Statistics}

$$
\text { Primary (Supplemental) Study }
$$

The subjects for the primary study were students in grades six through eight in the NAD of SDA schools. Two cohorts were used, grade six, comprised of 2457 students in the year 2006/2007 and grade seven, which had 2687 students in the year 2007/2008. Selection of subjects was based on the CG data collection procedure outlined in Thayer and Kido (2012). In the primary study, self-discipline was measured through four subscales: diligence, doing chores, taking responsibility, and distractions. Also, parental involvement was measured as four subscales: parent-school communication, parenting, volunteering, and learning at home. Table 10 presents descriptive statistics for grade six.

The minimum and maximum scores of each of the subscales of parental involvement as well as the means and standard deviations are provided. The ranges of the means of different subscales of parental involvement fall between 3.4 and 3.5 indicating that most scales were slightly above average. The means of the scales of self-discipline ranged between 1.6 to 3.6 reflecting much difference. 
Table 10

Grade 6 Descriptive Statistics

\begin{tabular}{llllll}
\hline & N & Minimum & Maximum & Mean & $\begin{array}{l}\text { Std. } \\
\text { Deviation }\end{array}$ \\
\hline ParentSchoolCommunication & 2457 & 1.00 & 4.00 & 3.4606 & .54979 \\
& & & & & \\
Parenting & 2457 & 1.00 & 5.00 & 3.5470 & 1.05482 \\
Volunteering & 2457 & 1.00 & 4.00 & 3.3177 & .65857 \\
LearningAtHome & 2457 & 1.00 & 5.00 & 3.5526 & .70317 \\
Diligence & 2457 & 1.00 & 4.00 & 3.6390 & .55068 \\
DoingChores & 2457 & 1.00 & 5.00 & 3.2072 & .75744 \\
TakingResponsibility & 2457 & 1.00 & 2.00 & 1.6077 & .48837 \\
Distractions & 2457 & 1.00 & 5.00 & 2.3039 & .74095 \\
NCEComposite & 2457 & 1.00 & 99.0 & 62.6679 & 17.96061 \\
Valid N (listwise) & 2457 & 1.00 & & & \\
& & & & & \\
\hline
\end{tabular}

Note: Only participants who responded to all questionnaire items were included in the data analysis.

Among the scales of self-discipline and parental involvement, diligence recorded the highest mean and standard deviation $(M=3.6390, S D=.55068)$. Apart from distraction and taking responsibility, the other scales had above average results: learning at home $(M=3.5526, S D=0.70317)$, parenting $(M=3.5470, S D=1.05482)$, parent school communication $(M=3.4606,0.54979)$, volunteering $(M=3.3177,0.65857)$, doing chores $(M=3.2072,0.75744)$, and distractions $(M=2.3039,74095)$. Since distraction is a negative scale, it is good that the mean was below average. Taking responsibility for learning had the lowest mean and standard deviation $(M=1.6077$, 0.48837). The mean for NCE Composite was slightly above average $(M=62.6679)$.

Grade 7 descriptive statistics were also calculated. As Table 11 shows, grade seven had similar results as grade six. Diligence had the highest mean and standard deviation $(M=3.5981, S D=0.56778)$ while among the scales of parental involvement, parenting had the highest mean and standard deviation $(M=3.4625, S D=1.04402)$. Also, in grade seven, same as in grade six, student taking responsibility for learning had 
Table 11

Grade 7 Descriptive Statistics

\begin{tabular}{llllll}
\hline & N & Minimum & Maximum & Mean & $\begin{array}{l}\text { Std. } \\
\text { Deviation }\end{array}$ \\
\hline ParentSchoolCommunication & 2687 & 1.00 & 4.00 & 3.4394 & .56336 \\
Parenting & 2687 & 1.00 & 5.00 & 3.4625 & 1.04402 \\
Volunteering & 2687 & 1.00 & 4.00 & 3.2676 & .68927 \\
LearningAtHome & 2687 & 1.00 & 5.00 & 3.4431 & .75871 \\
Diligence & 2687 & 1.00 & 4.00 & 3.5981 & .56778 \\
DoingChores & 2687 & 1.00 & 5.00 & 3.2311 & .73587 \\
TakingResponsibility & 2687 & 1.00 & 2.00 & 1.6621 & .47309 \\
Distractions & 2687 & 1.00 & 5.00 & 2.4580 & .78483 \\
NCEComposite & 2687 & 1.00 & 99.0 & 63.0123 & 17.42396 \\
& & & & & \\
\hline
\end{tabular}

Note: Only participants who responded to all questionnaire items were included in the data analysis.

the least mean and standard deviation $(M=1.6621, S D=0.47309)$. The NCE Composite for the preliminary study mean $(M=60.563)$ was similar to the primary study grade six mean $(M=62.6679)$ and grade seven $(M=63.0123)$. Both the mean for the preliminary and the primary study were slightly above average.

Table 12 presents information about the control variables. Parent education level, gender, ethnicity, and student's ability comprised the control variables. Table 12 summarizes results for these control variables as follows: for parent education level, $n=$ $2361(96.1 \%)$; for gender, $n=2450(99.75 \%)$; for ethnicity, $1461(59.5 \%)$, and for ability group $n=2457(100 \%)$. The level of parent education shows that $755(30.7 \%)$ parents had education level below average, $1032(42 \%)$ average and $574(23.4 \%)$ had above average education. More females (1289) than males (1161) participated in the study. Ethnicity shows that 117 (4.8\%) Asians, 213 (8.7) Blacks, 264 (10.7) Hispanics, and 867 (35.3) White students participated. Student ability of those who participated shows that $9.6 \%$ was below average, $51 \%$ average and 39.4 above average. Grade seven had similar 
Table 12

Grade 6 Control Variables

\begin{tabular}{llll}
\hline & Variable & Frequency & Percentage \\
\hline Parent Education & Below Average & 755 & 30.7 \\
Average & 1032 & 42 \\
Above Average & 574 & 23.4 \\
Total & 2361 & 96.1 \\
Gender & Female & & \\
& Male & 1289 & 52.5 \\
Total & 1161 & 47.3 \\
Ethnicity & 2450 & 99.7 \\
& Asian & & \\
Black & 117 & 4.8 \\
Hispanic & 213 & 8.7 \\
& White & 264 & 10.7 \\
& Total & 867 & 35.3 \\
& Below Average & 237 & 59.5 \\
& Average & 1253 & 9.6 \\
& Above Average & 967 & 51 \\
& Total & 2457 & 39.4 \\
\hline
\end{tabular}

Note: Parent Education: 'below average-college; 'above average'-graduate. Student Ability level: 'below average'-50-89; 'average'- 90-110; 'above average'-110-150.

results as grade six. In both grade six and seven, Whites were the majority of participants followed by Hispanics, Blacks and Asians. In both cohorts, majority of the parents of the students had average education followed by parents with below average. The least number of parents had above average level of education. Female participants were the majority. Table 13 presents grade seven control variables. 
Table 13

Grade 7 Control Variables

\begin{tabular}{|c|c|c|c|}
\hline Grade 7 & Variable & Frequency & Percentage \\
\hline \multirow[t]{4}{*}{ Parent Education } & $\begin{array}{l}\text { Below } \\
\text { Average }\end{array}$ & 848 & 31.6 \\
\hline & Average & 1058 & 39.4 \\
\hline & $\begin{array}{l}\text { Above } \\
\text { Average }\end{array}$ & 627 & 23.3 \\
\hline & Total & 2687 & 94.3 \\
\hline \multirow[t]{3}{*}{ Gender } & Female & 1429 & 53.2 \\
\hline & Male & 1252 & 46.6 \\
\hline & Total & 2681 & 99.8 \\
\hline \multirow[t]{5}{*}{ Ethnicity } & Asian & 122 & 4.5 \\
\hline & Black & 235 & 8.7 \\
\hline & Hispanic & 270 & 10 \\
\hline & White & 967 & 36 \\
\hline & Total & 1594 & 59.3 \\
\hline \multirow[t]{4}{*}{ Ability Group } & $\begin{array}{l}\text { Below } \\
\text { Average }\end{array}$ & 235 & 8.7 \\
\hline & Average & 1376 & 51.2 \\
\hline & $\begin{array}{l}\text { Above } \\
\text { Average }\end{array}$ & 1076 & 40 \\
\hline & Total & 2687 & 100 \\
\hline
\end{tabular}

Note: Parent education: below average: high school; average college; above Average: graduate. Student Ability Level: below average 50 -89; average 90 - 110; above average 110-150

\section{Results from Questionnaires}

To analyze the four research questions, three analyses were done: 1) the relationship between achievement and each self-discipline and parental involvement variable alone, 2) the relationship between achievement and all self-discipline and parental involvement variables together, and 3) the relationship between achievement and a small model of selected self-discipline and parental involvement variables together. Data are presented following research questions. 
Question 1. Is there a statistically significant relationship between student's selfdiscipline, as reported by students, and ITBS performance?

Correlations were run using Pearson's Correlations Coefficient of the independent variables, self-discipline, as related to ITBS. Results of each of the four self-discipline scales, alone, showed different correlation levels with ITBS, diligence $(r=0.151, p<$ $.001)$, doing chores $(r=-0.024, p<.05)$; distractions $(r=-0.198, p<.001)$ and responsibility for learning $(r=0.039, p>0.05)$ was not significant. The correlation of the self-discipline scales, alone, showed that diligence had the highest positive correlation with ITBS. Doing chores and distractions each was negatively correlated with ITBS. Student taking responsibility for learning was not significant. That could be because the items measuring student taking responsibility for learning were only two. Additionally, the items may not have been adequate to measure student taking responsibility for learning.

The model summary Table 14 or grade 6 self-discipline scales: distractions, taking responsibility, doing chores and diligence, showed R square at .058 (5.8\%) and $\mathrm{p}<.001$, which is significant, indicates that $6 \%$ of student academic performance (ITBS) is determined by student self-discipline. All the four scales of self-discipline together showed statistically significant relationship with ITBS. Each of the self-discipline scales when together presented slightly different levels of correlations from what each scale showed separately, diligence (part $r=0.129, p<.001$ ); doing chores (part $r=-0.084, p<$ .001 ); distractions (part $r=-0.116, p<.001$ ); and taking responsibility (part $r=0.024, p<$ .05). Diligence had still the highest positive correlation with ITBS. Doing chores and distractions maintained a negative correlation while taking responsibility showed a 
Table 14

Grade 6 Model Summary for Self-discipline Scales

\begin{tabular}{|c|c|c|c|c|c|c|c|c|}
\hline \multirow[b]{2}{*}{ Model } & \multirow[b]{2}{*}{$\mathrm{R}$} & \multirow[b]{2}{*}{$\begin{array}{l}\mathrm{R} \\
\text { Square }\end{array}$} & \multirow[b]{2}{*}{$\begin{array}{l}\text { Adjusted } \\
\text { R Square }\end{array}$} & \multirow[b]{2}{*}{$\begin{array}{l}\text { Std. Error of } \\
\text { the Estimate }\end{array}$} & \multicolumn{4}{|c|}{ Change Statistics } \\
\hline & & & & & $\begin{array}{c}\text { R Square } \\
\text { Change }\end{array}$ & $\begin{array}{c}\mathrm{F} \\
\text { Change }\end{array}$ & df1 & $\begin{array}{c}\text { Sig. F } \\
\text { Change }\end{array}$ \\
\hline 1 & .242 & .058 & .057 & 17.44246 & .058 & 38.021 & 4 & .000 \\
\hline
\end{tabular}

significant correlation with ITBS, unlike alone when it was not significant. See Table 15.

Further, using a backward stepwise analysis, the self-discipline scales that showed significance at $p<.001$ were selected to a small model. So, the scales that showed less significance were dropped to strengthen the model. Three of the self-discipline scales were selected to the small model and showed the following part correlations: diligence $(r$ $=0.130, p<.001)$; doing chores $(r=-0.082, p<.001)$; and distractions $(r=-0.117, p<$ .001). Taking responsibility was not selected to the small model. So, alone, together, and in the small model, the scales of self-discipline showed consistency. Diligence remained the most positively correlated with ITBS while distractions showed the highest negative correlation with ITBS. As Table 15 shows, doing chores presented high negative correlation up to the small model indicating that among the scales of self-discipline, diligence is the best projector of ITBS.

Grade seven shows that the scales of self-discipline had similar results as grade six. Alone, the correlation for diligence was $r=0.146, p<.001$, which was the highest compared to doing chores $r=-0.084, p<.001$, which was negative, and distractions $r=-$ $0.25, p<.001$, which was negative. Taking responsibility was not significant alone or together. All the grade seven results were much similar to that of grade six on all the 
Table 15

Grade 6: Contribution of Self-discipline Variables

\begin{tabular}{|c|c|c|c|c|c|c|c|c|c|c|}
\hline & & \multicolumn{3}{|c|}{ Alone } & \multicolumn{3}{|c|}{ Together } & \multirow{2}{*}{$\begin{array}{c}\text { Small } \\
\mathrm{r \dagger \dagger}\end{array}$} & \multicolumn{2}{|l|}{ Model } \\
\hline & & $\mathrm{r \dagger}$ & $\mathbf{r}^{2}$ & $\mathbf{p}$ & $\mathbf{r} \dagger$ & $\mathbf{r}^{2}$ & $\mathrm{p}$ & & $\mathbf{r}^{2}$ & $\mathrm{p}$ \\
\hline \multirow[t]{4}{*}{$\begin{array}{l}\text { Self - } \\
\text { Discipline }\end{array}$} & Diligence & 0.151 & 0.023 & $0.000 * * *$ & 0.129 & 0.017 & $0.000 * * *$ & 0.130 & 0.017 & $0.000 * * *$ \\
\hline & Doing Chores & -0.024 & 0.001 & 0.238 & -0.084 & 0.007 & $0.000 * * *$ & -0.082 & 0.007 & $0.000 * * *$ \\
\hline & Distractions & -0.198 & 0.039 & $0.000 * * *$ & -0.116 & 0.013 & $0.000 * * *$ & -0.117 & 0.014 & $0.000^{* * *}$ \\
\hline & $\begin{array}{l}\text { Responsibility } \\
\text { for Learning }\end{array}$ & 0.039 & 0.002 & 0.051 & 0.024 & 0.001 & 0.212 & & & \\
\hline
\end{tabular}

self-discipline scales, alone, together and also in the small model. Same as in grade six, in grade seven distractions had a negative correlation on ITBS performance. However, it was not as high alone $(r=-0.25, p<.001)$ as together (part $r=-0.166, p<.001)$, and in the small model (part $r=-0.167, p<.001$ ). Table 16 presents results for grade seven correlations.

Table 16

Grade 7: Contribution Self-discipline Variables

\begin{tabular}{|c|c|c|c|c|c|c|c|c|c|c|}
\hline & & \multicolumn{3}{|l|}{ Alone } & \multicolumn{3}{|c|}{ Together } & \multicolumn{3}{|c|}{ Small Model } \\
\hline & & $\mathrm{r \dagger}$ & $r^{2}$ & $\mathrm{p}$ & $\mathrm{r \dagger \dagger}$ & $\mathrm{r}^{2}$ & $\mathrm{p}$ & $\mathrm{r}+\dagger$ & $\mathrm{r}^{2}$ & $\mathrm{p}$ \\
\hline \multicolumn{11}{|c|}{ Self - } \\
\hline \multirow[t]{4}{*}{$\begin{array}{l}\text { Disci } \\
\text { pline }\end{array}$} & Diligence & 0.146 & 0.021316 & $0.000 * * *$ & 0.111 & 0.012 & $0.000 * * *$ & 0.113 & 0.013 & $0.000 * * *$ \\
\hline & Doing Chores & -0.084 & 0.007056 & $0.000 * * *$ & -0.113 & 0.013 & $0.000 * * *$ & -0.112 & 0.013 & $0.000^{* * * *}$ \\
\hline & Distractions & -0.25 & 0.0625 & $0.000 * * *$ & -0.166 & 0.028 & $0.000 * * *$ & -0.167 & 0.028 & $0.000 * * *$ \\
\hline & $\begin{array}{l}\text { Responsibility } \\
\text { for Learning }\end{array}$ & 0.039 & 0.0009 & $0.000 * * *$ & 0.033 & 0.001 & 0.06 & & & \\
\hline
\end{tabular}


In both grade six and seven diligence showed the highest correlation with ITBS while student's distractions showed the highest negative impact on ITBS performance. Results from both the preliminary and the primary study show trends about the relationship between student self-discipline academic performance that the more selfdisciplined a student, the higher the academic performance. The grade seven Model summary of self-discipline scales: distractions, taking responsibility, doing chores and diligence, showed $\mathrm{R}$ square at .086 and $p<.001$ indicating that $9 \%$ of student academic performance (ITBS) is determined by self-discipline. Table 16 presents grade 7 results for self-discipline variables.

Grade seven shows that the scales of self-discipline had similar results as grade six. Alone, the correlation for diligence was $r=0.146, p<.001$, which was the highest compared to doing chores $r=-0.084, p<.001$, which was negative, and distractions $r=-$ $0.25, p<.001$, which was negative. Taking responsibility was not significant alone or together. All the grade seven results were much similar to that of grade six on all the self-discipline scales, alone, together and also in the small model. Same as in grade six, in grade seven distractions had a negative correlation on ITBS performance. However, it was not as high alone $(r=-0.25, p<.001)$ as together (part $r=-0.166, p<.001$ ), and in the small model (part $r=-0.167, p<.001$ ). Table 16 presents results for grade seven correlations.

In both grade six and seven diligence showed the highest correlation with ITBS while student's distractions showed the highest negative impact on ITBS performance. Results from both the preliminary and the primary study show trends about the relationship between student self-discipline academic performance that the more self- 
disciplined a student, the higher the academic performance. The grade seven Model summary of self-discipline scales: distractions, taking responsibility, doing chores and diligence, showed $\mathrm{R}$ square at .086 and $p<.001$ indicating that $9 \%$ of student academic performance (ITBS) is determined by self-discipline.

Table 17 presents model summary for self-discipline scales. In grade seven, all the four self-discipline scales together showed a significant relationship with ITBS, (R square .086). The R square for grade $7(.086,9 \%)$ was higher than the $\mathrm{R}$ square for grade six $(6 \%)$ indicating that self-discipline and parental involvement had more impact in grade seven than in grade six. Grade six students seem to be more self-disciplined than grade seven students.

Table 17

Grade 7 Model Summary for Self-Discipline Scales

\begin{tabular}{|c|c|c|c|c|c|c|c|}
\hline \multirow[b]{3}{*}{ Model } & \multirow[b]{3}{*}{$\mathrm{R}$} & \multirow[b]{3}{*}{ R Square } & \multirow{3}{*}{$\begin{array}{c}\text { Adjusted R } \\
\text { Square }\end{array}$} & \multicolumn{4}{|c|}{ Change Statistics } \\
\hline & & & & R Square & & & Sig. F Change \\
\hline & & & & Change & F Change & df1 & \\
\hline 1 & $.294^{\mathrm{a}}$ & .086 & .085 & .086 & 63.335 & 4 & .000 \\
\hline
\end{tabular}

a. Predictors: (Constant), Distractions, TakingResponsibility, DoingChores, Diligence

Null Hypothesis 1: The first hypothesis in the primary study states that there is no statistically significant relationship between student's self-discipline, as reported by students, and student's ITBS performance. This study investigated the impact of students' self-discipline and parental involvement in their children's academic experiences on the students' academic performance. Pearson's Correlations Coefficient of self-discipline, as related to ITBS, were done to determine the relationship between all the self-discipline 
variables alone, together and in small model. Alpha level .05 was used to determine the level of significance in the relationships.

Except for taking responsibility, all the scales of self-discipline, alone, together, and in the small model, were significant at $p<0.001$. Therefore, the we reject the null hypothesis that there is no statistically significant relationship between student's selfdiscipline, as reported by students, and student's ITBS performance because results show the contrary.

Question 2: Is there a statistically significant relationship between parental involvement, as reported by parents, and students' ITBS performance

Analysis to determine correlations between parental involvement and ITBS scores were done through Pearson's r. Results of each of the four parental involvement scales, alone, showed statistically significance relationship between parental involvement and academic performance, parent school communication $(r=0.089, p<.001)$; parenting $(r=$ $0.206, p<.001)$; volunteering $(r=0.162, p<.001)$; and learning at home $(r=-0.093, p<$ .001). As results show, among the four scales of parental involvement, parenting had the highest positive correlation with ITBS followed by volunteering. Parent school communication had a significant positive correlation, but it was not very high. Learning at home presented unexpected negative correlation with ITBS.

The Model summary of the grade six parental involvement scales: parent school communication, parenting, volunteering and learning at home, showed R square at .085 $(8.5 \%)$ and $p<.001$, which was significant indicating that $9 \%$ of student academic performance was determined by parental involvement. Table 18 presents model summary for parental involvement scales. 
Table 18

Grade 6 Model Summary for Parental Involvement Scales

\begin{tabular}{|c|c|c|c|c|c|c|c|c|c|}
\hline \multirow[b]{2}{*}{ Model } & \multirow[b]{2}{*}{$\mathrm{R}$} & \multirow[b]{2}{*}{ R Square } & \multirow[b]{2}{*}{$\begin{array}{c}\text { Adjusted R } \\
\text { Square } \\
\end{array}$} & \multirow[b]{2}{*}{$\begin{array}{l}\text { Std. Error of } \\
\text { the Estimate }\end{array}$} & \multicolumn{5}{|c|}{ Change Statistics } \\
\hline & & & & & $\begin{array}{c}\text { R Square } \\
\text { Change }\end{array}$ & F Change & df1 & df2 & $\begin{array}{l}\text { Sig. F } \\
\text { Change }\end{array}$ \\
\hline 1 & $.291^{\mathrm{a}}$ & .085 & .083 & 17.19710 & .085 & 56.731 & 4 & 2452 & .000 \\
\hline
\end{tabular}

All the four scales of parental involvement together showed a statistically significant relationship with ITBS. Table 19 below presents the correlation results between parental involvement and ITBS, alone, together and in the small model.

Each of the parental involvement scales when together presented slightly different levels of correlations from what each scale showed separately, parent school communication (part $r=0.040, p<.05)$; parenting (part $r=0.177, p<.001)$; volunteering (part $r=0.098, p<.001$ ); and learning at home (part $r=-0.161, p<.001$ ). Surprisingly, parent school communication made a small contribution to the model. Nonetheless, it was

Table 19

Grade 6: Contribution of Parental Involvement Scales

\begin{tabular}{|c|c|c|c|c|c|c|c|c|c|c|}
\hline & & \multicolumn{3}{|c|}{ Alone } & \multicolumn{3}{|c|}{ Together } & \multicolumn{3}{|c|}{ Small Model } \\
\hline & & $\mathrm{r \dagger}$ & $\mathrm{r}^{2}$ & $\mathrm{p}$ & $\mathrm{rt \dagger}$ & $\mathrm{r}^{2}$ & $\mathrm{p}$ & $\mathrm{rit}$ & $\mathrm{r}^{2}$ & $\mathrm{p}$ \\
\hline \multirow[t]{4}{*}{$\begin{array}{l}\text { Parental } \\
\text { Involvement }\end{array}$} & $\begin{array}{l}\text { Parent-school } \\
\text { communication }\end{array}$ & 0.089 & 0.008 & $0.000 * * *$ & 0.040 & 0.002 & $0.035^{*}$ & & & \\
\hline & Parenting & 0.206 & 0.042 & $0.000 * * *$ & 0.177 & 0.031 & $0.000 * * *$ & 0.176 & 0.031 & $0.000^{* * *}$ \\
\hline & Volunteering & 0.162 & 0.026 & $0.000 * * *$ & 0.098 & 0.010 & $0.000 * * *$ & 0.117 & 0.014 & $0.000^{* * *}$ \\
\hline & $\begin{array}{l}\text { Learning at } \\
\text { home }\end{array}$ & $\begin{array}{l}- \\
0.093\end{array}$ & 0.009 & $0.000^{* * * *}$ & -0.161 & 0.026 & $0.000 * * *$ & $-\overline{0.163}$ & 0.027 & $0.000^{* * * *}$ \\
\hline
\end{tabular}


positive and significant. Parenting recorded the highest positive, and significant correlation with ITBS followed by volunteering. Learning at home had negative correlation with ITBS. Parenting and volunteering where one's children are attending seem helpful in ITBS academic performance.

A backward stepwise analysis was done on the parental involvement scales, and the scale that showed significance at $p<.001$ were selected to a small model. The backward stepwise analysis was employed to strengthen the model by eliminating weak variables which were either not significant or which made a very small contribution to the model. Stepwise was used because it is an effective way of removing the weak variables from the model instead of doing it manually. So, the scales that did not show significance at $p<.001$ were dropped. Three of the scales were selected to the small model and showed the following part correlations, parenting $(r=0.176, p<.001)$; volunteering $(r=0.117, p<.001)$; learning at home $(r=-0.163, p<.001)$. Parent school communication was not selected to the small model because it did not show high significance $(p<.001)$. Parent school communication showed similar results in the preliminary study, where the correlation with ITBS was not significant. Alone, together and in the small model parenting showed the highest positive correlation with ITBS followed by volunteering indicating that parenting and volunteering at the school where one's children are attending has positive impact in academic performance. Results indicated that parenting and volunteering showed the highest correlation with ITBS, even in the small model.

Data for grade seven were also analyzed. Results showed that grade seven had similar results with grade six on the correlation between self-discipline and parental 
involvement variables. In grade seven, volunteering had stronger correlation with ITBS performance alone $(r=0.242, p<.001)$ compared to grade six alone $(r=0.162, p<.001)$ and in small model (part $r=0.203, p<.001$ ) compared to grade six (part $r=0.117, p<$ .001). The results for both grade six and seven are similar. Parent-school communication showed low correlation while learning at home was negatively correlated with ITBS performance. Learning at home had similar results in the preliminary study as regards to Iowa NCE. In the preliminary study, the correlation between learning at home and ITBS was not significant. See Table 20.

Table 20

Grade 7: Contribution of Parental Involvement Scales

\begin{tabular}{|c|c|c|c|c|c|c|c|c|c|c|}
\hline & & \multicolumn{3}{|c|}{ Alone } & \multicolumn{3}{|c|}{ Together } & \multicolumn{3}{|c|}{ Small Model } \\
\hline & & $\mathrm{ri}$ & $\mathrm{r}+\dagger$ & $\mathrm{p}$ & $\mathrm{ri \dagger}$ & & $\mathrm{p}$ & & $\mathrm{r} \dagger$ & $r^{2}$ \\
\hline \multirow[t]{4}{*}{$\begin{array}{l}\text { Parental } \\
\text { Involve } \\
\text { ment }\end{array}$} & $\begin{array}{l}\text { Parent- } \\
\text { school } \\
\text { communic } \\
\text { ation }\end{array}$ & 0.100 & 0.01 & $0.000 * * *$ & 0.011 & 0.000 & $0.000 * * *$ & & & \\
\hline & Parenting & 0.156 & 0.024336 & $0.000 * * *$ & 0.095 & 0.009 & $0.000 * * *$ & 0.95 & 0.903 & $0.000 * * *$ \\
\hline & $\begin{array}{l}\text { Volunteeri } \\
\text { ng }\end{array}$ & 0.242 & 0.058564 & $0.000 * * *$ & 0.189 & 0.036 & $0.000 * * *$ & 0.203 & 0.041 & $0.000 * * *$ \\
\hline & $\begin{array}{l}\text { Learning } \\
\text { at home }\end{array}$ & -0.079 & 0.006241 & $0.000 * * *$ & -0.152 & 0.023 & $0.000 * * *$ & -0.154 & 0.024 & $0.000 * * *$ \\
\hline
\end{tabular}

Grade seven model summary for parental involvement scales: learning at home, parent school communication, parenting and volunteering, shows Adjusted R square at $9.5 \%$ and $\mathrm{p}$ value at $\mathrm{p}<.001$ indicating that parental involvement is significant in academic performance. Table 21 contains the model summary for parental involvement scales. The R square for grade seven $(9.5 \%)$ and the $\mathrm{p}$ value $(p<.001$ showed that 
Table 21

Grade 7 Model Summary for Parental Involvement Scales

\begin{tabular}{|c|c|c|c|c|c|c|c|}
\hline \multirow[b]{2}{*}{ Model } & \multirow[b]{2}{*}{$\mathrm{R}$} & \multirow[b]{2}{*}{ R Square } & \multirow{2}{*}{$\begin{array}{c}\text { Adjusted R } \\
\text { Square } \\
\end{array}$} & \multirow{2}{*}{$\begin{array}{c}\text { Std. Error of the } \\
\text { Estimate }\end{array}$} & \multicolumn{3}{|c|}{ Change Statistics } \\
\hline & & & & & R Square Change & df1 & Sig. \\
\hline 1 & $.308^{\mathrm{a}}$ & .095 & .093 & 16.58945 & .095 & 4 & .000 \\
\hline
\end{tabular}

parental involvement is significantly correlated with ITBS.

Null Hypothesis 2: There is no statistically significant relationship between parental involvement, as reported by parents, and students' ITBS performance. Correlations were run using Pearson's Correlations Coefficient of parental involvement, as related to ITBS, to determine the relationship between all the parental involvement variables alone, together and in small model. Alpha level .05 was used to determine the significance of the relationships. Results showed that there is statistically significant relationship between parental involvement, as reported by parents, and students' ITBS performance as indicated by both grade six and seven results. Alone, together all the variables of parental involvement were significant at $p<.001$. Also, in the small model, parenting, volunteering and learning at home were significant at $p<.001$. Therefore, we reject the null hypothesis that there is no statistically significant relationship between parental involvement and ITBS performance.

Question 3. Are there combined effects of student self-discipline, as perceived by students, and parental involvement, as perceived by parents, on student's ITBS performance?

The method used in studying interaction of the demographic variables involving parental involvement and student self-discipline in this study is given below. 
Boys: $\mathrm{R}$ squared $=1.00$

The regression equation: $\mathrm{Y}=2 \mathrm{X}$.

The part correlation (used to interpret the strength of the predictor) $=+1.00$

Girls: $\mathrm{R}$ squared $=1.00$

The regression equation: $\mathrm{Y}=25-4 \mathrm{X}$.

The part correlation (used to interpret the strength of the predictor) $=-1.00$

The method used in the dissertation was to examine statistics in regression equations run separately for each of the subgroups in the control variables (e.g., one equation for males, one equation for females). Researcher compared the $\mathrm{R}$ squared values to see if the strength of the relationship was different in the two equations. The part correlations of all of the independent variables were compared to see if they varied in the two equations. When either the R squared (strength) or the part correlations (strength and type) varied substantially, it was an indication of interaction.

The summary table of all variables of student self-discipline and parental involvement combined show R squared at .126 and $p<.001$. meaning that $13 \%$ of student's academic performance is explained by student's self-discipline and parental involvement. The statistically significant results $(p<.001)$ shows that there were significant combined effects of student's self-discipline, as perceived by students, and parental involvement, as perceived by parents. As Table 22 shows, the $\mathrm{R}^{2}$ indicates that $13 \%$ variance in academic performance is explained by student self-discipline and parental involvement. 
Table 22

Grade 6 Self-discipline and Parental Involvement Variables Combined

\begin{tabular}{|c|c|c|c|c|c|c|c|c|}
\hline \multirow[b]{2}{*}{ Model } & \multirow[b]{2}{*}{$\mathrm{R}$} & \multirow[b]{2}{*}{ R Square } & \multirow[b]{2}{*}{$\begin{array}{c}\text { Adjusted R } \\
\text { Square } \\
\end{array}$} & \multirow[b]{2}{*}{$\begin{array}{c}\text { Std. Error of the } \\
\text { Estimate }\end{array}$} & \multicolumn{4}{|c|}{ Change Statistics } \\
\hline & & & & & $\begin{array}{c}\text { R Square } \\
\text { Change }\end{array}$ & F Change & df1 & Sig. \\
\hline 1 & $.355^{\mathrm{a}}$ & .126 & .123 & 16.81819 & .126 & 44.124 & 8 & .000 \\
\hline
\end{tabular}

Table 23 below shows us more details of the contribution of all the independent variables as a group, both in big model of eight variables and also in small model, which is made up of six variables.

Diligence, parenting, and volunteering have a significant positive impact at .001 each. However, doing chores $(-0.084, p<.05)$ and distractions $(-0.116, p<.001)$ are also significant at .001 , but they are negatively related to student's academic performance on ITBS. Student taking responsibility for learning and parent school communication make small, insignificant contribution to the model.

Grade seven had similar results the following year, 2007/8. Table 24 shows that grade seven had similar results to grade six. Results show that in grade seven there were combined effects of student self-discipline, as perceived by students, and parental involvement, as perceived by parents, on student's ITBS performance. Compared to grade six $(12 \%)$, grade seven recorded higher percentage of combined effects of self-discipline and parental involvement on ITBS performance (16\%) suggesting that student selfdiscipline and parental involvement have more impact in grade seven students relating to ITBS performance. Apart from taking responsibility for learning which was not significant alone, all the other scales had a significant contribution $(p<.001)$ alone, 
Table 23

Grade 6: Contribution of All Independent Variables Together

\begin{tabular}{|c|c|c|c|c|c|c|c|c|c|c|}
\hline & & \multicolumn{3}{|c|}{ Alone } & \multicolumn{3}{|c|}{ Together } & \multicolumn{3}{|c|}{ Small Model } \\
\hline & & $\mathrm{r \dagger}$ & $\mathrm{r \dagger \dagger}$ & $\mathrm{p}$ & $\mathrm{rit}$ & $\mathrm{r}^{2}$ & $\mathrm{p}$ & $\mathrm{rit}$ & $\mathrm{r}^{2}$ & $\mathrm{p}$ \\
\hline $\begin{array}{l}\text { Self - } \\
\text { Discipline }\end{array}$ & $\begin{array}{l}\text { Diligence } \\
\text { Doing Chores }\end{array}$ & $\begin{array}{l}0.151 \\
-0.024\end{array}$ & $\begin{array}{l}0.023 \\
0.001\end{array}$ & $\begin{array}{l}0.000^{* * * *} \\
0.238\end{array}$ & $\begin{array}{l}0.129 \\
-0.084\end{array}$ & $\begin{array}{l}0.017 \\
0.007\end{array}$ & $\begin{array}{l}0.000^{* * * *} \\
0.000^{* * * *}\end{array}$ & $\begin{array}{l}0.130 \\
-0.082\end{array}$ & $\begin{array}{l}0.017 \\
0.007\end{array}$ & $\begin{array}{l}0.000^{* * *} \\
0.000^{* * *}\end{array}$ \\
\hline & Distractions & -0.198 & 0.039 & $0.000 * * *$ & -0.116 & 0.013 & $0.000 * * *$ & -0.117 & 0.014 & $0.000 * * *$ \\
\hline Parental & $\begin{array}{l}\text { Responsibility } \\
\text { for learning }\end{array}$ & 0.039 & 0.002 & 0.051 & 0.024 & 0.001 & 0.212 & & & \\
\hline Involvement & $\begin{array}{l}\text { communication } \\
\text { Parenting }\end{array}$ & $\begin{array}{l}0.089 \\
0.206\end{array}$ & $\begin{array}{l}0.008 \\
0.042\end{array}$ & $\begin{array}{l}0.000 * * * \\
0.000 * * *\end{array}$ & $\begin{array}{l}0.040 \\
0.177\end{array}$ & $\begin{array}{l}0.002 \\
0.031\end{array}$ & $\begin{array}{l}0.035 * \\
0.000 * * *\end{array}$ & 0.176 & 0.031 & $0.000 * * *$ \\
\hline & Volunteering & 0.162 & 0.026 & $0.000^{* * * *}$ & 0.098 & 0.010 & $0.000 * * *$ & 0.117 & 0.014 & $0.000 * * *$ \\
\hline & $\begin{array}{l}\text { Learning at } \\
\text { Home }\end{array}$ & -0.093 & 0.009 & $0.000 * * *$ & -0.161 & 0.026 & $0.000 * * *$ & -0.163 & 0.027 & $0.000 * * *$ \\
\hline
\end{tabular}

$\dagger$ Pearson $\mathrm{r}, \dagger \dagger$ Part $\mathrm{r}, * \mathrm{p}<.05, * * \mathrm{p}<.01, * * * \mathrm{p}<.001$

Table 24

Grade 7: Contribution of All Independent Variables Together

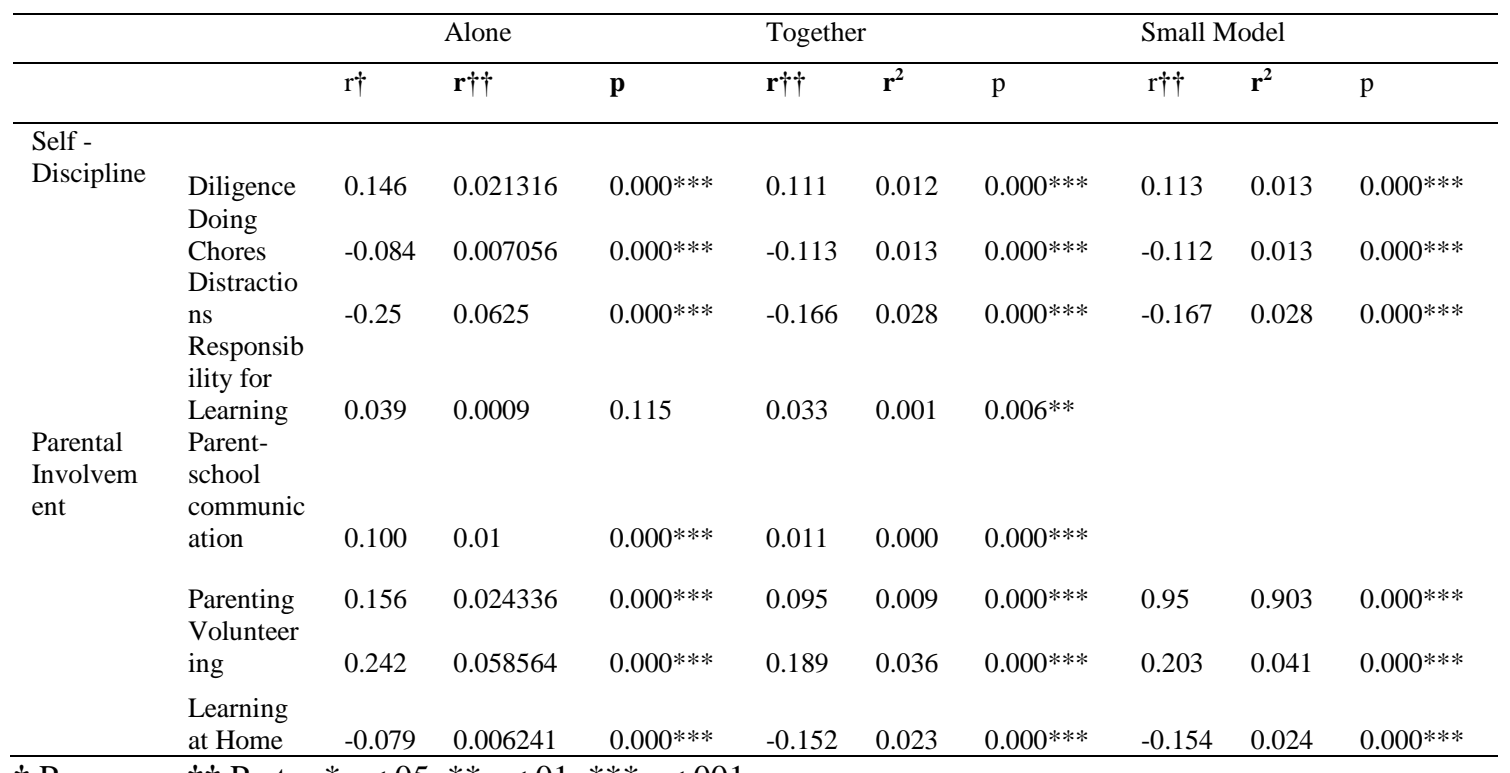

$\dagger$ Pearson $\mathrm{r}, \dagger \dagger$ Part $\mathrm{r}, * \mathrm{p}<.05, * * \mathrm{p}<.01, * * * \mathrm{p}<.001$ 
together (part) and in the small model. Results showed that in both grade six and seven, self-discipline and parental involvement had a statistically significant combined effect on academic performance. Table 25 contains parental involvement scales combined.

Table 25

Grade 7 Self-Discipline and Parental Involvement Scales Combined

\begin{tabular}{|c|c|c|c|c|c|c|c|c|}
\hline \multirow[b]{2}{*}{ Model } & \multirow[b]{2}{*}{$\mathrm{R}$} & \multirow[b]{2}{*}{ R Square } & \multirow[b]{2}{*}{$\begin{array}{l}\text { Adjusted R } \\
\text { Square }\end{array}$} & \multirow[b]{2}{*}{$\begin{array}{l}\text { Std. Error of } \\
\text { the Estimate }\end{array}$} & \multicolumn{4}{|c|}{ Change Statistics } \\
\hline & & & & & $\begin{array}{c}\text { R Square } \\
\text { Change }\end{array}$ & F Change & df1 & Sig. \\
\hline 1 & $.394^{\mathrm{a}}$ & .155 & .153 & 16.03976 & .155 & 61.450 & 8 & .000 \\
\hline
\end{tabular}

The summary Table 25 shows R square at .155 which means that almost $16 \%$ variance of student's academic performance is explained by student's self-discipline and parental involvement. The variables have a significant impact $(p<.001)$ which shows that there were combined effects of student's self-discipline, as perceived by students, and parental involvement, as perceived by parents.

From the equations, it is clear that $\mathrm{X}$ (parental involvement) is a perfect predictor of achievement for both boys and girls. The same is true for X (self-discipline). The "effect size" (R squared and part correlation) is the same for boys and girls. However, the type of effect is different: parental involvement and student self-discipline impacts boys more than it does boys.

Null Hypothesis 3: The primary study null hypothesis number three states that there are no combined effects of student self-discipline and parental involvement on 
student ITBS performance. After running correlations and regression analysis on all independent variables combined, results showed that the eight scales of self-discipline and parental involvement had combined effects on student's ITBS performance. The summary model results showed that $13 \%$ of grade six and $16 \%$ of grade seven academic performance is determined by student's self-discipline and parental involvement. The sig. for both grade six and seven was significant $(p<.001)$ showing that there are combined effects of student's self-discipline and parental involvement on student ITBS performance. So, we reject the null hypothesis.

4. Do ethnicity, gender, grade level, student's cognitive ability, and parental education level have an influence on the relationship between students' self-discipline (as reported by students), parental involvement (as reported by parents) and students' ITBS performance?

Results from the control variables portray the level of influence that the variables, parent education, gender, student ethnicity, student ability level, add on the relationship between student self-discipline and parental involvement and student's performance on the ITBS.

The prediction of the small model, as shown by the Small Model R Squared in Table 11 , is very similar for students who had parents of different education level $\left(r^{2}=\right.$ .098 to .121$)$, females and males $\left(r^{2}=.114\right.$ and .137$)$, and students of different ability level $\left(r^{2}=.044\right.$ to .067$)$. The model did not predict as well for Hispanic students $\left(r^{2}=\right.$ $.086)$ as for Asian, Black, and White students $\left(r^{2}=.128\right.$ to .146$)$.

The Small Model $\mathrm{R}^{2}$ was smaller for each of the student ability level groups since student ability is highly correlated with student achievement (the dependent variable), 
which reduced the variability of achievement within each of the student ability level groups, thus resulting in lower correlations.

The contribution of the six independent variables in the small model (parenting, volunteering, learning at home, diligence, doing chores, and distractions) was generally similar for all subgroups studied. Of the 72 different part correlations reported in Table 26; only 12 were less than half the size of the largest part correlation for the other groups for the same independent variable.

Table 26

Grade 6: Interactions

\begin{tabular}{|c|c|c|c|c|c|c|c|c|}
\hline & & $\begin{array}{l}\text { Small } \\
\text { Model }\end{array}$ & & & $\begin{array}{c}\text { Small } \\
\text { Model } \\
\text { Part r }\end{array}$ & & & \\
\hline & & $\mathrm{r}^{2}$ & Parenting & Volunteering & $\begin{array}{l}\text { Learning } \\
\text { at home }\end{array}$ & Diligence & $\begin{array}{c}\text { Doing } \\
\text { Chores }\end{array}$ & $\begin{array}{c}\text { Distractio } \\
\text { ns }\end{array}$ \\
\hline \multirow[t]{2}{*}{$\begin{array}{l}\text { Parent } \\
\text { Education }\end{array}$} & $\begin{array}{l}\text { Below } \\
\text { average }\end{array}$ & 0.108 & 0.178 & 0.101 & -0.143 & 0.137 & -0.069 & -0.129 \\
\hline & $\begin{array}{l}\text { Average } \\
\text { Above } \\
\text { average }\end{array}$ & 0.098 & 0.136 & 0.061 & -0.206 & 0.119 & -0.086 & -0.091 \\
\hline $\begin{array}{l}\text { Student } \\
\text { Gender }\end{array}$ & Female & 0.114 & 0.172 & 0.105 & -0.172 & 0.138 & -0.078 & -0.109 \\
\hline \multirow{2}{*}{$\begin{array}{l}\text { Student } \\
\text { Ethnicity }\end{array}$} & Male & 0.137 & 0.180 & 0.126 & -0.151 & 0.123 & -0.082 & -0.128 \\
\hline & $\begin{array}{l}\text { Asian } \\
\text { Black }\end{array}$ & $\begin{array}{l}0.146 \\
0.142\end{array}$ & $\begin{array}{l}0.137 \\
0.157\end{array}$ & $\begin{array}{l}0.180 \\
0.157\end{array}$ & $\begin{array}{l}-0.109 \\
-0.110\end{array}$ & $\begin{array}{l}0.175 \\
0.210\end{array}$ & $\begin{array}{l}-0.036 \\
-0.083\end{array}$ & $\begin{array}{l}-0.166 \\
-0.107\end{array}$ \\
\hline \multirow{4}{*}{$\begin{array}{l}\text { Student } \\
\text { Ability } \\
\text { Level }\end{array}$} & Hispanic & 0.086 & 0.205 & 0.084 & -0.153 & 0.061 & -0.102 & -0.056 \\
\hline & White & 0.128 & 0.203 & 0.056 & -0.196 & 0.128 & -0.048 & -0.102 \\
\hline & $\begin{array}{l}\text { Below } \\
\text { average }\end{array}$ & 0.044 & 0.090 & 0.027 & -0.112 & 0.101 & -0.064 & -0.080 \\
\hline & $\begin{array}{l}\text { Average } \\
\text { Above } \\
\text { average }\end{array}$ & 0.058 & 0.149 & 0.088 & -0.063 & 0.098 & -0.017 & -0.041 \\
\hline
\end{tabular}

Parent education: below average: high school; average: college_; above Average: graduate. Student Ability Level: below average 50 -89; average $90-110$; above average 110-150 
The part correlations for parenting were similar for all subgroups. The parenting part correlations for students with average parent education, females, Hispanics, Whites, and students with below average ability were less than half of the other groups for the same independent variable.

The correlations for learning at home were negative for all subgroups, but for student with average ability it was not a strong predictor $(r=-0.063)$. Diligence was a strong predictor for all subgroups (parent education, student gender, student ethnicity, and student ability level except for Hispanics $(r=0.061)$. Doing chores had a negative impact on all subgroups. Nonetheless, it was not a strong predictor except for Hispanics and Blacks. The prediction for distractions was similar in all subgroups, but it was not as strong predictor for Hispanics $(r=0.056)$ and students with average $(r=-0.041)$ and above average $(r=-0.067)$ ability level.

For students with parents with below average education, the contribution of all independent variables in the small model were not meaningfully different from the other groups. For students with parents with average education, volunteering was not as strong a predictor $(r=0.061)$ compared to below average $(r=0.101)$ and above average $(r=$ $0.135)$ in that independent variable. For students with parents with above average education, doing chores was not as strong a predictor $(r=-0.034)$. All the six variables in the Small Model were strong predictors of student gender. All variables were stronger predictors for males except for learning at home and diligence. Grade seven control variables are presented in Table 27 below. In grade seven, the control variables had similar results as in grade six. 
Table 27

Grade 7: Interactions

\begin{tabular}{|c|c|c|c|c|c|c|c|c|}
\hline & & $\begin{array}{l}\text { Small } \\
\text { Model }\end{array}$ & & & $\begin{array}{c}\text { Small Model } \\
\text { Part r }\end{array}$ & & & \\
\hline & & $\mathrm{R}^{2}$ & Parenting & $\begin{array}{c}\text { Volunte } \\
\text { ering }\end{array}$ & $\begin{array}{c}\text { Learning at } \\
\text { home }\end{array}$ & $\begin{array}{c}\text { Diligen } \\
\text { ce }\end{array}$ & $\begin{array}{l}\text { Doing } \\
\text { Chores }\end{array}$ & Distractions \\
\hline \multirow{6}{*}{$\begin{array}{l}\text { Parent } \\
\text { Education }\end{array}$} & Below & & & & & & & \\
\hline & Average & & & & & & & \\
\hline & & 0.090 & 0.057 & 0.169 & -0.141 & 0.103 & -0.141 & -0.067 \\
\hline & Average & 0.169 & 0.112 & 0.170 & -0.183 & 0.106 & -0.092 & -0.210 \\
\hline & Above & & & & & & & \\
\hline & Average & 0.155 & 0.088 & 0.154 & -0.179 & 0.153 & -0.056 & -0.196 \\
\hline \multirow[t]{2}{*}{ Gender } & Female & 0.151 & 0.106 & 0.194 & -0.168 & 0.097 & -0.072 & -0.170 \\
\hline & Male & 0.164 & 0.084 & 0.209 & -0.134 & 0.126 & -0.151 & -0.161 \\
\hline \multirow{5}{*}{$\begin{array}{l}\text { Student } \\
\text { Ethnicity }\end{array}$} & & & & 0211 & 0075 & 0018 & & \\
\hline & Astan & 0.192 & 0.131 & 0.211 & -0.025 & -0.018 & -0.210 & -0.216 \\
\hline & Black & 0.100 & 0.017 & 0.272 & -0.115 & -0.030 & -0.051 & -0.066 \\
\hline & Hispanic & 0.141 & 0.067 & 0.190 & -0.215 & 0.232 & -0.108 & -0.094 \\
\hline & White & 0.145 & 0.120 & 0.143 & -0.124 & 0.123 & -0.097 & -0.172 \\
\hline \multirow[t]{3}{*}{$\begin{array}{l}\text { Student } \\
\text { Ability } \\
\text { Level }\end{array}$} & $\begin{array}{l}\text { Below } \\
\text { average }\end{array}$ & 0.067 & 0.027 & 0.148 & -0.202 & 0.109 & -0.780 & -0.049 \\
\hline & Average & 0.056 & 0.056 & 0.183 & -0.083 & 0.030 & -0.026 & -0.069 \\
\hline & average & 0.105 & 0.084 & 0.091 & -0.123 & 0.114 & -0.078 & -0.189 \\
\hline
\end{tabular}

Parent education: below average: elementary; average: high school; above Average: college.

Student Ability Level: below average 50 -89; average 90 - 110; above average 110-150

Null hypothesis number 4 in the primary study was not determined because it is not easy to statistically determine the effects of the control variables on academic performance.

\section{Summary}

Chapter 4 presented results from both the preliminary and the primary studies, which includes descriptive statistics of the subjects and the inferential statistics. Correlations and graphs were done to analyze data in the preliminary study. Multiple regression analysis was used to analyze the primary, supplemental, data according to the 
research questions and the null hypotheses in Chapter 1 and 3. In the preliminary study, both the research questions and the hypotheses focused on the relationships between the impact of student's self-discipline and parental involvement on GPA and ITBS performance. The primary study focused on the relationships between self-discipline, parental involvement and ITBS. Also, Chapter 4 presents the results of the analysis of the influence of ethnicity, gender, grade level, student's cognitive ability, and parental education level on the relationship between students' self-discipline (as reported by students), parental involvement (as reported by parents) and students' ITBS performance. Results of correlations and multiple regression on the data showed that student's self-discipline and parental involvement are significant predictors of GPA and ITBS performance, as result tables show. Chapter 5 presents summary, conclusions and implications. 


\section{CHAPTER 5}

\section{DISCUSSION AND CONCLUSION}

This study was conducted to investigate the impact of student's self-discipline and parental involvement on academic performance. Chapter 5 presents a summary of the study, which includes restatement of the purpose of the study, research questions, method and a summary of findings. Specifically, this chapter interprets the findings of both the preliminary and the primary studies in order to address the research questions of both studies. Additionally, this chapter provides the conclusions and suggestions for future research. The interpretations of the results are presented in four main sections, 1) student's self-discipline, 2) parental involvement, 3) combination of self-discipline and parental involvement, and 4) control (demographic) variables.

\section{Summary of the Study}

This study sought to determine the impact of student's self-discipline and parental involvement on academic performance. The study sought to make a contribution toward improving academic performance (Duckworth \& Seligman, 2006; Epstein, 2008; Yu et al., 2012). In the preliminary study, academic performance was measured through GPA and ITBS. In the primary study, academic performance was measured through ITBS alone. The objective of the study was to find out whether student's self-discipline and parental involvement can help in improving academic performance. 
The subjects in the preliminary study were grade six through 12 students in Texas Conference of the SDAs. The subjects for the primary study were two cohorts, grade six and seven students in schools in the NAD of the SDAs. Specifically, the sample was drawn from students in SDA schools in North America.

In the preliminary study, researcher obtained the approval of IRB, school superintendent, school principals and the consent of the parents. Later the SCRS, a 33 items questionnaire which was adopted from Kendall and Wilcox (1979) was given to teachers to rate student's self-discipline. Additionally, PASS, a 24 items parent questionnaire, was mailed to the sampled schools for parents to rate their parental involvement in their children's academic activities.

Before conducting the primary study, researcher sent a letter to the owners of the CG data and requested them to allow researcher to use the CG data in the primary study. After receiving approval from IRB and from the owners of the CG data, researcher mined the data from which the primary study was done.

The design of the study was quantitative and cross-sectional. Pearson's $r$ and graphs were used in the preliminary study to determine the relationships between student self-discipline or parental involvement and GPA or ITBS. In the primary study, multiple regression analyses were conducted to determine the relationships between self-discipline or parental involvement and ITBS. Ethnicity, gender, grade level, age, cognitive ability and parent education level were evaluated as control variables.

The collected data were analyzed to answer research questions in both the preliminary and the primary study. 


\section{Preliminary Study Research Questions}

1. Is there a statistically significant relationship between the self-discipline of students in SDA schools, as reported by teachers, and student's GPA or ITBS performance?

2. Is there a statistically significant relationship between parental involvement, as reported by parents, and student's GPA or ITBS performance?

3. Are there combined effects of student self-discipline and parental involvement on student's GPA or ITBS performance? (in other words, do student self-discipline and parental involvement interact in their association with GPA or ITBS scores)?

4. Do ethnicity, gender, age and grade level have any statistically significant effects on the relationships between student's self-discipline, as reported by teachers, or parental involvement, as reported by parents, and student's GPA or ITBS performance?

\section{Primary Study Research Questions}

1. Is there a statistically significant relationship between student's self-discipline, as reported by students, and student's ITBS performance?

2. Is there a statistically significant relationship between parental involvement, as reported by parents, and student's ITBS performance?

3. Are there combined effects of student self-discipline and parental involvement on student ITBS performance?

4. Do ethnicity, gender, grade level, student's cognitive ability, and parental education level have any statistically significant effects on the relationship between student's self-discipline, as reported by students, or parental involvement, as reported by parents, and student's ITBS performance? 


\section{Conclusion and Discussion}

Results of the descriptive and inferential statistics from both the preliminary and the primary studies were reported in Chapter 4 . The results, which were used to answer the research questions, showed many significant correlations between various variables. It was clear that student's self-discipline and parental involvement can be used to predict student's academic performance. The findings are a unique contribution in the schools of the SDA, and a significant contribution to all schools. The next section discusses the findings according to the research questions guiding this study. The discussion is presented within the research questions, emphasizing the unique contribution of both the preliminary and the primary studies.

\section{Student Self-Discipline and Academic Performance}

The findings on the research questions concerning student self-discipline and academic performance, which is question number one in both the preliminary and the primary study, will be discussed in this section. Also, the first hypotheses from both studies will also be discussed in this section. The researcher hypothesized that there would be a statistically significant relationship between student self-discipline and GPA and ITBS performance. Results from both the preliminary and the primary study affirmed the hypotheses. Results in the preliminary study showed a high correlation between selfdiscipline and GPA $(r=0.720, p<.01)$. The statistically significant relationship between student self-discipline and GPA was confirmed by the graph linear relationship at $r^{2}=$ 0.518 indicating that $52 \%$ of the variance in GPA is explained by student's self- 
discipline. The results suggested that the more self-disciplined a student was, the higher the GPA.

The results were consisted with previous studies (Duckworth \& Seligman, 2005, 2006). Duckworth and Seligman did two longitudinal studies to investigate the impact of self-discipline on academic achievements. Results showed high correlation between selfdiscipline and academic performance. These past studies were done in public schools. The present study was conducted in the schools of the SDAs in NAD. Also, the past studies investigated self-discipline alone. The present study investigated the impact of student self-discipline and parental involvement on student's academic performance.

In addition, as shown in Chapter 4, the preliminary study showed that selfdiscipline significantly correlated with ITBS performance $(r=.643, p<01)$. Graph results confirmed the statistically significant relationship between self-discipline and ITBS scores $\left(r^{2}=0.414\right.$ showing that $41 \%$ of variance in ITBS performance is accounted for by student self-discipline, which is quite significant.

The primary study question one results confirmed the correlation between selfdiscipline and ITBS performance $(p<0.05)$. In the primary study, three tests were conducted to determine the relationship between achievement and each self-discipline and parental involvement variable alone, 2) the relationship between achievement and all self-discipline and parental involvement variables together, and 3) the relationship between achievement and a small model of selected self-discipline and parental involvement variables together.

Of all the four scales of self- discipline in the primary study (diligence, doing chores, taking responsibility and distractions), diligence had the highest positive 
correlation with ITBS scores $(r=0.151, p<.001$ alone, $r=129, p<.001$ together (part), $r=130, p<.001$ in the small model). Distractions had the highest negative correlations with ITBS performance $(r=-0.198, p<.001$ alone; $r=-0.116, p<.001$ together (part); $r$ $=-0.117, p<.001$ in the small model).

The results were consisted with a study Inal et al. (2012), which involved 1100 high school students randomly chosen from four state schools to investigate the impact of computer use and the internet on the high school students. Results indicated that most students who earned a GPA above 3.0 had computers at home, but they spent less than two hours on the computer, unless it was academic related activities. Some of the distractions investigated in this study included playing games on the computer and surfing the internet. It takes self-discipline to focus on school work instead of playing games on the computer.

In the primary study, the correlation between student taking responsibility and ITBS was not significant, but when put together with other variables, taking responsibility was significantly correlated with ITBS $(r=0.212, p<.05)$. That maybe because only two items in the CG data could be used to measure student taking responsibility for their education.

The correlation between student doing chores and ITBS was negative $(-0.024, p<$ .05 alone $),(r=-0.084, p<.001)$ together $)$ and $(r=-0.082, p<.001$ in the small model $)$, which was not surprising to the researcher. Research findings portray the necessity for students to engage in activities that foster academic enhancement even when they are at home. It is the responsibility of parents and guardians to ensure that children are in a conducive learning environment while at home (Hara \& Burke, 1998). But the findings of 
this study show that while parents, guardians and teachers have a responsibility to provide a conducive learning environment at home and at school, student have a responsibility, too, of focusing and diligently working on their academic work, without which academic performance suffers.

So, students need to realize that without them playing their part, the effort of parents and teachers is not enough to make them succeed academically. Even though the correlations in the primary study were low, maybe due to few items in the CG data to measure self-discipline and parental involvement, results show that diligence had the highest correlation with academic performance while student distractions produce negative results.

A study, Mullis, Rathge, and Mullis (2003), a longitudinal study which involved 24,599 middle school adolescents to investigate predictors of academic performance during early adolescence indicated that the strongest predictor of academic performance of the students was student behavior while in school. The behavior investigated in the study included poor attendance and fighting.

Policy makers need to consider the importance of student self-discipline in academic performance. Acts such as NCLB 2001 and the Every Student Succeed Act (ESSA) 2015 are endeavors, on the part of the federal government, to put in place laws that guide schools, parents and other stakeholders to help students to achieve academic success. The NCLB Act of 2001 failed to achieve the desired goal, which was to ensure that all students achieved academic performance. The ESSA was put in place in 2015 to replace the NCLB. But while the new act releases the much pressure that NCLB placed on teachers and school administrators to ensure that all their students performed, ESSA 
just like NCLB, fails to highlight the importance of student's self-discipline in academic performance. Ignoring the fact that students have a role to play in their own academic performance is a major mistake in setting an Act on improving academic performance.

In spite of the education Acts, several studies report that American students' PISA falls below that of students from many countries including Canada, United Kingdom, Australia, and New Zealand. (Yu et al., 2012). A study, Stevenson et al. (1985), that sought to determine whether there were any differences in cognitive abilities of Japanese, Chinese, and American children and also to establish any possible differences in cognitive task scores, differential scores in such activities as reading by children from the three countries showed similarities among children from the three countries. In areas such as variability and structure of cognitive abilities, the children showed similarities. Yet in spite of similar cognitive abilities among children from the three cultures, both Chinese and Japanese children achieved higher academic performance than American children.

The findings of the study Stevenson et al. (1985), indicate that the high academic performance of the Japanese and Chinese children can be attributed to focusing on academic work both at home and at school. Additionally, the study indicated that American children spend the least time on academic activities compared to Chinese and Japanese children. The differences of time the children had on academic activities were evidently portrayed in their academic performance. Results of the current study are consistent with the findings of Stevenson et al. (1985), in that while diligence has a very high positive correlation with academic performance, distractions showed the highest negative correlation of all the self-disciplined subscales. Distractions mean that a student is spending much time on other activities other than academic. 
The positive correlation between student self-discipline and academic performance suggest that one of the main factors lacking in the students who fail to achieve academic success is self-disciplie. It is interesting that so much emphasis is put on the importance for teachers and parents to ensure support to students. But there are not many studies or policies highlighting the importance of student self-discipline in academic performance. Yet self-discipline determines such a significant percentage of student's academic success. Students need to uphold self-discipline if they are to achieve academic success.

\section{Parental Involvement and Academic Performance}

This section discusses the findings of both number two research questions from both the Preliminary and the primary study. Research question two in the preliminary study focused on the relationship between parental involvement and GPA and also ITBS performance. Research question number two in primary study focused on the relationship between parental involvement and student's performance on ITBS. In this study, in both the preliminary and the primary study, parental involvement was designed to test Joyce Epstein's parental involvement model, which involves six factors: communicating, volunteering, especially at the school where one's children are attending, facilitating learning at home, parenting, decision making, and collaborating with community (Epstein, 2008). All the six parts of the framework were tested in the preliminary study. The questionnaire which was used to collect data in the preliminary study, PASS, was adopted from Ringenberg et al. (2005), an instrument which is based on Epstein's six factors of parental involvement. Specifically, the PASS questionnaire was constructed to measure the Epstein's six levels of parental involvement. But while all the factors of 
Epstein's parental involvement were tested in the preliminary study, in the primary study only four of the six factors were tested: communicating, parenting, volunteering and learning at home. The other two constructs, decision making and collaborating with community, were not evaluated in the primary study because the CG data, which was used in the primary study, did not have enough data on decision making and collaborating. So, the results discussed here cover the six factors in the preliminary study and four factors of the parental involvement in the primary study.

The researcher predicted that there would be a statistically significant relationship between parental involvement and GPA and also ITBS performance. Results in the preliminary study affirmed both predictions with the correlations between parental involvement and GPA $(r=.636 p<.001)$, and between parental involvement and ITBS performance $(r=.727 p<.001)$. Self-results confirmed the relationship, parental relationship and GPA $\left(r^{2}=0.404\right)$ and between parental involvement and ITBS performance $\left(r^{2}=0.529\right)$.

The subscales of parental involvement presented varying levels of correlation with GPA and ITBS. It was surprising that the correlation between communication and GPA was not significant, and neither was the correlation between communication and ITBS. Yet literature emphasizes the importance of parent school communication (Epstein, 2008). The reason for the lack of significance could be due to the small number of participants in the preliminary study $(N=16)$. In the primary study where participants were much more, 2457 in grade six, parent - school communication and ITBS was significant alone $(r=0.089, p<.001)$ and together $(r=0.040, p<0.035)$. So, even though the contribution of parent school communication was significant in the primary 
study, the contribution to the model was small, especially together. According to Epstein's model of parental involvement, parent's involvement encourages a two-way communication between home and school. The communication between home and school enable parents to stay informed about the progress of their children. The model shows that the communication between home and school yields academic success for students (Epstein, 2008).

Both in the preliminary and in the primary study, parenting and volunteering showed significance with both GPA and ITBS. Parenting was significant at $p<.01$ for both GPA and ITBS. The results show strength in Epstein's model for parental involvement, which states that when schools involve parents in the learning of their children, parents get equipped with knowledge on family support, and setting a learning environment at home. Also, parents get a chance to provide teachers with the family background, and setting goals for children (Epstein, 2008). The correlation between parenting and ITBS was the highest among the scales of parental involvement suggesting that parenting in crucial for academic success.

In the preliminary study, volunteering showed significance at GPA $(p<.05)$ and ITBS $(p<.001)$. The results on volunteering showed consistency with Epstein's model. Volunteering is encouraged so that parents and guardians can get a chance to be trained on educational activities that equip them to participate in school activities. The benefits of training parents and other volunteers include equipping them to talk to students on important topics such as careers (Epstein, 2008).

Both in the preliminary and in the primary study, learning at home produced very unexpected results. In the preliminary study, the correlation between learning at home 
and GPA was significant $(p<0.05)$, but with ITBS the correlation was not significant, $p$ $>$.05). In the primary study, learning at home presented negative correlation with ITBS, alone $(r=-0.093, p<.001)$, together (part $r=-0.161, p<.001)$ and in small model (part $r=-0.163, .001)$. The results were consistent with the findings of Duckworth, Quinn et al. (2011), a longitudinal study which tested the following two hypotheses: "Self-control is a better predictor than IQ of improvements in report card grades over time," and IQ is a better predictor than self-control of improvements in standardized achievement test scores over time" (p. 440). The study confirmed both hypotheses. In the Duckworth, Quinn et al. (2011) study, self-control refers to "the voluntary regulation of attention, emotion, and behavior in the service of personally valued goals and standards" (p. 440), which refers to similar traits as the definition of self-discipline in the current study. Thus, it is apparent that studying at home may impact GPA positively but not ITBS, which takes more than mastering the curriculum content. According to Duckworth, Quinn et al. (2011), IQ impacts standardized tests scores more that it does grades while focusing and working diligently on school work impacts GPA.

Another study, Willingham, Pollack, and Lewis (2002) which investigated the difference between standardized tests scores and grades reached the following conclusion,

The content assessed by standardized achievement tests diverges at least somewhat from the curricula students are actually exposed to ... the skills and knowledge acquired outside of formal instruction would be expected to improve standardized achievement test scores more so than report card grades. Conversely, the effort students put forth toward learning teacher-assigned material would be expected to improve report card grades more so than standardized achievement test scores. (as cited in, Duckworth, Quinn et al., 2011, p. 440) 
According to Willingham et al. (2002), standardized tests such as ITBS do not only test students on their curriculum content, but also on knowledge that the learners acquire from other sources. Consequently, ITBS performance may take more than diligence, such as studying at home, especially if a student just focuses on what teachers have taught at school.

In addition, the negative correlation may have resulted because two of the three items that were used to measure learning at home require parents to help students with homework and to check whether the student has completed homework. As literature shows, at middle school, students need to have developed enough self-discipline and academic skills to do their homework independently (Mullis et al., 2003). Helping with homework is not the kind of parental involvement that is needed at middle schools.

The negative correlation between learning at home in both the preliminary and in the primary study were consistent with Mullis et al. (2003), a longitudinal study which indicated that parent's supervision of one's child to do homework did not lead to high grades for middle school students.

Instead of helping middle school students with homework, parents need to help their adolescent children to grow in academic autonomy Hill and Tyson (2009). In a study in which Hill and Tyson (2009) investigated the type of parental involvement that lead to high academic achievement during the adolescent years, results showed that academic socialization was the highest positively correlated with academic performance during the middle school years.

Academic socialization includes the types of strategies that will scaffold adolescents' burgeoning autonomy, independence, and cognitive abilities. In addition, this type of involvement represents developmentally appropriate strategies of involvement, as it fosters and builds upon the development of internalized motivation for achievement, 
focuses on future plans, provides a link between school work and future goals and aspirations, and is consistent with the needs of middle school students. (Hill \&Tyson, 2009, p. 758)

While the findings of the present study are consistent with the results of Mullis et al. (2003) and Hill and Tyson (2009) in that parents helping middle school students with homework is not correlated with high academic performance, these findings are not consistent with Epstein's model of parental involvement concerning learning at home. According to Epstein's model of parental involvement, learning at home involves parents helping with homework and other curriculum related activities. More research needs to be done to ascertain the impact of parents helping adolescents with homework on academic performance.

In the preliminary study, the correlation between decision making and GPA was not significant. But the relationship between decision making and ITBS NCE showed a significant correlation at $(p<0.05)$. Maybe the reason is that ITBS is a standardized test that only tests an average of the objectives of the curriculum. As Duckworth, Quinn et al. (2011) posit, performance on standardized tests, such as ITBS, requires more than studying. Such performance also depends on high IQ. Willingham et al. (2002) state that standardized tests require knowledge that is gained from exposure to other sources of learning, other than the curriculum. Hence, learning at home reinforces the material which results in high GPA. Maybe decision-making impacts ITBS performance in that parent's decision enable students to get exposed to various experiences such as different activities that might impact ITBS performance positively. Epstein's model states that decision making includes involving parents in developing mission statements and improving school policies which affect students and families. Also, the results showed that student's self-discipline had a higher correlation with GPA than it was with ITBS, suggesting that self-discipline impact GPA more than it does ITBS. So, maybe the reason 
for the negative correlation between parent's decision making and student's GPA is that GPA performance requires student's diligence more than it does parent's decision. A parent may make the best decisions to help the child to achieve academic performance. But if the child does not do his or her part in focusing and working diligently on the academic work, the student may not achieve high academic performance.

Collaboration between parents, school and the community was significant, GPA $(r=0.0631, p<.01)$ and ITBS $(r=0.0568, p<.05)$. In the primary study, parenting, volunteering and learning at home were significantly correlated with ITBS at $(p<.001)$ alone, together, and in the small model. Communicating was significant with ITBS, alone $(p<.001$; and together $p<.05)$ suggesting that parental involvement impact academic performance. The results were consistent with past studies such as Coleman (1988) who posits that family and community support enable students to perform well not only in academic, but also in social and personal areas of their lives. Further, Coleman states that students' high performance in academics equip them with the ability to make economic attributes to their societies. Coleman continues to say that the amount of human capital available to students came from family and community social capital.

So, parenting, volunteering, and collaborating with community showed significant correlation between GPA and ITBS. Learning at home had positive significant correlation with GPA, but not with ITBS performance. Communication between home and school was not significant in the preliminary study. But in the primary study, communication showed a low correlation. Decision making had a significant correlation with ITBS but not with GPA. In spite of all the differences in correlation between the independent 
variables and academic performance, Epstein's model of parental involvement seems to work.

The results of the present study suggest that middle school students need academic support, but not involving parents with completing homework and doing academic activities together. In Epstein's model of parental involvement includes understanding the child and adolescent development, assisting the school to understand the family background and culture. These activities are important for a middle school child. But by the time children get to middle school, they need to have developed selfdiscipline and enough skills to work on their academic activities independently (Englund et al., 2004).

\section{Combined Effects of Student Self-discipline and Parental Involvement on GPA and ITBS}

This section discusses question three of both the preliminary study and the primary study. Specifically, question three in both studies focus on whether there are combined effects of student self-discipline and parental involvement on academic performance. The model summary table for the preliminary study showed R square at 0.718 , which was high. The summary table of all variables combined in the primary study shows R square at .126 and $p<.001$ meaning that $13 \%$ of student's academic performance is explained by student's self-discipline and parental involvement. The statistically significant results $(p<.001)$ shows that there were significant combined effects of student's self-discipline and parental involvement. However, parents, educators and students themselves need to realize that student diligence, parenting, and volunteering, communicating have a significant positive impact on academic performance. 
But doing chores and distractions had a significant negative correlation with ITBS $(p<.001)$ with ITBS. That suggests that involving students with too many family chores, or a student involving oneself with other activities such as playing computer games instead of spending afterschool time in academic related activities does not help with academic performance. Past research findings show that it is crucial for children to engage in activities that foster academic enhancement even when they are at home. It is the responsibility of parents and teachers to ensure that children are in a conducive learning environment both at school and at home (Hara \& Burke, 1998).

Student taking responsibility for learning was not significant alone. Maybe the results suggest that in middle school, student taking responsibility for learning is not entirely on students. The results may indicate that middle school students still need guidance. Parents and teachers may still need to hold middle school students responsible for their academic performance. Additionally, the $\mathrm{CG}$ data had only two items to measure student taking responsibility. Maybe the few items contributed to the negative correlation. Nonetheless, together, self-discipline and parental involvement showed significant impact on academic performance.

Even though there seems to be no past studies that combined students' selfdiscipline and parents' involvement on student's academic performance, various studies show that student's self-discipline improve academic performance (Duckworth \& Seligman, 2005, 2006). Other studies indicate that parent's involvement aid student's academic success (Epstein, 2008). Also, various studies indicate that cooperation between parents and teachers boosts student's academic performance. (Burke, 1998; Chavkin, 1994; Epstein, 2008; Friescen \& Osher 1996). Results of the current study 
shows consistency with the past studies. However, the present study makes a unique contribution to literature in that it combined both student self-discipline and parental involvement unlike past studies that investigated either of the independent variables.

\section{Impact of Demographic Variables on the Relationship Between \\ Student Self-discipline or Parental Involvement and \\ Student's ITBS Performance}

The fourth research question in the primary study, which involves investigating whether the control variables: parent education, student gender, student ethnicity, student ability, have any impact on the relationship between student self-discipline (diligence, doing chores, taking responsibility, distractions) or parental involvement (communication, parenting, volunteering, learning at home) and student's ITBS performance will be discussed in this section. The control variables were not included in the regression models. The control method used in this analysis was to compute a regression model separately for each subgroup of the control variable and see if the models were similar.

Table 26 presents the results which showed that the contribution of the six independent variables in the small model (parenting, volunteering, learning at home, diligence, doing chores, and distractions) were generally similar for all subgroups studied. Of the 72 different part correlations reported in Table 26, only 12 were less than half the size of the largest part correlation for the other groups for the same independent variable.

The control variables, parent education, gender, student ethnicity, student ability level did not have such a big effect on the relationship between student self-discipline, 
parental involvement and the academic performance. Nonetheless, there were some notable differences as reported below.

Results showed that a parent whose education level is below average had $r=$ 0.178 , the parent with above average level of education had $r=0.150$ while the one with average had $r=0.136$. Similar differences are manifested in volunteering, below average $r=0.101$, above average $r=0.061$, and average $r=0.135$. Also, the greatest level of distractions on students are recorded according to the level of parent education, below average -0.129 , above average -0.091 while average had -0.095 . The lower the level of education on the part of the parent, the more difference it makes on the relationship between student's self-discipline or parental involvement and student's performance on ITBS. Additionally, the lower the level of education on the part of the parent, the more the distractions on students.

The results of this study showed consistency with past studies that indicated a correlation between parent education level and their children's academic performance. Mullis et al. (2003) did a longitudinal study involving 24,599 middle school adolescents to investigate factors that contribute to academic performance during early adolescence. The findings indicated that factors such as parent education, parent income, and other resources related to learning opportunities were strong predictors of academic performance during middle school years of learning.

Student gender showed that student self-discipline and parental involvement had more influence on boys than girls. The summary model for females was $r^{2}=0.114$, while that of boys was $r^{2}=0.137$. Parenting for female was $r=0.172$ and male $r=0.180$. Volunteering recorded similar differences between the genders, female $r=0.105$ and 
male $r=0.260$. That showed that male needed more self-discipline and parental involvement than female, which means that females are more self-disciplined than males. Also, females scored higher in diligence $r=0.138$ than males $r=0.123$. But doing chores at home, males recorded higher negative influence $r=-0.082$ than females $r=-$ 0.078. But with distractions, males showed higher level of distraction $r=-0.128$ than females $r=-0.109$ suggesting that males were more prone to distractions than females.

The difference in academic performance based on gender has been reported by other studies (Duckworth \& Seligman, 2005, 2006). Duckworth and Seligman did a study which showed that girls were more self-discipline then boys.

Parents need to note the connection between their level of education and the academic performance of their children so that they can learn what is expected of them in order to help their children to achieve academic performance. They also need to make note of the need for boys to receive more keen training on self-discipline in order to help them with academic performance.

Student ethnicity results were not consistent with past studies. Research indicates major differences in academic performance along racial lines. Whites are shown to lead while minority groups underperform in all subjects (Altbach et al., 2011; Fritzberg, 2001). The current study showed that contribution of the six independent variables in the small model (parenting, volunteering, learning at home, diligence, doing chores, and distractions) was generally similar for all the races studied. The lack of association between race and academic performance maybe a reflection of the complexity of determining the impact of racial issues on academic performance. It may also indicate our inability to accurately measure the construct given the available data from the CG. 
Student ability level recorded slight differences among the levels. The lower the ability level on a student, the more difference it makes on the relationship between student's self-discipline, parental involvement and student's performance on ITBS. However, Duckworth, and Seligman (2005) did a longitudinal study that indicated that self-discipline outdoes IQ in academic performance. Results showed that self-discipline can predict academic performance, suggesting that the more time a student spent on school work the better the grades. The findings strongly indicate that a major reason why students fail to attain high grades is due to failure to exercise self-discipline.

\section{Implications}

The current study portrayed several areas of concern for parents, educators, policy-makers, and community at large. Various research findings show that academic performance of K-12 students in North America is a major problem. The current study revealed that academic performance is significantly correlated with student self-discipline and parental involvement. Without students doing their part in working diligently on their studies, the efforts of their parents and teachers alone may not earn student's high academic performance. Specific implications include the following:

1. Students need to be trained on self-discipline.

This study showed that students need to work diligently on academic activities and avoid distractions. Policy makers need to realize that holding teachers and school administrators accountable for the academic performance of their students will not help unless students are trained on self-discipline. “The principal's major responsibility and goal is measured by the degree of learning attained by the students...on state tests" (Shipman et al., p. 62, 2007). Results from the current study and findings from past studies show that students 
have a key role to play to ensure excellent academic achievement (Duckworth \& Seligman, 2005). According to Waschull (2005), one major factor in student's academic performance is the student's self-discipline, which impacts all areas of academic performance. It is no wonder that less self-disciplined students achieve low academic achievements compared to highly self-disciplined students.

2. Parents need to get involved in their children's academic activities. Specifically, parents need to uphold Epstein's six factors of parental involvement, which includes two-way communication between home and school. The communication between home and school enable parents to stay informed about the progress of their children. Open communication between school and home provides parents with information which they need to assist teachers in helping their children to achieve academic performance. Research shows that when teachers and parents work together, students are helped to achieve academic success. Also, research has shown that volunteering at the school where one's children are schooling enables parents and guardians to get trained on educational activities that equip them with knowledge on how to participate in school activities (Epstein, 2008).

Parenting, which is one of the six factors has shown the highest correlation with academic performance. Parents need to note that in this study, parenting includes understanding child and adolescent development, setting a conducive environment for learning at home, and assisting school with knowledge about the family background and culture, and helping children to set academic goals. Additionally, parents need to facilitate learning at home, which includes to involving children with academic related activities while at home. Decision making is another important factor of parental 
involvement, which has shown significant impact on student academic performance. Parents need to participate in policy making and other decision-making activities in schools where their children are schooling. Additionally, parents, schools and communities need to work together to avail resources for the benefit of students (Epstein, 2008).

3. Both student self-discipline and parental involvement need to be emphasized instead of focusing on either one alone.

This study showed that there is a combined effect of student self-discipline and parental involvement. Parents, students, policy makers and the society at large need to realize that ignoring one of these aspects will likely lead to poor academic performance.

4. Boys need more keen supervision and teaching on the need of focusing on academic activities because they are more prone to distractions than girls.

Parents, guardians and teachers need to realize that boys are more prone to distractions and lack of self-discipline than girls. Duckworth and Seligman (2006) did a study whose findings showed that girls were more disciplined than boys. While all students need to be taught the importance of their diligence and focusing on their academic work, boys need more help to stay focused on their academic activities.

\section{Conclusions}

The findings of this study revealed that student self-discipline and parental involvement are crucial factors in academic performance. Among the subscales of selfdiscipline, diligence showed the highest positive correlation with academic performance while distractions showed the highest negative correlation with academic performance. Parental involvement, too, was highly correlated with GPA and ITBS performance. 
Combined, student self-discipline and parental involvement revealed significant impact on academic performance. Boys showed to be more prone to distractions, hence portraying less self-discipline than girls. Findings indicated that in order to improve GPA and ITBS performance, parents need to participate actively in the academic activities of their children including communicating with the school, parenting, volunteering, decision making, facilitating learning at home, and collaborating with the community to put resources together to support the school.

\section{Suggested Further Research}

The following suggestions for further research on this subject are recommended.

1. This study needs to be replicated at the elementary level. Further study should investigate the impact of combining student self-discipline and parental involvement on academic performance.

2. Parents need to be equipped on how to train their children on self-discipline. A study should be conducted to determine whether there are specific effective ways of training children on self-discipline.

3. Findings in this study showed negative correlation between doing chores and academic performance. Further study should be done to determine whether there are specific chores that impact academic performance positively.

4. Findings in this study showed negative correlation between learning at home and ITBS. Further study should be conducted to determine whether similar results will be obtained. 
5. This study showed high correlation between student self-discipline and academic performance. Teachers spend most hours of the day with students. A study should be done to identify effective ways for teachers to train students on self-discipline. 
APPENDIX A

CORRELATIONS AND REGRESSIONS OUTPUTS 
Self-Discipline and Parental Involvement Variables

\section{Correlations}

\begin{tabular}{|c|c|c|c|}
\hline & & GPA & $\begin{array}{l}\text { IOWANCE IOWA } \\
\text { NCE }\end{array}$ \\
\hline \multirow[t]{3}{*}{ SelfDiscipline } & Pearson Correlation & .720 & .643 \\
\hline & Sig. (2-tailed) & .002 & .007 \\
\hline & $\mathrm{N}$ & 16 & 16 \\
\hline \multirow[t]{3}{*}{ Parentallnvolvement } & Pearson Correlation & .636 & .727 \\
\hline & Sig. (2-tailed) & .008 & .001 \\
\hline & $\mathrm{N}$ & 16 & 16 \\
\hline \multirow[t]{3}{*}{ Parenting } & Pearson Correlation & .723 & .757 \\
\hline & Sig. (2-tailed) & .002 & .001 \\
\hline & $\mathrm{N}$ & 16 & 16 \\
\hline \multirow[t]{3}{*}{ Communicating } & Pearson Correlation & .066 & .248 \\
\hline & Sig. (2-tailed) & .808 & .353 \\
\hline & $\mathrm{N}$ & 16 & 16 \\
\hline \multirow[t]{3}{*}{ Volunteering } & Pearson Correlation & .509 & .647 \\
\hline & Sig. (2-tailed) & .044 & .007 \\
\hline & $\mathrm{N}$ & 16 & 16 \\
\hline \multirow[t]{3}{*}{ LearningAtHome } & Pearson Correlation & .500 & .418 \\
\hline & Sig. (2-tailed) & .049 & .107 \\
\hline & $\mathrm{N}$ & 16 & 16 \\
\hline \multirow[t]{3}{*}{ DecisionMaking } & Pearson Correlation & .349 & .555 \\
\hline & Sig. (2-tailed) & .185 & .026 \\
\hline & $\mathrm{N}$ & 16 & 16 \\
\hline \multirow[t]{3}{*}{ Collaborating } & Pearson Correlation & .631 & .568 \\
\hline & Sig. (2-tailed) & .009 & .022 \\
\hline & $\mathrm{N}$ & 16 & 16 \\
\hline
\end{tabular}


Model Summary

\begin{tabular}{|l|r|r|r|r|}
\hline Model & \multicolumn{1}{|c|}{$\mathrm{R}$} & \multicolumn{1}{c|}{ R Square } & Adjusted R Square & \multicolumn{1}{c|}{$\begin{array}{c}\text { Std. Error of the } \\
\text { Estimate }\end{array}$} \\
\hline 1 & $.848^{\mathrm{a}}$ & .718 & .472 & .28472 \\
\hline
\end{tabular}

a. Predictors: (Constant), Collaborating, Communicating, LearningAtHome,

DecisionMaking, SelfDiscipline, Volunteering, Parenting

ANOVA $^{\mathrm{a}}$

\begin{tabular}{|c|c|c|c|c|c|}
\hline Model & Sum of Squares & df & Mean Square & $\mathrm{F}$ & Sig. \\
\hline Regression & 1.654 & 7 & .236 & \multirow[t]{3}{*}{2.914} & \multirow[t]{3}{*}{$.079^{b}$} \\
\hline Residual & .649 & 8 & .081 & & \\
\hline Total & 2.302 & 15 & & & \\
\hline
\end{tabular}

a. Dependent Variable: GPA

b. Predictors: (Constant), Collaborating, Communicating, LearningAtHome, DecisionMaking, SelfDiscipline, Volunteering, Parenting 
PRIMARY STUDY CORRELATIONS AND REGRESSIONS OUTPUTS

Grade 6

\section{Descriptive Statistics}

\begin{tabular}{|l|r|r|r|r|r|}
\hline & \multicolumn{1}{|c|}{$\mathrm{N}$} & \multicolumn{1}{c|}{ Minimum } & \multicolumn{1}{c|}{ Maximum } & \multicolumn{1}{c|}{ Mean } & Std. Deviation \\
\hline ParentSchoolCommunication & 2457 & 1.00 & 4.00 & 3.4606 & .54979 \\
Parenting & 2457 & 1.00 & 5.00 & 3.5470 & 1.05482 \\
Volunteering & 2457 & 1.00 & 4.00 & 3.3177 & .65857 \\
LearningAtHome & 2457 & 1.00 & 5.00 & 3.5526 & .70317 \\
Diligence & 2457 & 1.00 & 4.00 & 3.6390 & .55068 \\
DoingChores & 2457 & 1.00 & 5.00 & 3.2072 & .75744 \\
TakingResponsibility & 2457 & 1.00 & 2.00 & 1.6077 & .48837 \\
Distractions & 2457 & 1.00 & 5.00 & 2.3039 & .74095 \\
NCEComposite & 2457 & 3.00 & 99.00 & 62.6679 & 17.96061 \\
Valid N (listwise) & 2457 & & & & \\
\hline
\end{tabular}




\section{Correlations}

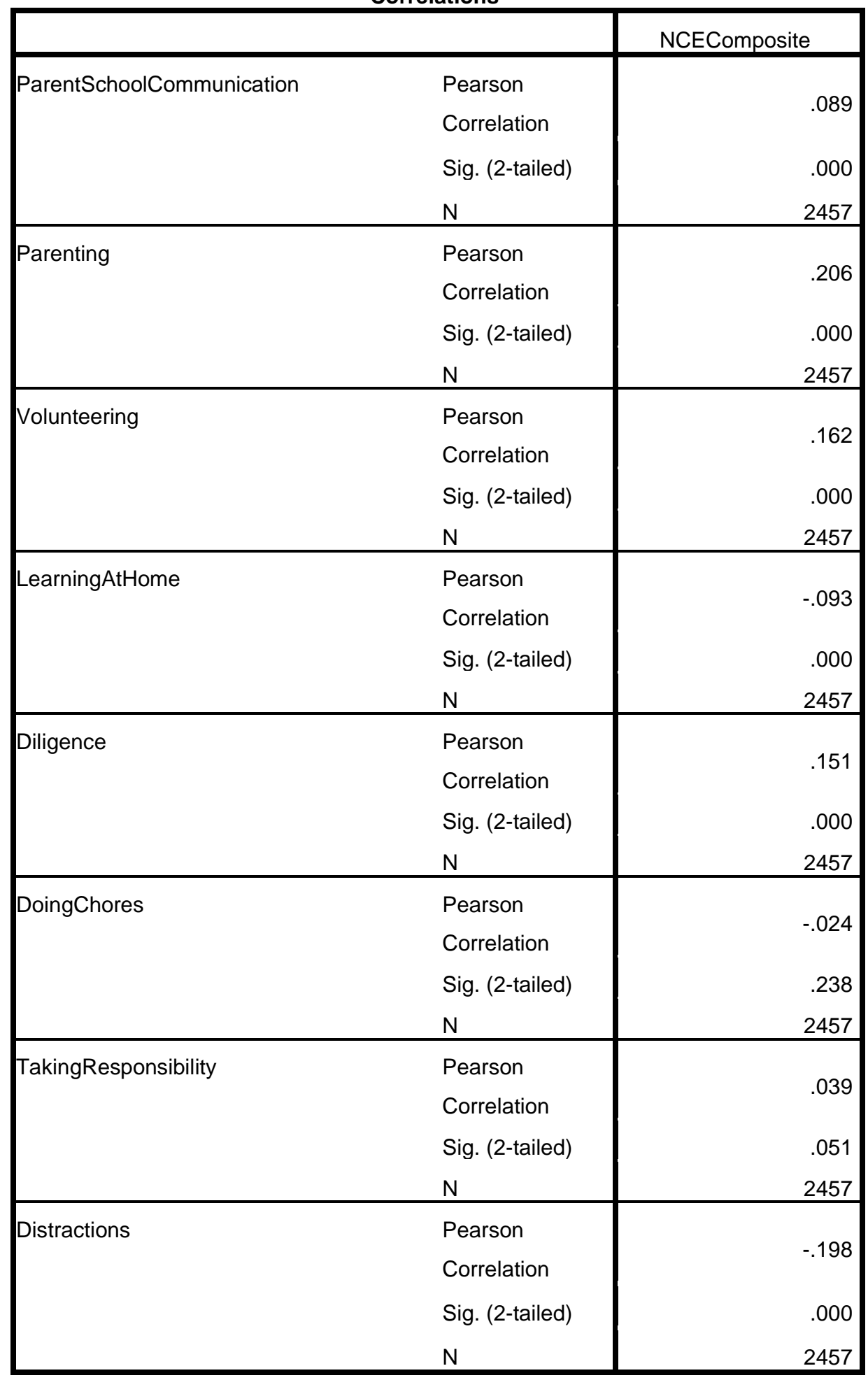




\section{Grade 6 Parental Involvement Scales}

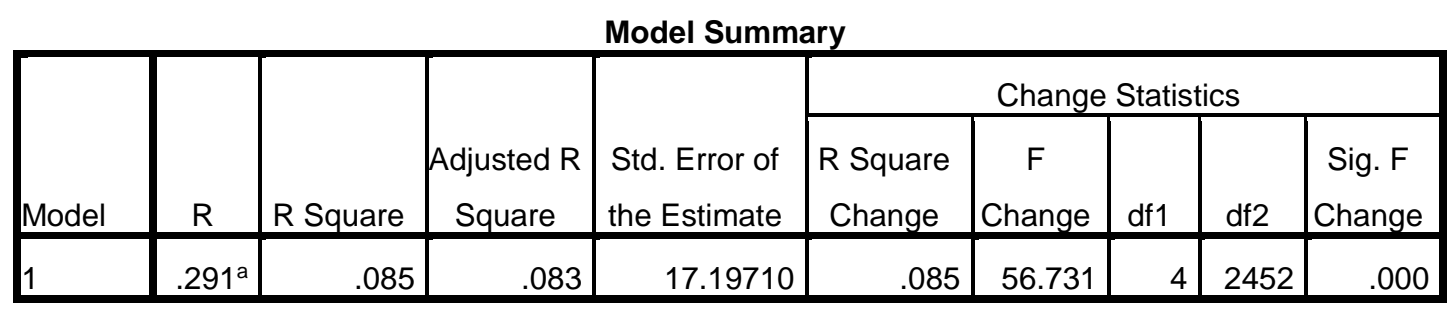

a. Predictors: (Constant), LearningAtHome, ParentSchoolCommunication, Parenting, Volunteering

\begin{tabular}{|c|c|c|c|c|c|c|}
\hline \multicolumn{7}{|c|}{ ANOVA $^{\mathrm{a}}$} \\
\hline \multicolumn{2}{|c|}{ Model } & Sum of Squares & $\mathrm{df}$ & Mean Square & $\mathrm{F}$ & Sig. \\
\hline \multirow[t]{3}{*}{1} & Regression & 67110.226 & 4 & 16777.556 & 56.731 & $.000^{\mathrm{b}}$ \\
\hline & Residual & 725154.771 & 2452 & 295.740 & & \\
\hline & Total & 792264.996 & 2456 & & & \\
\hline \multicolumn{7}{|c|}{ a. Dependent Variable: NCEComposite } \\
\hline \multicolumn{7}{|c|}{ b. Predictors: (Constant), LearningAtHome, ParentSchoolCommunication, Parenting, Volunteerin } \\
\hline
\end{tabular}

\begin{tabular}{|c|c|c|c|c|c|}
\hline \multicolumn{6}{|c|}{ Coefficients $^{a}$} \\
\hline \multirow[b]{2}{*}{ Model } & \multicolumn{2}{|c|}{ Unstandardized Coefficients } & \multirow{2}{*}{$\begin{array}{c}\text { Standardized } \\
\text { Coefficients } \\
\text { Beta }\end{array}$} & \multirow[b]{2}{*}{$t$} & \multirow[b]{2}{*}{ Sig. } \\
\hline & B & Std. Error & & & \\
\hline 1 (Constant) & 49.804 & 2.954 & & 16.860 & .000 \\
\hline ParentSchoolCommunication & 1.141 & .670 & .035 & 1.704 & .089 \\
\hline Parenting & 3.797 & .350 & .223 & 10.858 & .000 \\
\hline Volunteering & 3.335 & .575 & .122 & 5.802 & .000 \\
\hline LearningAtHome & -4.396 & .516 & -.172 & -8.526 & .000 \\
\hline
\end{tabular}




\begin{tabular}{|l|r|r|r|}
\hline \multirow{2}{*}{ Model } & \multicolumn{3}{|c|}{ Correlations } \\
\cline { 2 - 4 } $1 \quad$ (Constant) & Zero-order & Partial & Part \\
\hline ParentSchoolCommunication & .089 & & \\
Parenting & .206 & .034 & .033 \\
Volunteering & .162 & .214 & .210 \\
LearningAtHome & -.093 & -.170 & .112 \\
\hline
\end{tabular}

*Parental Involvement SMALL MODEL SELECTION.

*Backward Stepwise.

REGRESSION /MISSING LISTWISE /STATISTICS COEFF OUTS R ANOVA CHANGE ZPP

/CRITERIA=PIN (.0001) POUT $(.001) \quad /$ NOORIGIN

/DEPENDENT NCEComposite

/METHOD=ENTER parentschoolCommunication to LearningAtHome

/METHOD=STEPWISE parentschoolCommunication to LearningAtHome. 


\section{Grade 6 Self-Discipline Scales}

\begin{tabular}{|c|c|c|c|c|c|c|c|c|c|}
\hline \multicolumn{10}{|c|}{ Model Summary } \\
\hline \multirow[b]{2}{*}{ Model } & \multirow[b]{2}{*}{$\mathrm{R}$} & \multirow[b]{2}{*}{ R Square } & \multirow[b]{2}{*}{$\begin{array}{l}\text { Adjusted R } \\
\text { Square }\end{array}$} & \multirow[b]{2}{*}{$\begin{array}{l}\text { Std. Error of } \\
\text { the Estimate }\end{array}$} & \multicolumn{5}{|c|}{ Change Statistics } \\
\hline & & & & & $\begin{array}{c}\text { R Square } \\
\text { Change }\end{array}$ & F Change & df1 & $\mathrm{df2}$ & $\begin{array}{l}\text { Sig. F } \\
\text { Change }\end{array}$ \\
\hline 1 & .242 & .058 & .057 & 17.44246 & .058 & 38.021 & 4 & 2452 & .000 \\
\hline
\end{tabular}

ANOVA $^{a}$

\begin{tabular}{|ll|r|r|r|r|r|}
\hline Model & & Sum of Squares & df & Mean Square & F & Sig. \\
\hline 1 & Regression & 46270.254 & 4 & 11567.563 & 38.021 & $.000^{\mathrm{b}}$ \\
& Residual & 745994.743 & 2452 & 304.239 & & \\
Total & 792264.996 & 2456 & & & \\
\hline
\end{tabular}

a. Dependent Variable: NCEComposite

b. Predictors: (Constant), Distractions, DoingChores, TakingResponsibility, Diligence

Coefficients $^{a}$

\begin{tabular}{|c|c|c|c|c|c|}
\hline \multirow[b]{2}{*}{ Model } & \multicolumn{2}{|c|}{ Unstandardized Coefficients } & \multirow{2}{*}{$\begin{array}{c}\text { Standardized } \\
\text { Coefficients } \\
\text { Beta }\end{array}$} & \multirow[b]{2}{*}{$\mathrm{t}$} & \multirow[b]{2}{*}{ Sig. } \\
\hline & B & Std. Error & & & \\
\hline $1 \quad$ (Constant) & 59.505 & 3.186 & & 18.677 & .000 \\
\hline Diligence & 4.374 & .650 & .134 & 6.733 & .000 \\
\hline DoingChores & -1.124 & .468 & -.047 & -2.399 & .017 \\
\hline TakingResponsibility & .657 & .724 & .018 & .908 & .364 \\
\hline Distractions & -4.431 & .479 & -.183 & -9.241 & .000 \\
\hline
\end{tabular}


Coefficients $^{\mathrm{a}}$

\begin{tabular}{|c|c|c|c|c|}
\hline \multirow{2}{*}{\multicolumn{2}{|c|}{ Model }} & \multicolumn{3}{|c|}{ Correlations } \\
\hline & & Zero-order & Partial & Part \\
\hline \multirow[t]{5}{*}{1} & (Constant) & & & \\
\hline & Diligence & .151 & .135 & .132 \\
\hline & DoingChores & -.024 & -.048 & -.047 \\
\hline & TakingResponsibility & .039 & .018 & .018 \\
\hline & Distractions & -.198 & -.183 & -.181 \\
\hline
\end{tabular}

a. Dependent Variable: NCEComposite

*Self-Discipline SMALL MODEL SELECTION.

*Backward Stepwise.

REGRESSION /MISSING LISTWISE /STATISTICS COEFF OUTS R ANOVA CHANGE

ZPP /CRITERIA=PIN (.0001) POUT (.001) /NOORIGIN

/DEPENDENT NCEComposite

$/ \mathrm{METHOD}=\mathrm{ENTER}$ Diligence to Distractions

/METHOD=STEPWISE Diligence to Distractions. 
Combined Self-Discipline and Parental Involvement Scales

\begin{tabular}{|c|c|c|c|c|c|c|c|}
\hline \multicolumn{8}{|c|}{ Model Summary } \\
\hline \multirow[b]{2}{*}{ Model } & \multirow[b]{2}{*}{$\mathrm{R}$} & \multirow[b]{2}{*}{ R Square } & \multirow[b]{2}{*}{$\begin{array}{l}\text { Adjusted R } \\
\text { Square }\end{array}$} & \multirow[b]{2}{*}{$\begin{array}{c}\text { Std. Error of the } \\
\text { Estimate }\end{array}$} & \multicolumn{3}{|c|}{ Change Statistics } \\
\hline & & & & & $\begin{array}{l}\text { R Square } \\
\text { Change }\end{array}$ & F Change & df1 \\
\hline 1 & $.355^{a}$ & .126 & .123 & 16.81819 & .126 & 44.124 & 8 \\
\hline
\end{tabular}

\begin{tabular}{|l|rr|lr|}
\hline \multirow{2}{*}{ Model } & \multicolumn{4}{|c|}{ Change Statistics } \\
\cline { 2 - 5 } & \multicolumn{2}{|c|}{ df2 } & \multicolumn{2}{|c|}{ Sig. F Change } \\
\hline 1 & & 2448 & & .000 \\
\hline
\end{tabular}

a. Predictors: (Constant), Distractions, ParentSchoolCommunication, LearningAtHome, TakingResponsibility, Diligence, DoingChores, Volunteering, Parenting 
ANOVA $^{a}$

\begin{tabular}{|c|c|c|c|c|c|c|}
\hline \multicolumn{2}{|c|}{ Model } & Sum of Squares & $d f$ & Mean Square & $\mathrm{F}$ & Sig. \\
\hline \multirow[t]{3}{*}{1} & Regression & 99844.820 & 8 & 12480.603 & 44.124 & $.000^{\mathrm{b}}$ \\
\hline & Residual & 692420.176 & 2448 & 282.851 & & \\
\hline & Total & 792264.996 & 2456 & & & \\
\hline
\end{tabular}

a. Dependent Variable: NCEComposite

c. Predictors: (Constant), Distractions, ParentSchoolCommunication, LearningAtHome,

TakingResponsibility, Diligence, DoingChores, Volunteering, Parenting

Coefficients $^{\mathrm{a}}$

\begin{tabular}{|c|c|c|c|c|c|}
\hline & \multicolumn{2}{|c|}{ Unstandardized Coefficients } & \multirow{2}{*}{$\begin{array}{c}\text { Standardized } \\
\text { Coefficients }\end{array}$} & \multirow[b]{2}{*}{$\mathrm{t}$} & \multirow[b]{2}{*}{ Sig. } \\
\hline Model & $\mathrm{B}$ & Std. Error & & & \\
\hline (Constant) & 48.014 & 4.028 & & 11.919 & .000 \\
\hline ParentSchoolCommunication & 1.387 & .657 & .042 & 2.112 & .035 \\
\hline Parenting & 3.455 & .370 & .203 & 9.343 & .000 \\
\hline Volunteering & 2.925 & .564 & .107 & 5.182 & .000 \\
\hline LearningAtHome & -4.357 & .512 & -.171 & -8.512 & .000 \\
\hline Diligence & 4.307 & .632 & .132 & 6.811 & .000 \\
\hline DoingChores & -2.142 & .482 & -.090 & -4.440 & .000 \\
\hline TakingResponsibility & .873 & .700 & .024 & 1.248 & .212 \\
\hline Distractions & -2.965 & .483 & -.122 & -6.141 & .000 \\
\hline
\end{tabular}




\begin{tabular}{|l|r|r|r|}
\hline \multirow{2}{*}{ Model } & \multicolumn{3}{|c|}{ Correlations } \\
\cline { 2 - 4 } & \multicolumn{1}{|c|}{ Zero-order } & Partial & \multicolumn{1}{|c|}{ Part } \\
\hline 1 & & & \\
\hline (Constant) & .089 & .043 & .040 \\
\hline ParentSchoolCommunication & .206 & .186 & .177 \\
\hline Parenting & .162 & .104 & .098 \\
Volunteering & -.093 & -.170 & -.161 \\
LearningAtHome & .151 & .136 & .129 \\
Diligence & -.024 & -.089 & -.084 \\
DoingChores & .039 & .025 & .024 \\
TakingResponsibility & -.198 & -.123 & -.116 \\
\hline Distractions & & & \\
\hline
\end{tabular}

a. Dependent Variable: NCEComposite

*SMALL MODEL SELECTION.

*Backward Stepwise.

REGRESSION /MISSING LISTWISE /STATISTICS COEFF OUTS R ANOVA CHANGE ZPP /CRITERIA=PIN(.0001)

POUT(.001) /NOORIGIN

/DEPENDENT NCEComposite

/METHOD=ENTER parentschoolCommunication to Distractions

/METHOD=STEPWISE parentschoolCommunication to Distractions. 
APPENDIX B

IRB \& INSTITUTION APPROVAL LETTERS 
IRB APPROVAL LETTER

Institutional Review Board - 4150 Administration Dr Room 322 - Berrien Springs, MI 49104-0355 Tel: (269) 471-6361 Fax: (269) 471-6543 E-mail: irb@andrews.edu

February 27, 2017

Susan Mbaluka

Tel: 423-508-5512

Email: susanmbaluka@yahoo.com

\section{RE: APPLICATION FOR APPROVAL OF RESEARCH INVOLVING HUMAN SUBJECTS}

\section{IRB Protocol \#: 15-179 Application Type: Original Dept.: Leadership}

\section{Review Category: Expedited Action Taken: Approved Advisor: Sylvia Gonzalez}

Title: The impact of students' self-discipline and parents' involvement in students' academic activities on students' academic performance in schools in the Texas Conference of Seventh-day Adventists.

This letter is to advise you that the Institutional Review Board (IRB) has reviewed and approved your IRB modification and renewal application for research involving human subjects entitled: "The impact of students' self-discipline and parents' involvement in students' academic activities on students' academic performance in schools in the Texas Conference of Seventh-day Adventists" IRB protocol number 15-179 under Expedited category. This approval is valid until March 16, 2018. If your research is not completed by the end of this period you must apply for an extension at least four weeks prior to the expiration date. We ask that you inform IRB whenever you complete your research. Please reference the protocol number in future correspondence regarding this study.

Any future changes (see IRB Handbook pages 10-11) made to the study design and/or consent form require prior approval from the IRB before such changes can be implemented. Please use the attached report form to request for modifications, extension and completion of your study.

While there appears to be no more than minimum risk with your study, should an incidence occur that results in a research-related adverse reaction and/or physical injury, (see IRB Handbook page 11) this must be reported immediately in writing to the IRB. Any project-related physical injury must also be reported immediately to the University physician, Dr. Reichert, by calling (269) 473-2222. Please feel free to contact our office if you have questions.

Best wishes in your research.

Sincerely 
Mordekai Ongo

Research Integrity \& Compliance Officer 


\section{COGNITIVEGENESIS DATA PERMISSION}

February 15, 2017

To Andrews University Institutional Review Board:

I hereby give permission for Susan Mbaluka to use selected CognitiveGenesis data for her doctoral dissertation. The data will have all identifying information removed before giving the data to her.

The data given to Susan is limited to achievement and ability test scores, and selected parental and student variables.

This permission is being given after consulting with the co-researcher for CognitiveGenesis, Dr. Elissa Kido at La Sierra University.

Jerome Thayer

Professor Emeritus of Research and Statistical Methodology

Andrews University 


\section{SUPERINTENDENT TEXAS CONFERENCE SCHOOLS APPROVAL LETTER}

From: Danielle Bunkley <dbunkley@txsda.org>

To: susan mbaluka <susanmbaluka@yahoo.com>

Cc: John Hopps <jhopps@txsda.org>

Sent: Wednesday, January 27, 2016 9:38 AM

Subject: Research Request

Dear Susan,

The Board of Ed voted to approve your study, with it being entirely voluntary as you stated, and we need to know which schools you want your information sent to.

Thank you for your time and help,

Danielle Bunkley

Admin Asst. dbunkley@txsda.org

Office of Education

Texas Conference of Seventh-day Adventists

P O Box 800 Alvarado TX 76009

(817) 790-2255 ext. 2144

Romans 12:12 Rejoice in hope, be patient in tribulation, be constant in prayer. 
September 29, 2015

The School Superintendent

Texas Conference of Seventh day Adventists

P.O Box 800, Alvarado, TX 76009

Dear Mr. John Hopps,

\section{Re: Permission to Conduct Educational Research}

I am a doctoral student in the Education Administration department at Andrews University. I am requesting permission to do research in schools in the Texas Conference of Seventh-day Adventists this fall/winter to aid in my research project titled:

The Impact of Students' Self-Discipline and Parents' Involvement in Students' Academic Activities on Students' Academic Performance in Schools in the Texas Conference of Seventh-day Adventists

This research project focuses on middle and high school students. The purpose of the study is to investigate the impact of students' self-discipline and parents' involvement on academic performance. Specifically the study seeks to determine whether students' self-discipline levels and parental involvement in students' academic activities are associated with students' ITBS scores or their GPA. Results of this study may improve students' academic performance.

Researcher will collect data through four sources (1) Self-Control Rating Scale (SCRS), which will be given to teachers; (2) Parent And School Survey (PASS) to which parents will respond; (3) standardized exam- lowa Test of Basic Skills (ITBS); (4) students' GPA.

\section{The Schedule:}

Data collection for this study will take place within two months period. Between fall and Winter 2015-2016.

Fall/Winter 2015/2016 - Administration of Self-Control Rating Scale (SCRS) Fall/ Winter 2015/2016 - Administration of Parent And School Survey (PASS)

Fall/Winter 2015-2016 - Analysis of students' IOWA test results and GPA

\section{The Instruments:}

Self-Control Rating Scale (SCRS)

Parent And School Survey (PASS)

The Self-Control Rating Scale (SCRS) is a 33 item questionnaire with closed- ended questions, which will ask teachers to rate their students' level of self-discipline using a scale from 1 to 7. The SCRS is adopted from Kendall and Wilcox (1979). "The items tap 
the ability to inhibit behavior, follow rules, and control impulse reactions" (Duckworth \& Seligman, 2006, p.940). Parent And School Survey (PASS) is a questionnaire designed to measure parental involvement in their children's education. The PASS is adopted from Ringenberg, Funk, Mullen, Wilford, and Kramer (2005). The instrument is based on Epstein's six-construct framework: communicating; volunteering, especially at the school where one's children are attending; facilitating learning at home, guidance, decision making, and collaborating with community (Epstein, 2008).

Voluntary Participation: Participation in this study will be voluntary. Parents' written permission will be sought to allow researcher to access students' academic records such as IOWA test scores and GPA. Parents or teachers may withdraw from participation at any time. High levels of confidentiality will be maintained in this research. Only group data will be reported. Individual or school names will not be used in data analysis or reporting.

Attached is a list of 15 sampled schools in which researcher requests to collect data. Researcher needs an approval letter from you, the superintendent, and from each of the principals of the 15 sampled schools. Also, attached are the guidelines for the institutional approval letter from Andrews University.

Procedure: Two Teachers, one for Math and the other for Language Arts, will be requested to assess the self-discipline of their students in grades 6-12. The teachers' questionnaire, SCRS, will be mailed to the schools to be distributed to the teachers as regular mails. Parents' questionnaires will also be mailed to the schools. Class teachers will be requested to give the parents' questionnaires to the students who will be requested to take them to their parents. One parent or guardian of students in grades 6 12 will be requested to respond to the Parent And School Survey (PASS) questionnaires to assess their parental involvement in their children's education. Once parents' questionnaires are filled, students will be requested to take them back to their class teachers. Class teachers will drop the filled questionnaires in principals' office. Principals will be asked to mail the questionnaires to the researcher. Later, the findings of the study will be tabulated in group reports.

Contact Information: This research has been approved by faculty at Andrews University. In case you have any questions or concerns regarding children's, parents' or teachers' participation, in this research, you may contact the researcher, Susan Mbaluka at susanmbaluka@yahoo.com Cellphone: 423-508-5512. You may also contact Susan's advisor, Dr. Sylvia Gonzalez, professor in Leadership Department at sylviag@andrews.edu (269) 4716702

Sincerely, 
Susan Mbaluka

7911 Chatham Springs Ln

Cypress TX 77433

\section{To Parents of Middle and high school Students}

I am a doctoral student in the Education Administration department at Andrews University.

I am requesting permission to do research in schools in the Arkansas-Louisiana Conference

of Seventh-day Adventists in fall 2016 to aid in my research project titled:

The Impact of Students' Self-Discipline and Parents' Involvement in Students' Academic Activities on Students' Academic Performance.

The purpose of the study is to investigate the impact of students' self-discipline and parents' involvement on academic performance. Specifically the study seeks to determine whether students' self-discipline levels and parental involvement in students' academic activities are associated with students' ITBS scores or their GPA. Results of this study may improve students' academic performance.

This study focuses on students in grades 6 to 12. You are receiving this letter because your child falls in that category. Participation in the study is voluntary; refusal to participate will involve no penalty or loss of benefits to which you are otherwise entitled.

It will take you approximately 5 minutes to fill the questionnaire. By choosing to participate, you will give permission to the researcher to access the IOWA test scores and GPA results of your child. You will also give permission to the teachers of your child to assess your child's self-discipline. There will be no more than minimal risks involved in this study. But even the minimal chance is further reduced as explained below

Confidentiality: Your identity in this study will not be disclosed in any published document. There will be need to match students' IOWA test results and GPA with survey results. For that reason, students' names will initially be used to match them with artificial student identification numbers which will be created by researcher to maintain confidentiality of participants. Therefore, a student may possibly be identified by the researcher. But this minimal risk is greatly reduced by researcher, who will only use the artificial alphanumeric ID numbers to analyze data after it is taken from the surveys and is entered into an electronic database. Student's name or the name of the school will not appear in any report.

If you choose to participate, please discuss it with your child. The child will sign his/her consent form from the classteacher. Then click on the link below to sign the parent's 
consent form and to fill the questionnaire. If you choose not to participate, thank you for your time.

I choose to participate: Press Ctrl key and click on the link below https://goo.gl/forms/kSczAuO2LoJYGu203

Thank you very much.

Sincerely,

Susan Mbaluka

\section{Andrews University}

STUDENT INFORMED ASSENT FORM

\section{Statements About the Research:}

This research study is part of the requirements for my PhD program at Andrews University, Berrien Springs, Michigan. Your participation in this study is very much appreciated.

Title: The Impact of Students' Self-Discipline and Parents' Involvement in Students' Academic Activities on Students' Academic Performance.

Purpose of Study: I understand that the purpose of this research is to find out whether students' self-discipline and parents' help to their children's education help to get good IOWA test score or GPA.

Procedure I understand that as a participant in this study, my IOWA test results and GPA will be analyzed and that two of my teachers will fill a questionnaire to assess my selfdiscipline. I also understand that one of my parents or guardian will fill a questionnaire to assess his/her parental involvement in my academic activities.

Risks: I have been told that there is possibly a very small risk for me to participate in this study. Since researcher will have to put together the points that my parent/guardian will write on the questionnaire, researcher will first have to get my name and replace it with a fake ID number so that nobody else can know my performance. So researcher may possibly identify me. But that small risk will be reduced even more because research will only use the fake ID numbers in reports. Researcher will not use my name or the name of my school in reports. 
Benefits: I agree that I will not be paid to be involved in this study, but I understand that by participating, I will help the researcher, my parents, teachers and the leaders of education to understand more about the importance of students' self-discipline and parents' involvement in their children's education on academic performance.

Voluntary Participation: I have been told that my participation in this study is voluntary. I am only participating because I want to. I can decide not to participate at any point, and I will not be punished by my teachers or parents.

Confidentiality: I understand that researcher will not reveal my name or the name of my school.

Contact: I understand that I can contact the supervisor of Susan Mbaluka, Dr. Jay Brand, professor in Leadership Department at brand@andrews.edu or 269.471.3784 for answers to questions related to this study. I can also contact Susan Mbaluka at susanmbaluka@yahoo.com or (423)-508-5512 if I have questions about this study.

\section{Signature (Subject) Date}


March 8, 2016

Institutional Review Board

Andrews University

4150 Administrative Drive, Room 322

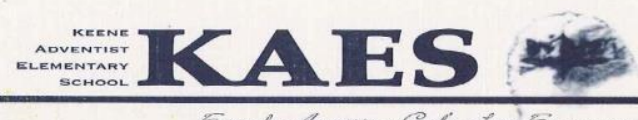

Berrien Springs, MI 49104-0355

This is to inform you that permission has been granted to Susan Mbaluka to collect data for her research study titled "The impact of Students' self-Discipline and Parents' involvement in Students' Academic Activities on Students" Academic performance in schools in the Texas conference of Seventh-day Adventists." The permission has been granted to the extent of the procedures outlined in the IRB application, and to allow the researcher to recruit participants and to collect data via mailing questionnaires and consent documents that will be filled by teachers of students in grades $6-12$. The researcher will have to secure informed consent from participants as the decision to participate in the study is completely voluntary.

The KEENE ADVENTIST ELEMENTARY SCHOOL will allow researcher to access IOWA test results and GPA of students whose parents will give their consent.

Please feel free to contact us for any needed information related to this consent.

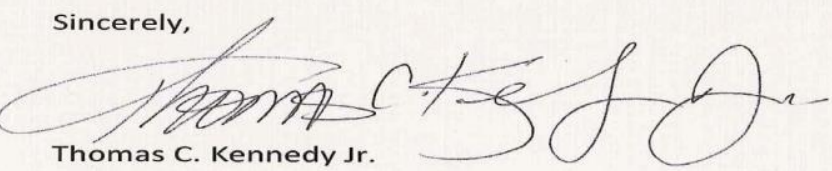

Thomas C. Kennedy Jr.

Principal

Keene Adventist Elementary School

FAX $817-645-9271$

3O2 PECAN STREET

KEENE, TEXAS 76059 


\section{TAS \\ Tyler Adventist School \\ 2931 SSE Loop 323, Tyler, TX 75701 \\ (903) 595-6706 Phone $\uparrow$ (903) 593-1210 Fax \\ Annette Bradley Martes, Principal}

April 8, 2016

Institutional Review Board

Andrews University

4150 Administrative Drive, Room 322

Berrien Springs, Ml 49104-0355

To Whom It May Concern:

Tyler Adventist School has granted permission to Susan Mbaluka to collect data for her research study titled, The Impact of Students' Self-Discipline and Parents' Involvement in Students' Academic Activities on Students' Academic Performance in Schools in the Texas Conference of Seventhday Adventists. The data will be collected through mailing questionnaires and consent forms that will be filled by parents, and teachers of students in grads 6-12. The researcher will secure informed consent from participants since participation in the study is completely voluntary.

The researcher will be provided access to ITBS, and GPA data as a part of her investigation provided she secures written parental consent to view such data for each student included in the study.

Please feel free to contat us for any needed information related to this consent.

\section{Sincerely,}

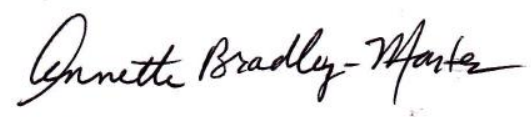

Annette Bradley Martes, Principal

Tyler Adventist School 


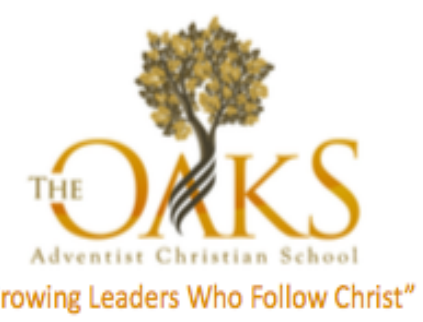

March 14, 2016

Institutional Review Board

Andrews University

4150 Administrative Drive, Room 322

Berrien Springs, Ml 49104-0355

To Whom it May Concern:

This is to inform you that permission has been granted to Susan Mbaluka to collect data for her research study titled The Impact of Students' Self-Discipline and Parents' Involvement in Students' Academic Activities on Students' Academic Performance in Schools in the Texas Conference of Seventh-day Adventists. The permission has been granted to the extent of the procedures outlined in the IRB application, and to allow the researcher to recruit participants and to collect data via mailing questionnaires and consent documents that will be filled by teachers of students in grades 6-12. The researcher will have to secure informed consent from participants as the decision to participate in the study is completely voluntary.

The researcher will be provided access to ITBS data and GPA data as a part of her investigation provided she secures written parental consent to view such data for each student included in the study.

Please feel free to contact us for any needed information related to this consent

In His Service,

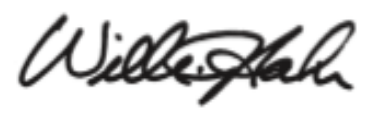

William J. (Jeff) Hahn

Principal

11735 Grant Rd. • Cypress, TX 77429

713-896-0071 • Fax 713-896-0721

http://www.houstonoakssda.org 
APPENDIX C

SURVEY INSTRUMENTS 


\section{Parents And School Survey (PASS)}

Parent Name:

Date:

\section{Name of School Child Attends}

Below are several statements followed by answers. Please read them and circle the answer that best describes how much you agree with the sta+ctement. It is most helpful if you try to answer honestly and accurately. This information helps us plan how to make the program as helpful to parents as possible.

\begin{tabular}{|c|c|c|c|c|c|c|}
\hline & & $\begin{array}{l}\text { Strongly } \\
\text { Agree }\end{array}$ & Agree & $\begin{array}{l}\text { Partially } \\
\text { Agree } \\
\text { Partially } \\
\text { Disagree }\end{array}$ & Disagree & $\begin{array}{l}\text { Strongly } \\
\text { Disagree }\end{array}$ \\
\hline 1. & $\begin{array}{l}\text { I feel very comfortable visiting my } \\
\text { child's school. }\end{array}$ & 1 & 2 & 3 & 4 & 5 \\
\hline 2. & $\begin{array}{l}\text { My child's schoolwork is always } \\
\text { displayed in our home (e.g. hang } \\
\text { papers on the refrigerator). }\end{array}$ & 1 & 2 & 3 & 4 & 5 \\
\hline 3. & $\begin{array}{l}\text { If my child misbehaved at school, I } \\
\text { would know about it soon afterward. }\end{array}$ & 1 & 2 & 3 & 4 & 5 \\
\hline 4. & $\begin{array}{l}\text { I frequently explain difficult ideas to } \\
\text { my child when she/he doesn't } \\
\text { understand. }\end{array}$ & 1 & 2 & 3 & 4 & 5 \\
\hline 5. & $\begin{array}{l}\text { Every time my child does something } \\
\text { well at school I compliment him/her. }\end{array}$ & 1 & 2 & 3 & 4 & 5 \\
\hline 6. & $\begin{array}{l}\text { Talking with my child's principal } \\
\text { makes me uncomfortable. }\end{array}$ & 1 & 2 & 3 & 4 & 5 \\
\hline 7. & $\begin{array}{l}\text { I always know how well my child is } \\
\text { doing in school. }\end{array}$ & 1 & 2 & 3 & 4 & 5 \\
\hline 8. & $\begin{array}{l}\text { I am confused about my legal rights } \\
\text { as a parent of a student. }\end{array}$ & 1 & 2 & 3 & 4 & 5 \\
\hline 9. & I read to my child every day. & 1 & 2 & 3 & 4 & 5 \\
\hline 10. & $\begin{array}{l}\text { I talk with other parents frequently } \\
\text { about educational issues. }\end{array}$ & 1 & 2 & 3 & 4 & 5 \\
\hline 11. & $\begin{array}{l}\text { My child attends community } \\
\text { programs (e.g. YMCA, park/rec, } \\
\text { community theatre) regularly. }\end{array}$ & 1 & 2 & 3 & 4 & 5 \\
\hline 12. & $\begin{array}{l}\text { I have visited my child's classroom } \\
\text { several times in the past year. }\end{array}$ & 1 & 2 & 3 & 4 & 5 \\
\hline 13. & $\begin{array}{l}\text { I have made suggestions to my } \\
\text { child's teachers about how to help my } \\
\text { child learn. }\end{array}$ & 1 & 2 & 3 & 4 & 5 \\
\hline 14. & $\begin{array}{l}\text { There are many children's books in } \\
\text { our house. }\end{array}$ & 1 & 2 & 3 & 4 & 5 \\
\hline 15. & $\begin{array}{l}\text { In the past } 12 \text { months I have attended } \\
\text { activities at my child's school several } \\
\text { times (e.g. fun nights performances, } \\
\text { awards nights). }\end{array}$ & 1 & 2 & 3 & 4 & 5 \\
\hline 16. & $\begin{array}{l}\text { My child misses school several days } \\
\text { each semester. }\end{array}$ & 1 & 2 & 3 & 4 & 5 \\
\hline 17. & $\begin{array}{l}\text { Talking with my child's current } \\
\text { teacher makes me somewhat } \\
\text { uncomfortable. }\end{array}$ & 1 & 2 & 3 & 4 & 5 \\
\hline
\end{tabular}




\begin{tabular}{|c|l|c|c|c|c|c|}
\hline 18. & $\begin{array}{l}\text { I don't understand the assignments } \\
\text { my child brings home. }\end{array}$ & 1 & 2 & 3 & 4 & 5 \\
\hline 19. & $\begin{array}{l}\text { Reading books is a regular activity in } \\
\text { our home. }\end{array}$ & 1 & 2 & 3 & 4 & 5 \\
\hline 20. & $\begin{array}{l}\text { If my child was having trouble in } \\
\text { school I would not know how to get } \\
\text { extra help for him / her. }\end{array}$ & 1 & 2 & 3 & 4 & 5 \\
\hline 21. & $\begin{array}{l}\text { I know the laws governing schools } \\
\text { well. }\end{array}$ & 1 & 2 & 3 & 4 & 5 \\
\hline 22. & $\begin{array}{l}\text { In the past 12 months I attended } \\
\text { several school board meetings. }\end{array}$ & 1 & 2 & 3 & 4 & 5 \\
\hline 23. & $\begin{array}{l}\text { In the past 12 months I volunteered at } \\
\text { my child's school at least 3 times. }\end{array}$ & 1 & 2 & 3 & 4 & 5 \\
\hline 24. & $\begin{array}{l}\text { I know about many programs for } \\
\text { youth in my community. }\end{array}$ & 1 & 2 & 3 & 4 & 5 \\
\hline
\end{tabular}




\section{Self-Control Rating Scale ${ }^{i}$}


Please rate this child according to the description below by circling the appropriate number.

The underlined 4 in the center of each row represents where the average child would fall on this item. Please do not hesitate o use the entire range of possible rating.

\begin{tabular}{|c|c|c|c|c|c|c|c|c|}
\hline 1 & $\begin{array}{l}\text { When the child promises to do } \\
\text { something, can you count on him or } \\
\text { her to do it? }\end{array}$ & $\begin{array}{c}1 \\
\text { Alway } \\
s\end{array}$ & 2 & 3 & $\underline{4}$ & 5 & 6 & $\begin{array}{c}7 \\
\text { Never }\end{array}$ \\
\hline 2. & $\begin{array}{l}\text { Does the child butt into games or } \\
\text { activities even when he or she hasn't } \\
\text { been invited? }\end{array}$ & $\begin{array}{c}1 \\
\text { Never }\end{array}$ & 2 & 3 & $\underline{4}$ & 5 & 6 & $\begin{array}{c}7 \\
\text { Often }\end{array}$ \\
\hline 3. & $\begin{array}{l}\text { Can the child deliberately calm down } \\
\text { when he or she is excited or all wound } \\
\text { up? }\end{array}$ & $\begin{array}{c}1 \\
Y e s\end{array}$ & 2 & 3 & $\underline{4}$ & 5 & 6 & $\begin{array}{c}7 \\
\text { No }\end{array}$ \\
\hline 4. & $\begin{array}{l}\text { Is the quality of the child's work all } \\
\text { about the same or does it vary a lot? }\end{array}$ & $\begin{array}{c}1 \\
\text { Same }\end{array}$ & 2 & 3 & $\underline{4}$ & 5 & 6 & $\begin{array}{c}7 \\
\text { Varie } \\
s\end{array}$ \\
\hline 5. & $\begin{array}{l}\text { Does the child work for long-range } \\
\text { goals? }\end{array}$ & $\begin{array}{c}1 \\
Y e s\end{array}$ & 2 & 3 & $\underline{4}$ & 5 & 6 & $\begin{array}{c}7 \\
\text { No }\end{array}$ \\
\hline 6. & $\begin{array}{l}\text { When the child asks a question, does } \\
\text { he or she wait for an answer, or jump } \\
\text { to something else (e.g., a new } \\
\text { question) before waiting for an } \\
\text { answer? }\end{array}$ & $\begin{array}{c}1 \\
\text { Waits }\end{array}$ & 2 & 3 & $\underline{4}$ & 5 & 6 & $\begin{array}{c}7 \\
\text { Jump } \\
s\end{array}$ \\
\hline 7. & $\begin{array}{l}\text { Does the child interrupt } \\
\text { inappropriately in conversations with } \\
\text { peers, or wait his or her turn to } \\
\text { speak? }\end{array}$ & $\begin{array}{c}1 \\
\text { Waits }\end{array}$ & 2 & 3 & $\underline{4}$ & 5 & 6 & $\begin{array}{c}7 \\
\text { Interr } \\
\text { upts }\end{array}$ \\
\hline 8. & $\begin{array}{l}\text { Does the child stick to what he or she } \\
\text { is doing until he or she is finished with } \\
\text { it? }\end{array}$ & $\begin{array}{c}1 \\
Y e s\end{array}$ & 2 & 3 & $\underline{4}$ & 5 & 6 & $\begin{array}{c}7 \\
\text { No }\end{array}$ \\
\hline 9. & $\begin{array}{l}\text { Does the child follow the instructions } \\
\text { of responsible adults? }\end{array}$ & $\begin{array}{c}1 \\
\text { Alway } \\
\quad s\end{array}$ & 2 & 3 & $\underline{4}$ & 5 & 6 & $\begin{array}{c}7 \\
\text { Never }\end{array}$ \\
\hline 10. & $\begin{array}{l}\text { Does the child have to have } \\
\text { everything right away? }\end{array}$ & $\begin{array}{c}1 \\
\text { No }\end{array}$ & 2 & 3 & $\underline{4}$ & 5 & 6 & $\begin{array}{c}7 \\
\text { Yes }\end{array}$ \\
\hline 11. & $\begin{array}{l}\text { When the child has to wait in line, } \\
\text { does he or she do so patiently? }\end{array}$ & $\begin{array}{c}1 \\
Y e s\end{array}$ & 2 & 3 & $\underline{4}$ & 5 & 6 & $\begin{array}{c}7 \\
\text { No }\end{array}$ \\
\hline 12. & Does the child sit still? & $\begin{array}{c}1 \\
Y e s\end{array}$ & 2 & 3 & $\underline{4}$ & 5 & 6 & $\begin{array}{c}7 \\
\text { No }\end{array}$ \\
\hline 13. & $\begin{array}{l}\text { Can the child follow suggestions of } \\
\text { others in group projects, or does he or } \\
\text { she insist on imposing his or her own } \\
\text { ideas? }\end{array}$ & $\begin{array}{c}1 \\
\text { Follo } \\
w s\end{array}$ & 2 & 3 & $\underline{4}$ & 5 & 6 & $\begin{array}{c}7 \\
\text { Impos } \\
\text { es }\end{array}$ \\
\hline 14. & $\begin{array}{l}\text { Does the child have to be reminded } \\
\text { several times to do something before } \\
\text { he or she does it? }\end{array}$ & $\begin{array}{c}1 \\
\text { Never }\end{array}$ & 2 & 3 & $\underline{4}$ & 5 & 6 & $\begin{array}{c}7 \\
\text { Alway } \\
s\end{array}$ \\
\hline 15. & $\begin{array}{l}\text { When reprimanded, does the child } \\
\text { answer back inappropriately? }\end{array}$ & $\begin{array}{c}1 \\
\text { Never }\end{array}$ & 2 & 3 & $\underline{4}$ & 5 & 6 & 7 \\
\hline
\end{tabular}




\begin{tabular}{|c|c|c|c|c|c|c|c|c|}
\hline & & & & & & & & $\begin{array}{c}\text { Alway } \\
s\end{array}$ \\
\hline 16. & Is the child accident prone? & $\begin{array}{c}1 \\
N o\end{array}$ & 2 & 3 & $\underline{4}$ & 5 & 6 & $\begin{array}{c}7 \\
\text { Yes }\end{array}$ \\
\hline 17. & $\begin{array}{l}\text { Does the child neglect or forget } \\
\text { regular chores or tasks? }\end{array}$ & $\begin{array}{c}1 \\
\text { Never }\end{array}$ & 2 & 3 & $\underline{4}$ & 5 & 6 & $\begin{array}{c}7 \\
\text { Alway } \\
s\end{array}$ \\
\hline 18. & $\begin{array}{l}\text { Are there days when the child seems } \\
\text { incapable of settling down to work? }\end{array}$ & $\begin{array}{c}1 \\
\text { Never }\end{array}$ & 2 & 3 & $\underline{4}$ & 5 & 6 & $\begin{array}{c}7 \\
\text { Often }\end{array}$ \\
\hline 19. & $\begin{array}{l}\text { Would the child more likely grab a } \\
\text { smaller toy today or wait for a larger } \\
\text { toy tomorrow, if given the choice? }\end{array}$ & $\begin{array}{c}1 \\
\text { Wait }\end{array}$ & 2 & 3 & $\underline{4}$ & 5 & 6 & $\begin{array}{c}7 \\
\text { Grab }\end{array}$ \\
\hline 20. & $\begin{array}{l}\text { Does the child grab for the belongings } \\
\text { of others? }\end{array}$ & $\begin{array}{c}1 \\
\text { Never }\end{array}$ & 2 & 3 & $\underline{4}$ & 5 & 6 & $\begin{array}{c}7 \\
\text { Often }\end{array}$ \\
\hline 21. & $\begin{array}{l}\text { Does the child bother others when } \\
\text { they're trying to do things? }\end{array}$ & $\begin{array}{c}1 \\
\text { No }\end{array}$ & 2 & 3 & $\underline{4}$ & 5 & 6 & $\begin{array}{c}7 \\
\text { Yes }\end{array}$ \\
\hline 22. & Does the child break basic rules? & $\begin{array}{c}1 \\
\text { Never }\end{array}$ & 2 & 3 & $\underline{4}$ & 5 & 6 & $\begin{array}{c}7 \\
\text { Alway } \\
s\end{array}$ \\
\hline 23. & $\begin{array}{l}\text { Does the child watch where he or she } \\
\text { is going? }\end{array}$ & $\begin{array}{c}1 \\
\text { Alway } \\
s\end{array}$ & 2 & 3 & $\underline{4}$ & 5 & 6 & $\begin{array}{c}7 \\
\text { Never }\end{array}$ \\
\hline 24. & $\begin{array}{l}\text { In answering questions, does the child } \\
\text { give one thoughtful answer, or blurt } \\
\text { out several answers all at once? }\end{array}$ & $\begin{array}{c}1 \\
\text { One }\end{array}$ & 2 & 3 & $\underline{4}$ & 5 & 6 & $\begin{array}{c}7 \\
\text { Sever } \\
\text { al }\end{array}$ \\
\hline 25. & $\begin{array}{l}\text { Is the child easily distracted from his } \\
\text { or her work or chores? }\end{array}$ & $\begin{array}{c}1 \\
\text { No }\end{array}$ & 2 & 3 & $\underline{4}$ & 5 & 6 & $\begin{array}{c}7 \\
\text { Yes }\end{array}$ \\
\hline 26. & $\begin{array}{l}\text { Would you describe this child more as } \\
\text { careful or careless? }\end{array}$ & $\begin{array}{c}1 \\
\text { Caref } \\
u l\end{array}$ & 2 & 3 & $\underline{4}$ & 5 & 6 & $\begin{array}{c}7 \\
\text { Carel } \\
\text { ess }\end{array}$ \\
\hline
\end{tabular}

\begin{tabular}{|l|l|c|c|c|c|c|c|c|}
\hline 27. & $\begin{array}{l}\text { Does the child play well with peers } \\
\text { (follows rules, waits turn, cooperates) }\end{array}$ & $\begin{array}{c}\mathbf{1} \\
\text { Yes }\end{array}$ & 2 & 3 & $\mathbf{4}$ & 5 & 6 & $\begin{array}{c}\mathbf{7} \\
\text { No }\end{array}$ \\
\hline 28. & $\begin{array}{l}\text { Does the child jump or switch from } \\
\text { activity to activity rather than sticking } \\
\text { to one thing at a time? }\end{array}$ & $\begin{array}{c}\mathbf{1} \\
\text { Stick } \\
\text { to one }\end{array}$ & 2 & 3 & $\mathbf{4}$ & 5 & 6 & $\begin{array}{c}\mathbf{7} \\
\text { Switc } \\
\text { hes }\end{array}$ \\
\hline 29. & $\begin{array}{l}\text { If a task is at first too difficult for the } \\
\text { child, will he or she get frustrated and } \\
\text { quit, or first seek help with the } \\
\text { problem? }\end{array}$ & $\begin{array}{c}\mathbf{1} \\
\text { Seek } \\
\text { help }\end{array}$ & 2 & 3 & $\underline{4}$ & 5 & 6 & $\begin{array}{c}\mathbf{7} \\
\text { Quit }\end{array}$ \\
\hline 30. & $\begin{array}{l}\text { Does the child disrupt games? } \\
\text { Never }\end{array}$ & 2 & 3 & $\underline{\mathbf{4}}$ & 5 & 6 & $\begin{array}{c}\mathbf{7} \\
\text { Often }\end{array}$ \\
\hline
\end{tabular}




\begin{tabular}{|l|l|c|c|c|c|c|c|c|}
\hline 31. & $\begin{array}{l}\text { Does the child think before he or she } \\
\text { acts? }\end{array}$ & $\begin{array}{c}\mathbf{1} \\
\text { Alwa } \\
\text { ys }\end{array}$ & 2 & 3 & $\mathbf{4}$ & 5 & 6 & $\begin{array}{c}\mathbf{7} \\
\text { Never }\end{array}$ \\
\hline 32. & $\begin{array}{l}\text { If the child paid more attention to his or } \\
\text { her work, do you think he or she would } \\
\text { do much better than at present? }\end{array}$ & $\begin{array}{c}\mathbf{1} \\
\text { No }\end{array}$ & 2 & 3 & $\mathbf{4}$ & 5 & 6 & $\begin{array}{c}\text { Y } \\
\text { Yes }\end{array}$ \\
\hline 33. & $\begin{array}{l}\text { Does the child do too many things at } \\
\text { once, or does he or she concentrate on } \\
\text { one thing at a time? }\end{array}$ & $\begin{array}{c}\mathbf{1} \\
\text { One } \\
\text { at a } \\
\text { time }\end{array}$ & 2 & 3 & $\mathbf{4}$ & 5 & 6 & $\begin{array}{c}\text { Too } \\
\text { many }\end{array}$ \\
\hline
\end{tabular}

(C) 1979, Phillip Kendall, Ph.D.

${ }^{1}$ Kendall, P.C. \& Wilcox (1979). Self-control in children: The development of a rating scale.

Journal of Consulting and Clinical Psychology, 47, 1020-1030. 


\section{CognitiveGenesis Parent Survey Rating Scales}

Question No. Scale

1.

How knowledgeable are you about this school?

Very knowledgeable 3

Somewhat knowledgeable 2

Not knowledgeable 1

2.

Rate the communication between your family and this school.

$\begin{array}{ll}\text { Excellent } & 4 \\ \text { Good } & 3 \\ \text { Fair } & 2 \\ \text { Poor } & 1\end{array}$

3.

How involved is your family in school activities?

Very involved 2

Somewhat involved 1

Not involved 0

4.

How far in school do you want your child/children to go?

Finish high school 1

A few years of college/university 2

Graduate from college/university 3

Master's degree 4

$\mathrm{PhD}$, MD, Law degree, or other advanced degree 5

7

What best describes the extent to which English is spoken in your home?

English is the only or primary language spoken 3

English and another language are both

frequently spoken

Another language is the only or primary

language spoken

8.

Which of the following people are usually at home when your child/children returns from school? 
(Choose all that apply.)

Mother

Father

Other adult relative 5

A non-relative adult/sitter 4

Older brother/sister 3

Younger brother/

Sister

1

No one

0

9.

What best describes the home arrangement for your child/children?

Two parents: father and mother: Yes No

11.

14.

High school or less

Some college/university

College/university

Graduate

Post graduate degree

(MA, PhD, MD, Law

degree, or other

advanced degree) 


\section{Cognitive Genesis Student Survey}

Question No. Wording \& Numbers

11. On a typical school night, how many hours of sleep do you get?

$\begin{array}{ll}5 \text { or less } & 1 \\ 6 & 2 \\ 7 & 3 \\ 8 & 4 \\ 9 \text { or more } & 5\end{array}$

14. How diligent are you in your schoolwork?

I always try to do my best 4

I usually try to do a good job 3

I try hard enough to just get by 2

I don't put forth much effort 1

17 How many times in the last month have you had a good conversation with one of your parents that lasted 10 minutes or more?

$\begin{array}{ll}\text { None } & 0 \\ \text { Few } & 1 \\ \text { Many } & 2\end{array}$

How much do your parents attend or participate in your afterschool activities such as musical programs, athletic programs, social events, weekend programs, etc?

Almost always

Some of the time

Very seldom

Never

22. How much time in a typical day do you spend interacting (talking, shopping, working, etc?) with your parents?

A lot 
Sometimes

A little bit

Almost never

How much time do you spend each

day after school doing the following?

$\begin{array}{ll}\text { No time } & 0 \\ \text { Less than } 1 \text { hour } & 1 \\ \text { 1-2 hours } & 2 \\ \text { 3-4 hours } & 3 \\ 5 \text { or more hours } & 4\end{array}$

1. Do schoolwork or study at home

2. Read for pleasure (not counting reading for school)

3. Watch TV

4. Listen to music for fun.

5. Play or sing in a school musical group such as band or choir.

6. Participate in varsity sports activities (practice or games).

7. Participate in intramural sports activities

8. Exercise in other activities.

9. Talk with my friends on the phone or by computer

10. Play on a computer (games, surfing the internet)

11. Work on a job (provided by my school)

12. Work on a job (not provided by my school)

13. Do family chores or work around the house 


\section{REFERENCES}

Allen, J., Robbins, S., \& Casillas, A. (2008). Third-year college retention and transfer: Effects of academic performance, motivation, and social connectedness. Research in Higher Education, 49(7), 647-664.

Alliance for Excellent Education. (2008). How does the United States stack up? International comparisons of academic achievement. Fact Sheet. Retrieved from http://www.all4ed.org/files/IntlComp_FactSheet.pdf

Allred, C. G. (2008). Improving academics, behavior and character. Leadership, 38(2), 26-29.

Altbach, P. G., Berhdahl, R. O., \& Gumport, P. J. (2011). American higher education in the twenty-first century: Social, political and economic challenges. Baltimore, MD: The Johns Hopkins University Press.

Anila, M. M. (2016). Mindfulness based stress reduction for reducing anxiety, enhancing self-control and improving academic performance among adolescent students. Indian Journal of Positive Psychology, 7(4), 390-397.

Barge, J. K., \& Loges, W. E. (2003). Parent, student, and teacher perceptions of parental involvement. Journal of Applied Communication Research, 31(2), 140-163

Bartko, J. J. (1991). Measurement and reliability: Statistical thinking considerations. Schizophr Bul, 17(3), 483-489.

Bembenutty, H. (2011). Meaningful and maladaptive homework practices: The role of self-efficacy and self-regulation. Journal of Advanced Academic, 22(3), 448-473.

Bower, B. (2007). Oldest siblings show slight IQ advantage. Science News, 172(1), 14.

Bright Education Services \& Testing. (2015). Iowa assessments (ITBS) practice tests. Retrieved from http://brighted.funeducation.com/Practice-Test/IowaAssessments.

Brigman, G., \& Campbell, C. (2003). Helping students improve academic achievement and school success behavior. Professional School Counseling, 7(2). 
Bryant, M. J., Hammond, K. A., Bocian, K. M., Rettig, M. F., Miller, C. A., \& Cardullo, R. A. (2008). School performance will fail to meet legislated benchmarks. Science, 321(5897), 1781-1782.

Cabus, S. J., \& Aries, R. J. (2017). What do parents teach their children? - The effects of parental involvement on student performance in Dutch compulsory education. Education Review, 3(69), 285-302.

Chamopro-Premuzic, T., \& Furnham, A. (2003). Personality traits and academic examination performance. European Journal of Personality, 17(3), 237-250.

Chavkin, N. F. (1994). Evaluating family-school-community partnership. The School Community Journal, 4(2), 91-94. Retrieved from http://www.adi.org/journal/fw94/ChavkinFall1994.pdf

Coleman, J. S. (1988). Social capital in the creation of human capital. American Journal of Sociology, 94(95), 95-120.

Combs, A. W. (2001). Achieving self-discipline: Some basic principles. Theory Introduction Practices, 85(24), 1260-263.

Creswell, J. W. (2012). Educational research planning, conducting, and evaluating quantitative and qualitative research ( ${ }^{\text {th }}$ ed.). Upper Saddle River, NJ: Pearson Education.

Deci, E. L., \& Ryan, R. M. (1985). Intrinsic motivation and self-determination in human behavior. New York, NY: Plenum.

Deci, E. L., \& Ryan, R. M. (2000). The "what" and "why" of goal pursuits: Human needs and the self-determination of behavior. Psychological Inquiry, 11(4), 227-268.

Duckworth, A., Grant, H., Loew, B., Oettingen, G. \& Gollwitzer, P.M. (2011). Selfregulation strategies improve self-discipline in adolescents: Benefits of mental contrasting and implementation intentions. Educational Psychology: An International Journal of Experimental Educational Psychology, 31(1), 17-26.

Duckworth, A., Quinn, P., Tsukayama, E. (2011). What No Child Left Behind leaves behind: The roles of IQ and self-control in predicting standardized achievement test scores and report card grades. Journal of Educational Psychology, 104(2), 439-451. doi: $10.1037 / \mathrm{a} 0026280$

Duckworth, A. L., \& Seligman, M. E. P. (2005). Self-discipline outdoes IQ in predicting academic performance of adolescents. Psychological Science, 16(12), 939-944. 
Duckworth, A. L., \& Seligman, M. E. P. (2006). Self-discipline gives girls the edge: Gender in self-discipline, grades, and achievement test scores. Journal of Educational Psychology, 98(1), 198-208.

Edvalda, A. L., Miranda,G. J., Carmo, S., \& Roberto, C. (2013). Self-determination theory: An analysis of student motivation in an accounting degree program. Revista Contabilidade \& Financas-USP, 24(62), 163-173.

Eilam, B., Zeidner, M., \& Aharon I. (2009). Student conscientiousness, self-regulated learning, and science achievement: An explorative field study. Psychology in the Schools, 46(5), 420-432.

Englund, M. M., Luckner, A. E., \& Whaley, G.J. (2004). Children's achievement in early elementary school: Longitudinal effects of parental involvement, expectations, and quality of assistance. Journal of Educational Psychology, 96(4), 723-730.

Epstein, J. L. (1986). Parents reactions to teachers practices of parent involvement. The Elementary School Journal, 86(3), 277-294.

Epstein, J. L. (1995). School/family/community partnerships. Phi Delta Kappan, 76(9), 701-712.

Epstein, J. L. (2008). Improving family and community involvement in secondary schools. Education Digest, 73(6), 9-12.

Evans, M. D. R., Kelley, J., \& Sikora, J. (2014). Scholarly culture and academic performance in 42 nations. Social forces, 92(4), 1573-1605

Fazal, S., Hussein, S., Majoka, M. I., \& Masood, S. (2012). The role of study skills in academic achievement of students: A closer focus on gender. Pakistan Journal of Psychological Research, 27(1), 37-51.

Finn, J. D., \& Rock, D. A. (1997). Academic success among students at risk for school failure. Journal of Applied Psychology, 82(2), 14.

Friesen, B. J., \& Osher, T. (1996). Involving families in change: Challenges and opportunities. Special Services in the Schools, 11(112), 187-207.

Fritzberg, G. J. (2001). Less than equal: A former urban schoolteacher examines the causes of educational disadvantagement. Urban Review, 33(2), 107.

Guner, N. (2012). Using metaphor analysis to explore high school students' attitudes towards learning mathematics. Education, 133(1), 39-48. 
Hara, S. R., \& Burke, D. J. (1998). Parent involvement: The key to improved student achievement. The School Community Journal, 8(2), 9-19. Retrieved from http://www.adi.org/journal/ss01/chapters/Chapter16-Hara

Heitin, L. (2013). Global test shows U.S. stagnating. American Education's Newspaper of Record. Education Week, 33(14), 1-15.

Hill, N. E., \& Craft, S. A. (2003). Parent-school involvement and school performance: Mediated pathways among socioeconomically comparable African American and Euro-American families. Journal of Educational Psychology, 96(1), 74-83

Hill, N. E., \& Taylor, L. C. (2004). Parental school involvement and children's academic achievement. Current Directions in Psychological Science, 13(4), 161-164.

Hill, N. E., \& Tyson, D. F. (2009). Parental involvement in middle school: A metaanalytic assessment of the strategies that promote achievement. American Psychological Association, 45(3), 740-776.

Inal, S., Kelleci, M., \& Canbulat, N. (2012). Internet use and its relation with the academic performance for a sample of high school students. Journal of Society for Development in New Net Environment in B\&H, 6(5), 1643-1650.

Kendall, P.C., \& Wilcox (1979). Self-control in children: The development of a rating scale. Journal of Consulting and Clinical Psychology, 47, 1020-1030.

Kohl, G. O., Lengua, L. J., \& McMahon, R. J. (2000). Parent involvement in school conceptualizing multiple dimensions and their relations with family and demographic risk factors. Journal of School Psychology, 38(6), 501-523.

Konrad, K. (2014). Teaching piano and the invaluable life skill of self-discipline. Clavier Companion, 6(3), 29-32.

Krejcie, R. V., \& Morgan, D. W. (1970). Determining sample size for research activities. Educational and Psychological Measurements, 30(1), 607-610.

Lenka, S. K., \& Kant, R. (2012). A study of effects of parental participation on academic attainment of secondary school students. European Journal of Social Publishing, $33(4), 517-524$.

Lohman, D. F., \& Hagen, E. P. (2002). Cognitive ability research handbook. Itasca, IL: Riverside Publishing.

Mark, S. B. (2012). Academic achievement of children in single parent homes: A critical review. The Hilltop Review, 5(1), 13-21. Retrieved from http://scholarworks.wmich.edu/cgi/viewcontent.cgi?article=1044\&context=hilltop review 
McGee, G. W. (2004). Closing the achievement gap: Lessons from Illinois' Golden Spike high-poverty high-performing schools. Journal of Education for Students, 9(2), 97-125.

Mullis, R. L., Rathge, R., \& Mullis, A. K. (2003). Predictors of academic performance during early adolescence: A contextual view. International Journal of Behavioral Development, 27(6), 541-548.

Murnane, R. J. (2007). Improving the education of children living in poverty. Future of Children, 17(2), 161-182.

Myers, D. E., Milne, A. M., Baker, K., \& Ginsburg, A. (1987). Student discipline and high school performance. Sociology of Education, 60(1), 18-33.

Nachiappan, S., Marimuthu, V., Andi, H. K. \& Veeran, P. K. (2012). Academic activities after school that help secondary school children's cognitive development through hermeneutic analysis. Asian Social Science, 8(10), 223-227.

Newman, I., \& McNeil, K. (1998). Conducting survey research in the social sciences. Lanham, MD: University Press of America.

Organization for Economic Cooperation and Development. (2015). PISA 2015 results in focus. Retrieved from https://www.oecd.org/pisa/pisa-2015-results-in-focus.pdf.

Osher, D., Bear, G. G., Sprague, J. R., \& Doyle, W. (2010). How can we improve school discipline? Educational Researcher, 39(1), 48-58.

Oxford University Press. (2017). Definition of self-discipline in English. Retrieved from https://en.oxforddictionaries.com/definition/self-discipline.

Radcliffe, R. A., \& Bos, B. (2013). Strategies to prepare middle school and high school students for college and career readiness. The Clearing House, 86(4), 136-141.

Ramdass, D., \& Zimmerman, B. J. (2011). Developing self-regulation skills: The important role of homework. Journal of Advanced Academics, 22(2), 194-218.

Ringenberg, M., Funk, V., Mullen, K., Wilford, A., \& Kramer, J. (2005). Test-retest reliability of the parent and school survey (PASS). The School Community Journal, 15(2), 121-134.

Rodríguez, S., Piñeiro, I., Gómez-Taibo, M., Regueiro, B., Estévez, I. \& Valle. A. (2017). An explanatory model of maths achievement: Perceived parental involvement and academic motivation. Psicothema, 2(29), 184-190 
Self-Discipline. (1989). In English Oxford Living Dictionaries online (2 ${ }^{\text {nd }}$ ed.). Retrieved from https://en.oxforddictionaries.com/definition/us/self-discipline

Sheldon, S. B., \& Epstein, J. L. (2005). Involvement counts: Family and community partnerships and mathematics achievement. Journal of Educational Research, 98(4), 196-206.

Shimada, K., Moriyama, J., \& Matsuura, M. (2006). The structure of students' knowledge and self-concepts. Part B. The structure of students' self-concepts in industrial high school. International Journal of Technology \& Design Education, $17(1), 45-54$.

Shipman, N. J., Queen, J. A., \& Peel, H. A. (2007). Transforming school leadership. Larchmont, NY: Eye on Education.

Shute, V. J., Hansen, E. G., Underwood, J. S., \& Razzouk, R. (2011. A review of relationship between parental involvement and secondary school students' academic achievement. Educational Research International, 2011(915326), 1-10. doi: $10.1155 / 2011 / 915326$.

Snowman, J., McCown, R., \& Biehler, R. (2012). Psychology applied to teaching. (13 ${ }^{\text {th }}$ ed.). Wadsworth, CA: Cengage Learning.

Sowell, T. (1977). New light on black I.Q. Retrieved from http://www.nytimes.com/1977/03/27/archives/new-light-on-black-iq.html.

Stevenson, H. W., Lee, S. Y., \& Stigler, J. (1986). Mathematics achievement of Chinese, Japanese and American children. Science, 231(4739), 693-699.

Stevenson, H. W., Stigler, J. W., Lee, S. Y., Lucker, G. W., Kitamura, S., \& Hsu, C.-C. (1985). Cognitive performance and academic achievement of Japanese, Chinese, and American children. Child Development, 56(3), 718.

Stigler, J. W., Lee, S. Y., \& Stevenson, H. W. (1987). Mathematics classrooms in Japan, Taiwan, and the United States. Child Development, 58(5), 1272.

Tangney, J. P., Baumeister, R. F. \& Boone, A. L. (2004). High self-control predicts good adjustment, less pathology, better grades and interpersonal success. Journal of Personality, 72(2), 271-324.

Taylor, G., Jungert, T., Geneviève, A., Mageau, G. Schattke, K., Dedic, H., ... \& Koestner, R. (2014). A self-determination theory approach to predicting school achievement over time: the unique role of intrinsic motivation. Contemporary Educational Psychology, 39(4), 342-358 
Thayer, J., \& Kido, E. (2012). Cognitive Genesis (CG): Assessing academic achievement and cognitive ability in Adventist schools. Journal of Research on Christian Education, 21(2), 99-115.

Wang, H., \& Cai, T. (2017). Parental involvement, adolescents' self-determined learning and academic achievement in urban China. International Journal of Psychology, $1(52), 58-66$.

Waschull, S. B. (2005). Predicting success in online psychology courses: Self-discipline and motivation. Teaching of Psychology, 32(3), p190-192.

Wentzel, K. R. (1993). Does being good make the grade? Social behavior and academic competence in middle school. Journal of Educational Psychology, 85(2), 357364.

Willingham, W. W., Pollack, J. M., Lewis, C. (2002). Grades and test scores: Accounting for observed differences. Journal of Educational Measurement, 39(1), 37-39.

Yu, C. H., Kaprolet, C., Jannasch-Pel, A., \& DiGang, S. (2012). A data mining approach to comparing American and Canadian grade 10 students' PISA science test performance. Journal of Data Science, 10(24), 441-464.

Zimmerman, B. J. (1990). Self-regulated learning and academic achievement: An overview. Educational Psychologist, 25(1), 3-17.

Zimmerman, B. J., \& Kitsantas, A. (2014). Comparing students' self-discipline and selfregulation measures and their prediction of academic achievement. Contemporary Educational Psychology, 39(2), 145-155

Zimmerman, B. J., \& Ramdass, D. (2011). Developing self-regulation skills: The important role of homework. Journal of Advanced Academics, 22(2), 194-218. 


\title{
VITA
}

\author{
Susan N. Mbaluka \\ mbalukas@andrews.edu
}

$11 / 13 / 17$

\section{EDUCATION}

\section{Andrews University}

PhD Candidate

2017

\section{University of Eastern Africa, Baraton}

M. Ed, Master of Curriculum Development and Instruction, 2000

B. Ed, Bachelor of Education, Concentration: English, 1993

\section{RESEARCH EXPERIENCE}

Dissertation

2016-2017

"The Impact of Student Self-Discipline and Parental Involvement in Students' Academic Activities on Student Academic Performance." Advisors: Professor Gustavo Gregorutti, Dr. Jay Brand \& Dr. Bordes Saturne.

\section{Thesis}

"A Survey of the Portrayal of Women Images in Literature Set Books for Kenyan Secondary Schools." Advisors: Dr. Ruth N. Otunga, Dr. Denford B. Musvosvi, \& Dr. John Mativo.

\section{PROFESSIONAL EXPERIENCE}

Director, Great Foundation JILO Academy, Texas

Curriculum Developer, Advent Home Learning Center, TN 
Principal, Masii Adventist Secondary School grades 9-12, Kenya 2006-2007

Principal, Kitui Adventist School Grades K - 12, Kenya 2004-2006

Instructor, Century Park College, Kenya 2001-2003

Instructor, University of Eastern Africa, Baraton, Kenya 1999-2000

Teacher, Mutitu S.D.A Secondary School grades 9-12 1984-1989

\section{SERVICES}

School Board Member, Oaks Adventist School, Texas 2016 - Present

Head, Education Ministry, West Houston SDA Church 2016- Present

Head deaconess, West Houston SDA Church, Texas 2013- Present

Church Board member, West Houston SDA Church, Texas 2013- Present

\section{CERTIFICATION}

E.A. Sutherland Education Association, TN 2010

- Teaching Certificate

University of Nairobi, Kenya

2003

- Certificate in Guidance \& Counseling.

Century- 20- Park College, Kenya 2002

- Certificate in Computer Operations.

\section{SEMINARS \& CONFERENCES}

“Adventist Online Learning Conference” Andrews University 2017

"The Institutional Journey of Hope. Kenya Adventist Heads Association." 2006 Mombasa

"The Implementation of the Kenya Education Sector Support Program." 2005

Government Training Institute, Kenya.

“Challenges of teaching English at secondary school level.” Kitui, Kenya 


\section{PRESENTATIONS}

“Program portfolio Development.” Andrews University Orientation. 2017

“Assessment Guidelines.” Oaks Adventist School, Texas 2014

“School, Second Home.” Century Park College, Kenya 2002

\section{PUBLICATIONS}

\section{Books}

Mbaluka, Susan (2012). God Makes a Way. TEACH Services, Inc. Publishing.

Mbaluka, Susan (2017). Victory in Surrender, Ready for publication. 